\title{
Mineralization Worked Examples for the TEA and LCA Guidelines for $\mathrm{CO}_{2}$ Utilization
}


Published Dec 2018

This work is available under DOI: $10.3998 / 2027.42 / 147467$

ISBN: 978-1-9164639-3-6

Published by CO2Chem Media and Publishing Ltd

\section{Main Contributors}

The University of Sheffield

Stephen McCord

Ana Villa Zaragoza

Peter Sanderson

Katy Armstrong

Peter Styring

\section{Further Contributions}

\section{Carbon8 Systems}

Colin Hills

Paula Carey

Mark Osbourne

RWTH Aachen University

Leonard Müller

André Bardow 


\section{Foreword from $\mathrm{CO}_{2}$ Sciences}

Climate change is one of the largest challenges of our time. One of the major causes of anthropogenic climate change, carbon dioxide, also leads to ocean acidification. Left unaddressed, these two challenges will alter ecosystems and fundamentally change life, as we know it. Under the auspices of the UN Framework Convention on Climate Change and through the Paris Agreement, there is a commitment to keep global temperature increase to well below two degrees Celsius. This will require a variety of strategies including increased renewable power generation and broad scale electrification, increased energy efficiency, and carbon-negative technologies.

We believe that Life Cycle Assessment (LCA) is necessary to prove that a technology could contribute to the mitigation of environmental impacts and that Techno-Economic Assessment (TEA) will show how the technology could be competitively delivered in the market. Together they are a valuable toolkit for promoting carbon capture and utilization (CCU) technology development.

The work presented here was made possible through the vision of the Chairman of $\mathrm{CO}_{2}$ Sciences Inc., Bernard David, and the expertise of the $\mathrm{CEO}$ of $\mathrm{CO}_{2}$ Sciences Inc., Issam Dairanieh.

The Global $\mathrm{CO}_{2}$ Initiative was launched during the 2016 meeting of the World Economic Forum with the goal of catalyzing innovative research in $\mathrm{CO}_{2}$ utilization. Starting July of 2018, the Initiative will continue its work as The Global $\mathrm{CO}_{2}$ Initiative at the University of Michigan.

Development of standardized $\mathrm{CO}_{2}$ Life Cycle and Techno-economic Assessment Guidelines was commissioned by $\mathrm{CO}_{2}$ Sciences, Inc., with the support of $3 \mathrm{M}$, EIT Climate- $\mathrm{KIC}, \mathrm{CO}_{2}$ Value Europe, Emissions Reduction Alberta, Grantham Foundation for the Protection of the Environment, R. K. Mellon Foundation, Cynthia and George Mitchell Foundation, National Institute of Clean and Low Carbon Energy, Praxair, Inc., XPrize and generous individuals who are committed to action to address climate change.

Global CO2 Initiative@UM, August 2018

\section{SUPPORTED BY}

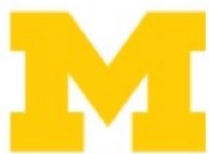

GLOBAL $\mathrm{CO}_{2}$

INITIATIVE

UNIVERSITY OF MICHIGAN

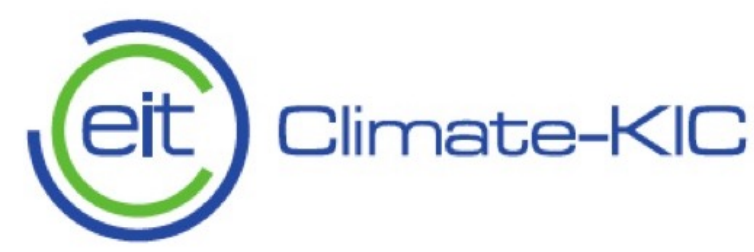

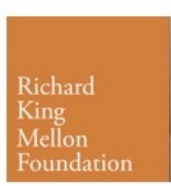




\section{List of abbreviations}

\begin{tabular}{|c|c|}
\hline $\mathrm{APCr}$ & Air Pollution Control Residue \\
\hline BDF & Block flow diagram \\
\hline C8S & Carbon8 Systems \\
\hline CAPEX & Capital Cost \\
\hline CAPM & Capital asset pricing model \\
\hline CCS & Carbon capture and storage \\
\hline CCU & Carbon capture and utilization \\
\hline CEPCI & Chemical Engineering Plant Cost Index \\
\hline $\mathrm{CO}_{2}$ & Carbon dioxide \\
\hline COGM & Cost of goods manufactured \\
\hline COGS & Cost of goods sold \\
\hline EFW & Energy from Waste \\
\hline ETS & Emission trading system \\
\hline EU & European Union \\
\hline $\mathbf{F C l}$ & Fixed capital investment \\
\hline FOAK & First of a kind \\
\hline GWP & Global warming potential \\
\hline $\mathrm{H}_{2}$ & Hydrogen \\
\hline IRR & Internal rate of return \\
\hline ISBL & Inside battery limits \\
\hline ISO & International standardization organization \\
\hline LCA & Life cycle assessment \\
\hline LCC & Life cycle costing \\
\hline $\mathbf{L C l}$ & Life cycle inventory \\
\hline LCOE & Levelized cost of electricity \\
\hline LHV & Lower heating value \\
\hline MADM & Multiple attribute decision making \\
\hline MCDA & Multicriteria decision analysis \\
\hline MODM & Multiple objective decision making \\
\hline MSW & Municipal Solid Waste \\
\hline NGO & Non-Governmental Organisation \\
\hline NOAK & Nth of a kind \\
\hline NOX & Nitrous Oxides \\
\hline NPV & Net present value \\
\hline OPEX & Operational Cost \\
\hline OSBL & Outside/off-site battery limits \\
\hline P\&ID & Piping and instrumentation diagram \\
\hline PEM & Proton exchange membrane \\
\hline PFD & Process flow diagram \\
\hline R\&D & Research and Development \\
\hline RDF & Refuse derived fuel \\
\hline ROI & Return on investment \\
\hline SA & Sensitivity analysis \\
\hline SI-UNITS & International System of Units \\
\hline $\mathrm{TCl}$ & Total capital investment \\
\hline TEA & Techno-economic assessment \\
\hline TRL & Technology readiness level \\
\hline UA & Uncertainty analysis \\
\hline USD & United States Dollars \\
\hline WACC & Weighted average cost of capital \\
\hline
\end{tabular}




\section{PART A Introduction}

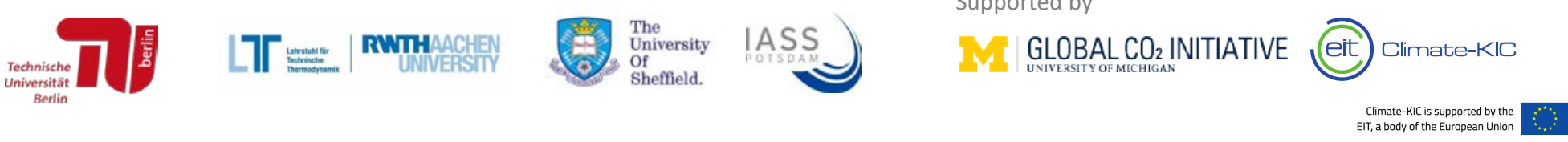




\section{Contents}

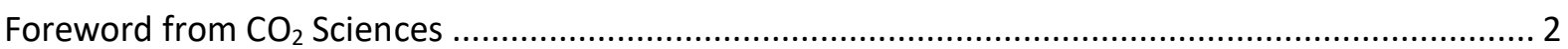

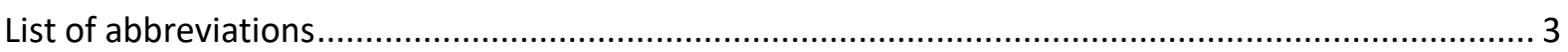

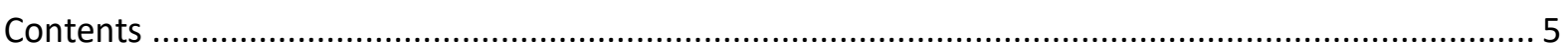

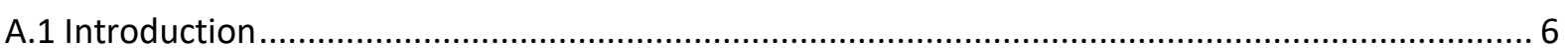

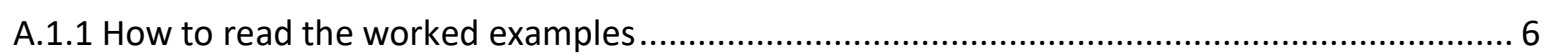

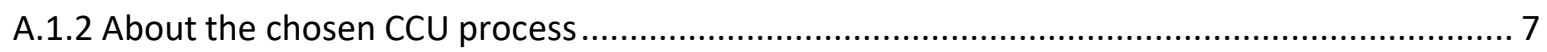

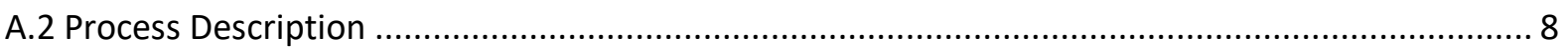

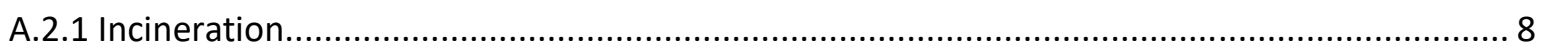

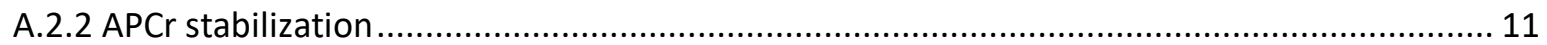

A.2.3 Carbonation of APCr (Carbon8 Systems process) …........................................................ 12

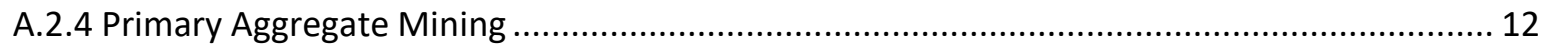

A.2.5 Concrete Masonry Unit (CMU)/ Block Production ............................................................. 14

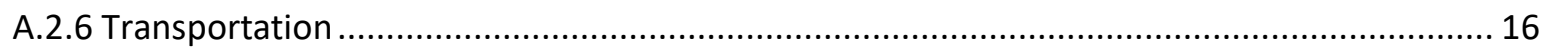

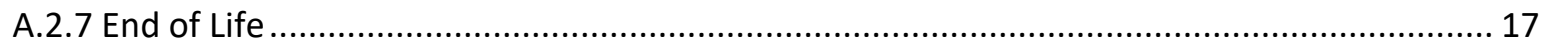

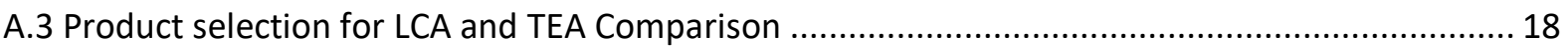

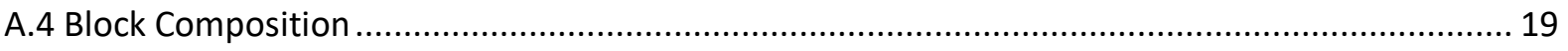

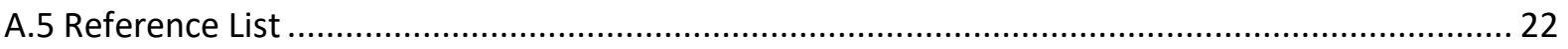




\section{A.1 Introduction}

This document contains worked examples of how to apply the accompanying "Guideline for TechnoEconomic Assessment of $\mathrm{CO}_{2}$ Utilization" and "Guideline for Life Cycle Assessment of $\mathrm{CO}_{2}$ Utilization", hereafter referred to as "the TEA and LCA guidelines".

These worked examples are not intended to be a definitive TEA or LCA report on the process described, but are provided as supporting material to show how the TEA and LCA methodologies described in the guidelines can be specifically applied to tackle the issues surrounding $\mathrm{CO}_{2}$ utilization.

This example was constructed using data collected from a demonstration plant operated by Carbon8 Systems in Ontario, Canada, together with data obtained from the literature and from the ecoinvent database v3.4. As with the methanol worked example, the aim is not to prove whether the selected process is economically or environmentally viable or to make process alterations to make it so, but to clearly demonstrate how the proposed guidelines can be used to conduct a transparent TEA and LCA which can then be followed by others.

The TEA example is provided in Part B, followed by the LCA example in Part C. In Part D, the reader will find a short example of how a TEA and LCA can be integrated. This integration is not an exhaustive example. As many aspects can be analyzed to produce combined indicators and many approaches to multi-criteria decision making applied. However, it is included here to provide a starting point and initial example of how integration can be carried out.

\section{A.1.1 How to read the worked examples}

The subsequent TEA and LCA are written as worked examples, not in the format of a formal report for either academic, corporate or policy audiences. The examples are structured in this way to enable the reader to clearly understand how the guidelines have been applied by the authors, rather than focus on a specific style of reporting.

To enhance understanding the following explanations have been included:

- Grey-coloured text boxes are used to refer the reader to specific sections of the guidelines:

\section{Reference to Guidelines}

- Blue-coloured speech bubbles give an explanation of why certain decisions were taken or choices made:

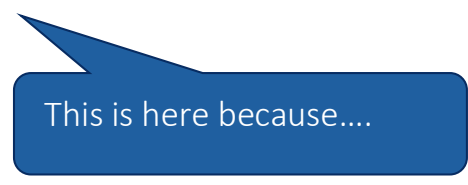

The studies contain example Executive and Technical Summaries for the reader's benefit. All 'shall' aspects of the guidelines are covered and 'should' and 'may' aspects and included as appropriate to each study. 
The guidelines for conducting LCA and TEA of $\mathrm{CO}_{2}$ utilization processes, together with the accompanying worked examples, were commissioned by The Global $\mathrm{CO}_{2}$ Initiative $/ \mathrm{CO}_{2}$ Sciences.

\section{A.1.2 About the chosen CCU process}

These examples focus upon the mineralization of $\mathrm{CO}_{2}$ with air pollution control residue (APCr) to produce an aggregate which is made into concrete blocks for building. This mineralization process was chosen as it involves decisions which differs from those made in the methanol worked example. As with the methanol worked example, it is hoped that the reader will be able to focus on the described methodology for conducting the assessment rather than understanding the specifics of the process route. For this reason, the detailed description of the modelled process used for the TEA and LCA worked examples is presented here in Part A, rather than repeating it in Parts B and $C$ and only the critical data used for modelling the sections which are specific to CCU are provided within the main body of the respective reports. In this format, the reader will be able to focus upon the application of the TEA and LCA guidelines and not be distracted by tables of data. Having said that, the limitations of the data used is discussed in the examples, as this is likely to be an issue for many TEA and LCA reports of CCU technologies.

The following studies are presented as a reference on how to apply the guidelines for $\mathrm{CO}_{2}$ utilization to a comparative assessment between a CCU technology and a conventional (reference or benchmark) technology. These examples are for public use and are targeted at the TEA and LCA practitioner who wishes to assess a CCU process. 


\section{A.2 Process Description}

\section{A.2.1 Incineration}

Incineration is a term used to cover the thermal treatments utilized for the disposal of various wastes, including but not limited to municipal solid waste (MSW), industrial and commercial waste, refuse derived fuel (RDF) and clinical waste. There are multiple different forms of Energy from waste (EfW) technologies used around the globe, including gasification, pyrolysis, thermal hydrolysis and anaerobic digestion.

In this worked example, only incineration of MSW is considered with energy recovered from the waste in the form of electricity and heat. The table below gives a summary of key process data for MSW incineration.

Table 1. Summary of key process data for MSW incineration.

\begin{tabular}{|l|c|l|}
\hline Property & Value & Source \\
\hline Typical energy content of raw MSW & $8-11 \mathrm{MJ} / \mathrm{Kg}$ & {$[1]$} \\
\hline Energy content of MSW \& IC\&I waste in example (MJ/kg) & $12.76 \mathrm{MJ} / \mathrm{Kg}$ & {$[2]$} \\
\hline Carbon content & $28-30 \%$ (wet) & {$[3]$} \\
\hline Expected carbon ratio (biogenic to fossil) & $2: 1$ & {$[3]$} \\
\hline Thermal generation efficiency & $17-30 \%$ & {$[1]$} \\
\hline Typical electrical efficiency (gross) & $27 \%$ & {$[1]$} \\
\hline Typical maximum electrical efficiency (net) & & {$[1]$} \\
\hline
\end{tabular}

The values above provide only guidelines for generic plants. The energy content, carbon content and ratio of biogenic to fossil carbon will vary from location to location and are also likely to vary on a temporal/seasonal basis. Additional sorting, separation and drying of MSW (to generate something more akin to RDF) will see an increase in energy content. In the above table the thermal generation efficiency refers to the percentage of energy recovered in the form of steam from the combustion of MSW.

The incinerator modelled in detail within this worked example is the Emerald Energy from Waste Incinerator located in Brampton, Greater Toronto Area, Ontario, Canada. The incinerator treats a combination of MSW and industrial, commercial and institutional (IC\&I) waste. It is expected that the addition of IC\&I waste and the sorting undertaken on the tip floor accounts for this increased energy content.

The term "incineration" tends to be used for simple, mass burn thermal treatment approaches whereas the two-stage process used by Emerald Energy from Waste has aspects which are similar to gasification. However, for simplicity, the term incineration will be used in this study. The modelled incinerator is capable of treating up to 500 tonnes of MSW daily. An overview of the plant is provided below, with a simple process flow diagram presented as Figure 1.

Waste is delivered to the incinerator tip floor, where the waste is screened for unacceptable materials before being stacked. Waste is transferred to the incinerator by a front-end loader (a manual operation). The floor can store 2250 tonnes of waste (approximately 4.5 days of feedstock).

The facility houses five incinerators, each capable of treating $90-120$ tonnes of MSW/day. The incinerators are stated to be "CONSUMAT Controlled-Air Incinerator" gasifiers [4]. Each gasifier consists of two chambers, an upper and a lower chamber. MSW is fed into the lower chamber, where the residence time is 
approximately 6 hours. Waste is treated at a temperature of $850^{\circ} \mathrm{C}$ in a low-oxygen environment (50\% airto-fuel mixture), resulting in the partial oxidation/gasification of the combustible fraction of the waste. After combustion, the remaining solids (bottom ash) is non-hazardous and is currently disposed of in landfill. However, alternative uses are under consideration.

The resultant gas produced (a combination of primarily carbon monoxide, hydrogen, carbon dioxide and nitrogen) is drawn into the upper chamber where it is combusted in an oxygen rich (200\% air-to-fuel mixture) atmosphere. The upper chamber operates at a temperature between 1000 and $1100{ }^{\circ} \mathrm{C}$, with combustion gas residence time being a minimum of 1 second.

The incinerator units are designed to treat waste with a heating value of $12.76 \mathrm{MJ} / \mathrm{kg}$ of $\mathrm{MSW}$, with this value taken used as the heating value of MSW in this worked example.

Each incineration unit has a dedicated boiler for heat recovery. Steam is produced at a pressure of 4.24 bar (gauge) and a temperature of $343{ }^{\circ} \mathrm{C}$ (super-heated steam, with $189{ }^{\circ} \mathrm{C}$ of superheat [5]). The capacity of each boiler is $12,250 \mathrm{~kg} /$ hour of steam.

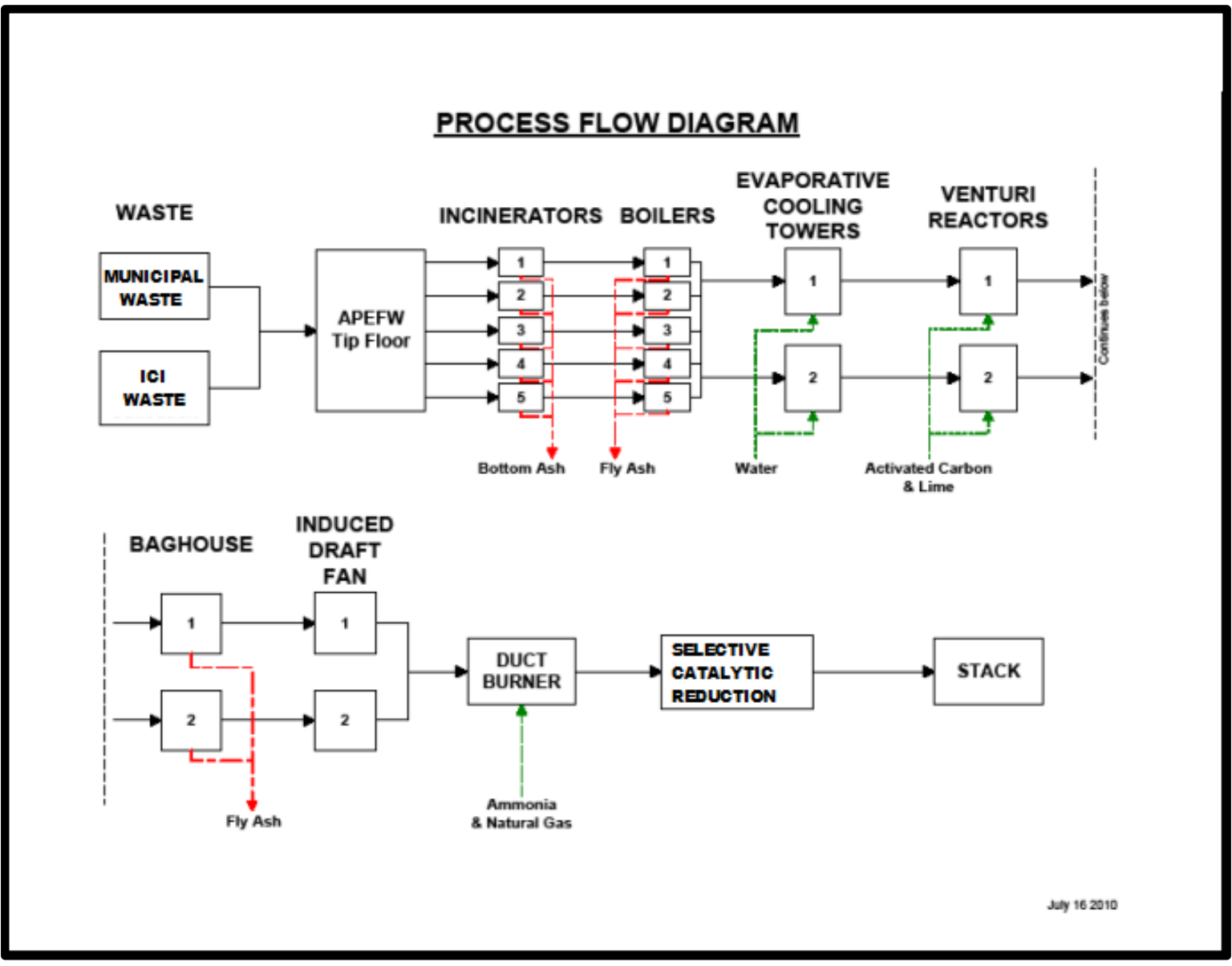

Figure 1. Simplified process flow diagram [2]

The generated steam is then sent from the boilers to a steam turbine generator, with an output rated at 9.31 MWe. The steam produced in the incinerator is also used to provide heat to a nearby paper mill via an 800 metre pipeline. Saturated steam is supplied at a pressure of 13.8 bar (gauge) at an average flow of 
$31,750 \mathrm{~kg} / \mathrm{hour}$, the steam is used in the paper mill and the condensate returned to the waste to energy plant.

After combustion in the upper chamber of the incinerator, the gas produced in the process has to be scrubbed before it can be released to atmosphere. Emissions produced in MSW incineration that need to be removed from raw flue gas before release include: dioxins, furans, $\mathrm{HCl}$, mercury \& other heavy metals, particulate matter/air pollution control residue (APCr), $\mathrm{SO}_{x}$ and $\mathrm{NO}_{x}$ compounds.

\section{Emissions limits for incinerators in Canada}

Waste to energy incinerators are covered within the wider "Canada Wide Standards" (CWS) that set targets and emission limits for various compounds deemed hazardous to the environment and hazardous to the health of humans and wildlife. The CWS can be achieved through voluntary action, or through compliance with regulated or legally enforceable limits.

Substances managed by the CWS for incinerators include:

- Mercury and its compounds

- Pentachloro-benzene (PeCB)

- Tetrachloro-benzenes (TeCBs)

- Polychlorinated dibenzodioxins (Dioxins)

- Polychlorinated dibenzofurans (Furans)

Emissions of dioxins and furans are reported in $\mathrm{g} / \mathrm{TEQ} / \mathrm{yr}$ (TEQ being the toxic equivalency quotient)

The total amount of dioxins and furans released from incineration equates to $44.9 \mathrm{~g} / \mathrm{TEQ} / \mathrm{yr}-$ this is roughly $22.5 \%$ of the total releases to atmosphere for Canada.

The Emerald incinerator utilises the following technologies in its flue gas clean up facility:

- An evaporative cooling tower to reduce the temperature of flue gases to $185^{\circ} \mathrm{C}$.

- A Venturi scrubber/reactor where the gas is contacted with activated carbon (for removal of mercury and other heavy metals) and dry $\mathrm{CaO}$ (for removal of acid gases).

- A baghouse for the filtration and removal of particulate matter (APCr), the APCr primarily consists of unreacted lime from the scrubber, calcium compounds and un-combusted materials from the incinerator (top ash).

- A selective catalytic reduction (SCR) unit is used to remove $\mathrm{NO}_{x}-\mathrm{NO}_{x}$ is reacted with ammonia to produce nitrogen and oxygen in the presence of a catalyst [6]. The SCR unit also allows for the oxidation of furans and dioxins in the flue gas, these gases are oxidized to form $\mathrm{CO}_{2}, \mathrm{HCl}$ and $\mathrm{H}_{2} \mathrm{O}$. 


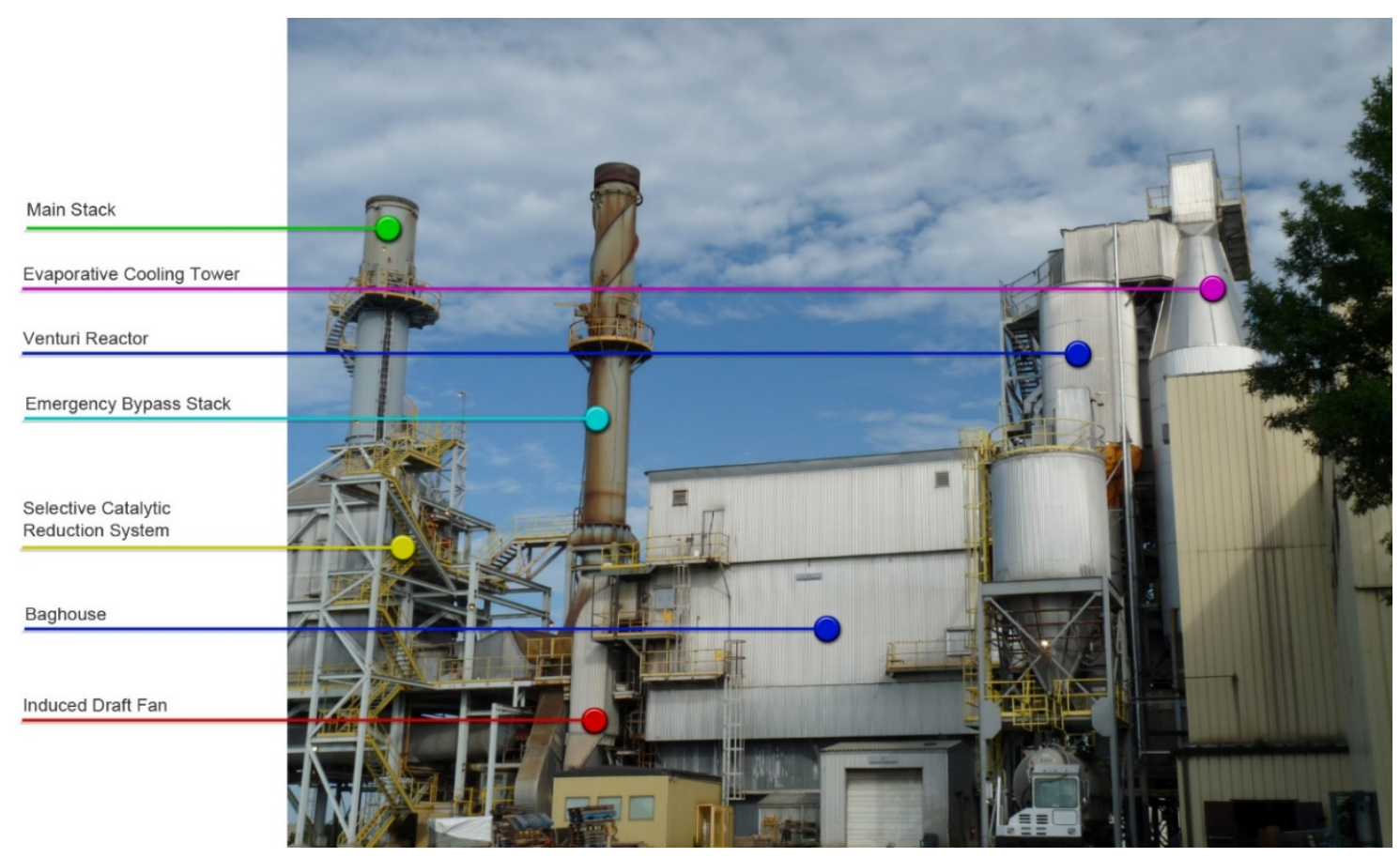

Figure 2. Photograph of the Emerald Energy from Waste facility [2].

After scrubbing, the flue gases are released via the stack, leaving only the APCr material to be treated. In Canada and many other locations APCr is considered a hazardous waste that must be treated before being utilised or sequestered/landfilled.

The following sections detail how this APCr is treated currently (Section 1.2) and the proposed alternative treatment (Section 1.3).

\section{A.2.2 APCr stabilization}

The reference treatment for the APCr, which is a hazardous waste when untreated, is the Stablex process. This is a commercial process which was initially developed in the UK over 40 years ago and involves mixing wastes to neutralize the $\mathrm{pH}$ prior to adding reagents to enable polymerization to a concrete-like material, which is then landfilled [7]. A similar process is used today in the UK by FCC Environment. APCr from a MSW EfW facility is initially treated with water, or an acid if required to reduce its alkalinity, before being mixed with cement or pulverized fly ash (PFA) depending upon its composition. The mixture is then disposed of in mono-cell landfills [8].

The Emerald EfW plant use a company called Stablex, based in Blainville, Quebec which operates a similar commercial process. According to their website, initial chemical analysis of the waste determines its subsequent treatment. Since the APCr is already in the form of a dry powder, no physical processing is required prior to the initial chemical treatment to neutralize the high $\mathrm{pH}$ and cause precipitation so that the contaminants become insoluble to reduce their leachability. Unspecified reagents are used to bind the contaminants into mixed silicates and trap the insoluble precipitates. This material is finally placed into engineered landfill cells where it cures to form a compressive strength similar to a lean concrete. Once full, the cell is capped [9]. 
Due to the lack of data specific to the stabilization of Emerald's APCr, for the purposes of modelling the conventional reference stabilization process, published data was used. The commonest binding agent used industrially for the stabilization/solidification of APCr is Portland cement at a ratio of $620 \mathrm{~g}$ cement/Kg APCr, together with $780 \mathrm{ml}$ water/Kg APCr [10].

\section{A.2.3 Carbonation of APCr (Carbon8 Systems process)}

The proposed alternative to stabilizing and then landfilling the APCr, which will be piloted at Emerald, is a process that entails transforming the APCr into aggregate material through accelerated carbonation. This process is a modified form of the existing Carbon8 Systems (C8S) process which is successfully operated in the UK, utilising various APCr stocks from various MSW EfW facilities to produce aggregate through accelerated carbonation using pure, bottled $\mathrm{CO}_{2}$ and a number of other components/bulking agents.

In this modified process, APCr is once again reacted with $\mathrm{CO}_{2}$, water and mixed with bulking agents. However, the $\mathrm{CO}_{2}$ is not purchased at high purity from a market source but is directly sourced from the flue gas of the incinerator stack (post-scrubbing). The flue gas $\mathrm{CO}_{2}$ is utilised without any further need for separation, beyond the gas clean up technology described above.

Unlike the larger scale, fixed plants in the UK which treat around 30,000 tonnes annually, the modified process takes place in a portable, modular plant capable of treating the 3000 tonnes of APCr produced by Emerald, annually.

The process is staged, with the first stage taking place in a mixer where the APCr is mixed with water and the flue gas containing carbon dioxide. The calcium oxide (and potentially magnesium oxide and $\mathrm{Ca} / \mathrm{Mg}$ silicates) in the APCr reacts with carbon dioxide and the water to produce carbonated material.

$$
\begin{array}{lr}
\mathrm{CaO}+\mathrm{H}_{2} \mathrm{O}_{(\mathrm{L})}->\mathrm{Ca}(\mathrm{OH})_{2} & \Delta \mathrm{H}=-65 \mathrm{~kJ} / \mathrm{mol} \\
\mathrm{Ca}(\mathrm{OH})_{2}+\mathrm{CO}_{2} \rightarrow \mathrm{CaCO}_{3}+\mathrm{H}_{2} \mathrm{O}_{(\mathrm{L})} & \Delta \mathrm{H}=-113 \mathrm{~kJ} / \mathrm{mol}
\end{array}
$$

The reactions that take place are exothermic and thermodynamically favourable, resulting in the need for little energy in put at this stage. The kinetics of carbonation are typically modelled on a shrinking core model in literature sources, suggesting the APCr particle diameter is an important factor in determining reaction time. The temperature, operating pressure and residence time of the primary stage mixer are controlled to maximize carbonation of the APCr.

In the second stage of the process, the carbonated APCr is fed into a second mixer where it is mixed with bulking agents, such as sand. If the APCr has been fully carbonated to manage the risks of heavy metal leaching, it will not react further with $\mathrm{CO}_{2}$. Under these circumstances it may be necessary to add another carbonate-able material such as another waste or portland cement powder. The current model uses Portland cement powder for simplicity. The mixture is then fed to a pelletizer with additional $\mathrm{CO}_{2}$ and the aggregate is formed. A fraction of the water input into the mixture is evaporated during the production of rounded aggregate particles of various sizes. The total mass of each non-APCr input varies dependent on the composition of the APCr used.

\section{A.2.4 Primary Aggregate Mining}

Aggregate is widely used in many forms of construction - either loose or formed into blocks with other materials. A number of materials are used as aggregate including but not limited to: sand, gravel, crushed stone, slag and recycled concrete. As can be seen from the examples given, aggregate materials come from a range of sources. These sources have been classified by the British Geological Survey as follows: 
- Primary aggregate - aggregate produced from naturally occurring materials extracted specifically for use as aggregate and used for the first time. Examples include: crushed hard rock, sand and gravel.

- Secondary aggregate - aggregate obtained as a by-product of other quarrying or mining operations or aggregates obtained as a by-product of other industries. Examples include: china clay waste, colliery spill waste, blast-furnace/steel slag, coal-fired power station ash, incinerator ash and spent foundry sand.

- Recycled aggregate - aggregate sourced from demolition or construction of buildings and structures or from civil engineering works. Examples include: asphalt planings from road resurfacing, railway ballast, bricks and concrete blocks.

Most construction aggregates are produced from hard \& strong rock sources, with the local geology having an influence on the materials most commonly used. An overview of the Ontario aggregate market is provided below [11].

Between 1996 and 2016, Ontario consumed approximately 3.4 billion tonnes of aggregate material, this equates to approximately 170 million tonnes annually on average. This average is expected to rise by $13 \%$ over the next 20 years. Such a large annual market ensures that the aggregate produced through accelerated carbonation is unlikely to have an impact on market prices.

The aggregate used by Ontario is mainly from primary sources, although an increasing amount of secondary aggregate has been utilised. Most of this aggregate material is sourced from Ontario pits and quarries. Over half of the aggregate used in the greater Toronto area is sourced from neighbouring areas, largely within the outer ring of the Greater Golden Horseshoe.

Due to this utilisation of predominantly local material, research into the surrounding counties aggregate industry was required. The waste to energy plant is located in Brampton, within the municipality of Peel, the neighbouring municipalities of York and Halton were also investigated (both within the greater Toronto area). Geology Ontario offer comprehensive resource studies for aggregate in both Peel [12] and York [13] municipalities. The reports can be summarised as follows:

- Significant resources for sand and gravel are available in Peel (17 licensed pits) and York (14 licensed pits) and to a lesser extent Halton (6 licensed pits), a large number of operations are capable of producing aggregate quality material across the municipalities. The numbers above do not include abandoned/unlicensed pits. In Peel a number of large sand and gravel pits are clustered near the town of Caledon, approximately $16 \mathrm{~km}$ north of Brampton.

- Bedrock resources/formations are found across the Peel municipality - most of these formations are not deemed to produce material capable of use as aggregate. The Queenston formation exposed in the central region of Caledon has been used extensively for the production of brick making clay and shale (quarry operated by Brampton Brick Ltd). The only source of bedrock suitable for aggregate production is located south of Caledon (the Amabel formation), the rock from this formation is dolostone and is deemed "high quality" capable as use as aggregate in numerous production processes.

- Bedrock resources in York municipality can also be found, although no areas of particular promise are highlighted in the resource inventory/report by Geology Ontario.

- Bedrock resources in Halton are significant, with 11 licensed quarries operating in the municipality. The Amabel formation is quarried in several locations, providing a source of high-quality crushed rock material. A dolostone quarry (Acton Quarry, operated by Dufferin Aggregates) close to the town of Milton (located in Halton Hills, approximately $30 \mathrm{~km}$ from Brampton) is reported to produce 
high-quality aggregate material from the Amabel formation. This is the largest licensed quarry in the area. Dufferin operate a second site approximately $10 \mathrm{~km}$ away from this first site, closer to the town of Milton.

- Acton Quarry is of particular value due to the bedrock formation being found relatively close to the surface, allowing for increased efficiency in mining. The dolomitic limestone present is also up to 30 metres thick providing a significant volume (and mass) of rock material [14].

From the materials listed above, dolomitic limestone (also referred to as dolostone/dolomite) can be utilised as aggregate when quarried (the rock is normally crushed and broken). Shale clay can also be used to form lightweight aggregate when processed. Aggregate is formed through the expanding and vitrifying of shale clay into a ceramic type material in a rotary kiln [15] although it is unclear if lightweight aggregate is produced in the area from the shale formations.

It is expected that any aggregate produced from accelerated carbonation will likely replace primary aggregate produced from one of these potential sources.

\section{A.2.5 Concrete Masonry Unit (CMU)/ Block Production}

Whist aggregate has many uses in the construction industry, only the production of concrete blocks (masonry units) is here. The range of concrete blocks available is diverse, both in terms of geometry and technical specification (with varying strengths density, durability and material of construction amongst other properties).

Concrete blocks are typically produced with one of three geometries:

- Solid blocks - no formed voids or cavities

- Cellular blocks - which have one of more formed voids or cavities which do not pass through the block.

- Hollow blocks - which have one or more formed voids or cavities which pass right through the block.

Technical datasheets for concrete blocks usually provide information on the "solid percentage" of the block, which is calculated by dividing the net volume of the block by its gross volume (or the volume of the block that is solid).

In Canada, concrete blocks are classified by the type of concrete used to produce the block [16]. The classification is established by investigating the oven-dry density of the particular concrete used in the production of a unit/block. The oven-dry density is determined by test, in accordance with ASTM C 140. Referring to CSA A-165.1 (with CAN/CSA A-165 being the Canadian standard on CMUs), the density can be used to provide a classification for the concrete type. CSA A-165.1 quantitatively identifies four classifications of concrete using the density as shown in the table below. The table below provides details on each type and also provides the common construction name.

Table 2. Concrete classifications in Canada in accordance with CSA A-165.1

\begin{tabular}{|c|c|c|}
\hline Concrete Type & $\begin{array}{c}\text { Concrete Density } \\
\left(\mathrm{kg} / \mathrm{m}^{3}\right)\end{array}$ & Common construction name \\
\hline A & $>2000$ & Normal weight \\
\hline B & $1800-2000$ & Medium weight \\
\hline C & $1700-1800$ & Medium or Semi-light weight \\
\hline
\end{tabular}




\begin{tabular}{|c|c|c|}
\hline D & $<1700$ & Light weight \\
\hline N & No limit & Unclassified \\
\hline
\end{tabular}

The type of concrete is dependent primarily on the type of aggregate used in the manufacture of the block, with "normal weight" and "light weight" referring to the type of aggregate used in the concrete mix. Typical normal weight aggregates include sand, gravel and crushed stone - all of which are readily available on location in the greater Toronto area as discussed in section 1.4 above. Natural light weight aggregates include expanded shale and clay (found in the local area) and volcanic pumice (not found in the area). There are a range of light weight aggregates that are produced as or from industrial by-products (including fly ash and furnace clinker), with the aggregate produced by accelerated carbonation of APCr being an example of this. Medium or semi-medium weight concretes (types B and C respectively) are produced by blending a mixture of normal and light weight aggregates.

In Canada the standard overall dimensions of blocks are covered by standard CSA A-165.1-04. The standard nominal height is $200 \mathrm{~mm}$ (190 mm actual/manufactured), the standard nominal length is $400 \mathrm{~mm}(390 \mathrm{~mm}$ actual/manufactured) with half-sizes also available for both the height and length. The standard nominal widths are $100 \mathrm{~mm}, 150 \mathrm{~mm}, 200 \mathrm{~mm}, 250 \mathrm{~mm}$ and $300 \mathrm{~mm}$ (or 90, 140, 190, 240 and $290 \mathrm{~mm}$ actual/manufactured respectively). A combination of the density of the concrete, the size of the block and the solid percentage of the block will give the overall weight of the block.

Another key property of concrete blocks that needs to be considered is the compressive strength of the product. This is a key performance indicator, as blocks with a higher compressive strength are capable of withstanding greater loading. The compressive strength of a concrete masonry units varies with the cement and aggregate content, and aggregate type [16]. The compressive strength of a concrete masonry unit is determined primarily through direct testing. The compressive strength of a concrete block should not be confused with the compressive strength of masonry (where concrete blocks are used). Some examples of common unit strengths (compressive strengths) are as follows (all with units $\mathrm{N} / \mathrm{mm}^{2}$ ): 2.9, 3.6, 7.3, 10.4, 17.5, 22.5, 30.0 and 40.0. [16] Most blocks containing light weight aggregates (light weight and medium weight blocks) typically have compressive strengths of $10.4 \mathrm{~N} / \mathrm{mm}^{2}$ or less.

The construction of blocks is a process that has been highly automated in most modern block making plants in the UK, it is expected that the situation is similar in Canada. In automated plants, earth-dry concrete is fed to the mould where it is vibro-compacted onto steel, timber or plastic pallets. After this, the blocks are immediately de-moulded and transported on a pallet by a conveyor to a curing chamber where they can be treated with heated air or steam to accelerate the strength increase. After curing blocks are taken from the chamber and stacked for delivery and use [17].

However, a large number of less-automated plants still exist. A typical example of this would by the use of an "egg layer" machine. In this instance mixed concrete is loaded into a hopper and the material is fed into moulds before being vibrated and left on a slab to cure. The machine moves along the slab and repeats the process. The process is relatively simple and all that is needed is a concrete mixing plant, a vehicle to transport the concrete to the block machine and a flat slab to press the blocks. Fresh blocks are typically left on the slab for two to three days to gain strength.

Concrete is fabricated from a mixture of aggregates (either coarse or fine, or a mixture of both), Portland cement and water. Other materials can be added if required, such as admixtures and fibres (to change the properties of the concrete). The composition of the concrete mix is known to vary (Table 3), the percentages (vol \%) are taken from multiple sources to give an indication of typical compositions. 
Table 3. Concrete compositions from different sources.

\begin{tabular}{|l|c|c|c|}
\hline Component & Portland Cement Asc. & Concrete Network & US Federal HA \\
\hline Aggregate $(\%$ vol) & $60-75$ & $60-80$ & $60-75$ \\
\hline Portland cement (\% vol) & $7-15$ & $7-15$ & $7-15$ \\
\hline Water (\% vol) & $14-21$ & $14-18$ & $14-21$ \\
\hline Air (\% vol) & Up to 8 & $2-8$ & Up to 8 \\
\hline
\end{tabular}

The final source in Table 3 provides a rough indication of how this volume percentage relates to mass for aggregate; the aggregate typically accounts for 80 to $85 \%$ of the concrete mass. Materials such as coal fly ash and granulated blast furnace slag (secondary aggregates) act as cementing agents by being pozzolanic in their nature.

\section{A.2.6 Transportation}

In this worked example, not all of the processes discussed in sections 1.1 to 1.6 occur on the same site. To account for this, transport between sites must be considered along with the associated costs and emissions. Whilst most journeys are assumed to be relatively local, the existing APCr disposal procedure requires the transportation of the APCr to the Stablex site in Blainville, Quebec, $584 \mathrm{~km}$ away. Other key distances (determined using Google Maps) are as follows:

- Sand quarry to mineralisation site: $35 \mathrm{~km}$ (Lafarge, Caledon Village)

- Cement production site to mineralisation site: $35 \mathrm{~km}$ (CRH Mississauga)

- Mineralisation site to site of block manufacture: $16 \mathrm{~km}$ (Brampton Blocks)

- Sand quarry to site of block manufacture: $21 \mathrm{~km}$ (Lafarge, Caledon Village)

- Aggregate quarry to site of block manufacture: $26 \mathrm{~km}$ (Dufferin Aggregates, Acton)

- Cement production site to site of block manufacture: $45 \mathrm{~km}$ (CRH Mississauga)

- Site of block manufacture to market: $50 \mathrm{~km}$ (Toronto City Hall)

A map showing potential locations of key sites in the Brampton area is included below. 


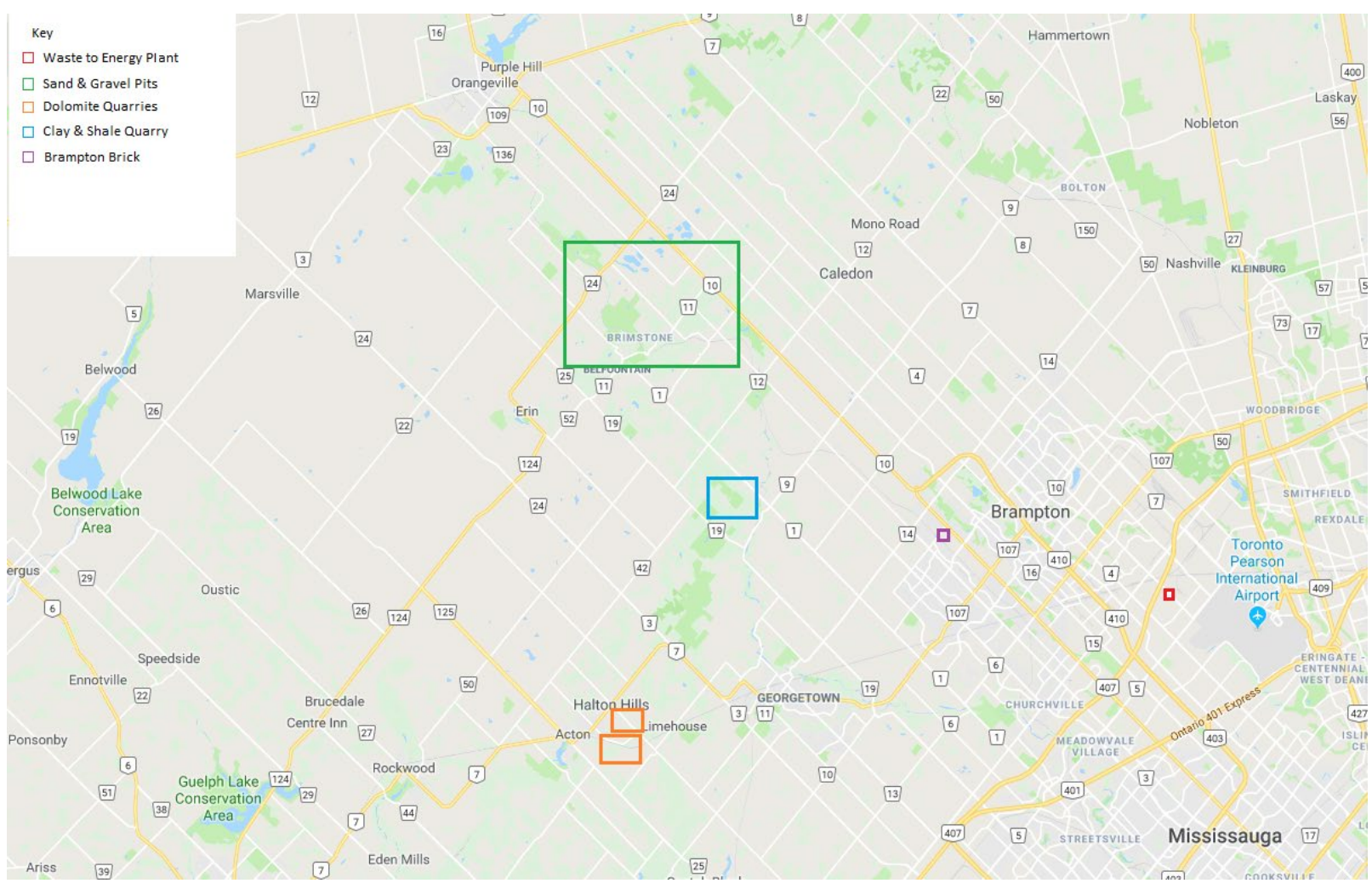

Figure 3. Map showing key locations in the Brampton area, adapted from source [18]

The only locations not shown on the map are the APCr stabilization and landfilling process and the cement works located in Mississauga.

As part of a sensitivity analysis alternative locations were considered to allow for investigation into the sensitivity of the environmental impacts of the process with regards to transport.

Transport of the APCr is undertaken in 30 tonne powder tankers. Transport of the other materials is assumed to be by 30 tonne trucks.

\section{A.2.7 End of Life}

It is assumed that at their end-of-life, the used blocks will be crushed and recycled as a loose aggregate - a process used increasingly in many countries. 


\section{A.3 Product selection for LCA and TEA Comparison}

To analyze the financial and environmental implications of replacing primary aggregate in this process with secondary aggregate produced by Carbon8 Systems, a fair comparison between block functionality must be made. This requires the setting of a scenario, specifically one that is applicable to the greater Toronto area. The basis of this scenario is as follows:

1. A concrete masonry unit/block is deemed to be equal in functionality to a second block when the geometry and compressive strength of the two blocks are equal, regardless of the materials used to construct the block and concrete type (A, B, C or D).

2. All concrete masonry units/blocks that are to be compared should be representative of blocks that are readily available on the local market or could feasibly be produced locally at an economically viable price.

The first statement accounts for the need to have a product that could be swapped "like for like" with the comparative block - if the size or compressive strength differ this may not be possible.

Whilst the thermal conductivity is another important property of a concrete block, only limited consideration of this has been included in this work. Any significant difference between thermal conductivities of the blocks compared should be reported, to allow for consideration of the impacts of this in (increased thermal conductivity will see an increase in heat loss which may be problematic in some scenarios/functions).

The second statement accounts for the need to compare market-available blocks in the greater Toronto area to blocks that could be produced using C8S aggregate. Block making in the greater Toronto area typically uses local primary aggregate (as established above), with dolomitic limestone, gravel and sand being the materials most readily available. The C8S aggregate can be substituted in for this aggregate in block production. As the aggregate and masonry industries are typically localized, in this instance it would be of questionable use to compare C8S blocks to those made long distances away.

As dolomitic limestone/dolostone is readily available blocks which use this as a primary aggregate are considered primarily in this work. The comparison made is between blocks using only dolostone and using blocks in which C8S aggregate is substituted for between $10 \%$ and $20 \%$ of the dolostone aggregate. It is assumed no other secondary aggregate is used in the block making process. 


\section{A.4 Block Composition}

Concrete masonry units (CMUs) manufactured from aggregates are available in a wide range of specifications, as detailed in Section A.2 Process Description. As such it is necessary to determine a specification for the aggregates blocks to be assessed as part of this study.

A major component of this specification is the composition of the block, with compositions needed for both the standard CMU and the C8S aggregate containing CMU. To determine a suitable composition a literature search was undertaken, with the data found used to provide an indication of what an average block would consist of. Figure 4 below gives a simplified breakdown of the components of a typical CMU.

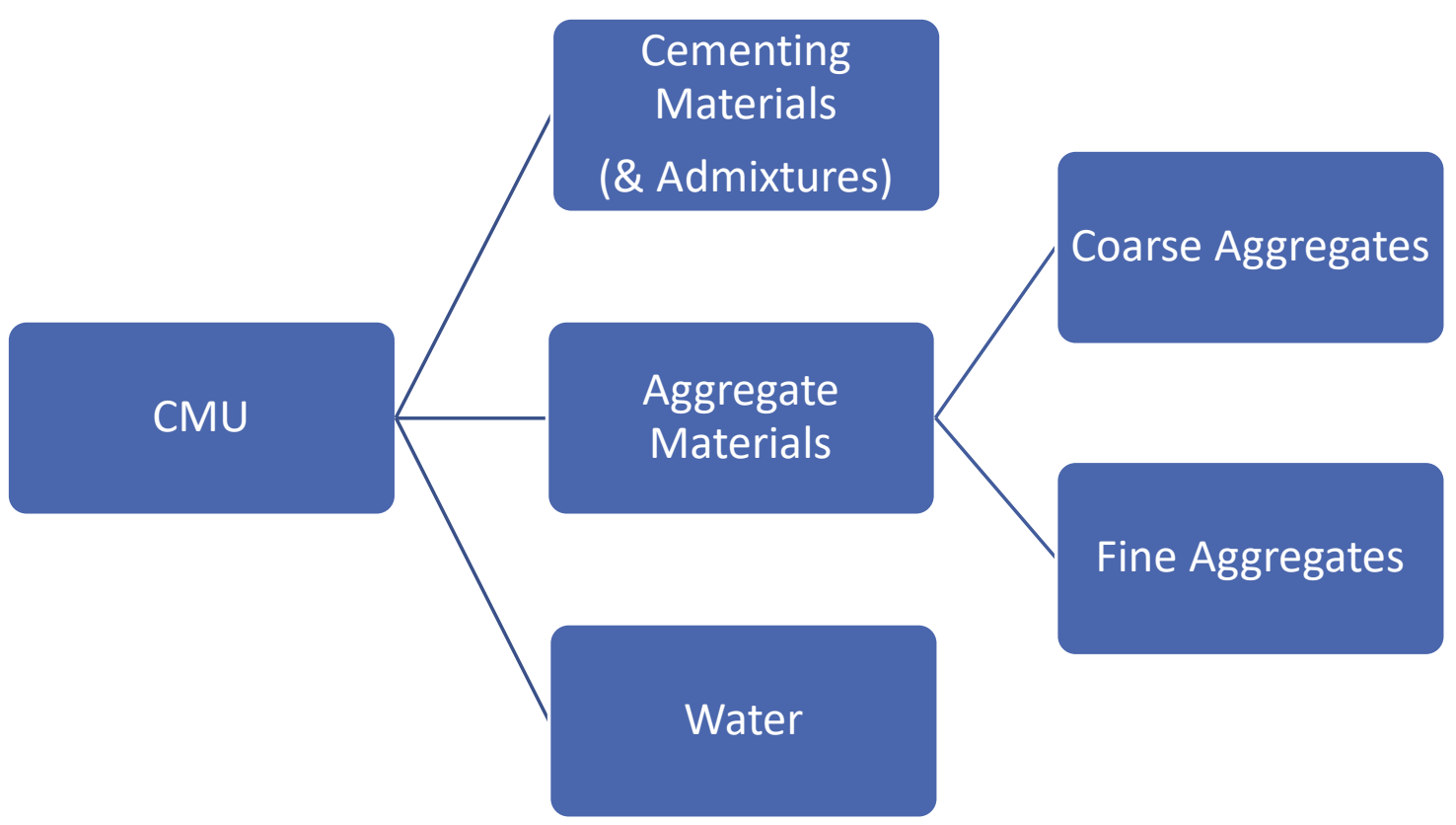

Figure 4. Components of Concrete masonry units.

A total of eight CMU compositions were found across 7 different sources. For both cementing materials and aggregate materials, a range of products were found to be utilised across the studies reviewed.

- Cementing materials included Portland cement (most common), blended cement, slag cement, fly ash. Some studies reported the use of admixtures, typically as a generic additive (no chemical formula provided).

- Aggregate materials could broadly be classified as fine and coarse types, with some materials such as crushed rock capable of being graded as either. Sand and gravel are examples of common fine aggregates, other examples found in studies included silica flour, glass powder and pumice. 
- Water bound into the final was found to primarily be treated water, with small amounts of untreated water used in some cases.

From the investigation four key properties were determined for each source:

- Average composition of a CMU (mass basis)

- Aggregate to cement ratio

- Cement to water ratio

- Fine to coarse aggregate ratio

The ratios are derived from the mass composition, but act as a useful guideline for the determination of an average $\mathrm{CMU}$ (both these ratios are often referred to in general literature on the topic, even when the mass or volume composition is not). The fine to coarse aggregate ratio is not as widely reported as the mass composition. Those that do report it often don't specify the cut-off between fine and coarse specifications, the ratio between the two also varies significantly from source to source. This is understandable, as different ratios will likely produce CMUs with different properties.

From the data collected in the literature search, an average mass composition as attained. This was then used as the basis for the composition of the two types of CMU to be modelled within the study, referred to as block 1 (reference block) and block 2 (C8S aggregate containing block) in Table 4.

Table 4 Summary of the composition of the 2 blocks to be modelled.

\begin{tabular}{|c|c|c|c|}
\hline Material & $\begin{array}{l}\text { Assumed Density } \\
\left(\mathrm{kg} / \mathrm{m}^{3} \text { material) }\right.\end{array}$ & $\begin{array}{c}\text { Block } 1 \\
\left.\text { (kg material } / \mathrm{m}^{3} \mathrm{CMU}\right)\end{array}$ & $\begin{array}{c}\text { Block } 2 \\
\text { (kg material/ } \mathrm{m}^{3} \\
\mathrm{CMU})\end{array}$ \\
\hline Dolomitic limestone & 2500 & 1025 & 775 \\
\hline Sand & 1442 & 591 & 447 \\
\hline C8S aggregate & 1100 & 0 & 220 \\
\hline Cement & 1450 & 174 & 174 \\
\hline Water & 1000 & 60 & 60 \\
\hline TOTAL & & 1850 & 1676 \\
\hline
\end{tabular}

The assumed densities reflect that each material has a range of reported densities, with a specific value needed here. The use of sand and dolomitic limestone as the fine and coarse aggregates is due to their local availability, discussed in greater detail in Section A.2 Process Description. It is assumed that the C8S aggregate replaces a fraction of the sand and of the dolomitic limestone. In this example C8S aggregate accounts for approximately $13 \%$ of the total mass of $1 \mathrm{~m}^{3}$ of CMU. This falls within the valid mass fraction range quoted by the company Carbon8 Aggregates Ltd. The compositions of the blocks above are not those of any available on the market and are merely used here as a viable example confined within the averages found within this study.

Figure 5 shows the mass compositions of each study and the mass compositions of blocks 1 and 2 . Both figures refer to data from sources [19][20][21][22][23][24][25]. 


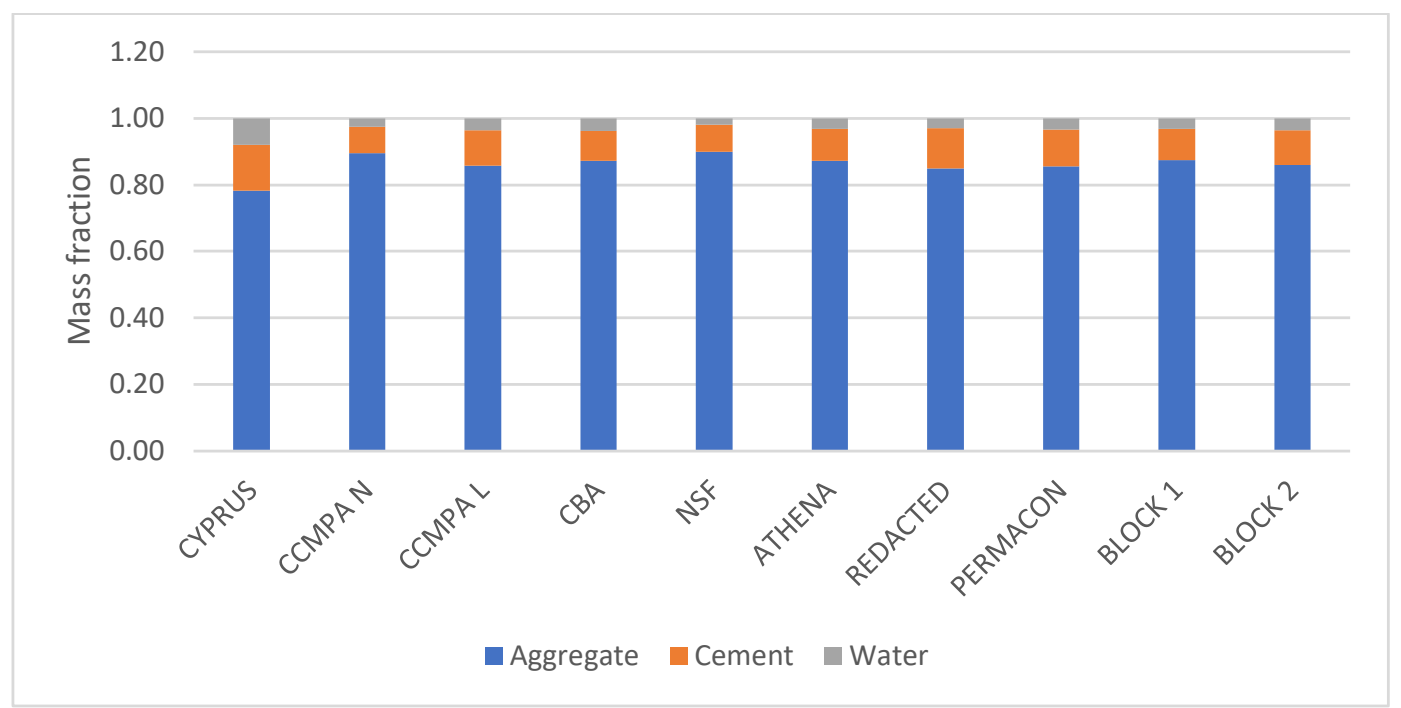

Figure 5.

As can be seen the mass composition of block 1 and block 2 are within the averages found.

Figure 6 shows a scatter plot of the cement to water and aggregate to cement ratios, once again blocks 1 and 2 are shown to be within the confines of the average.

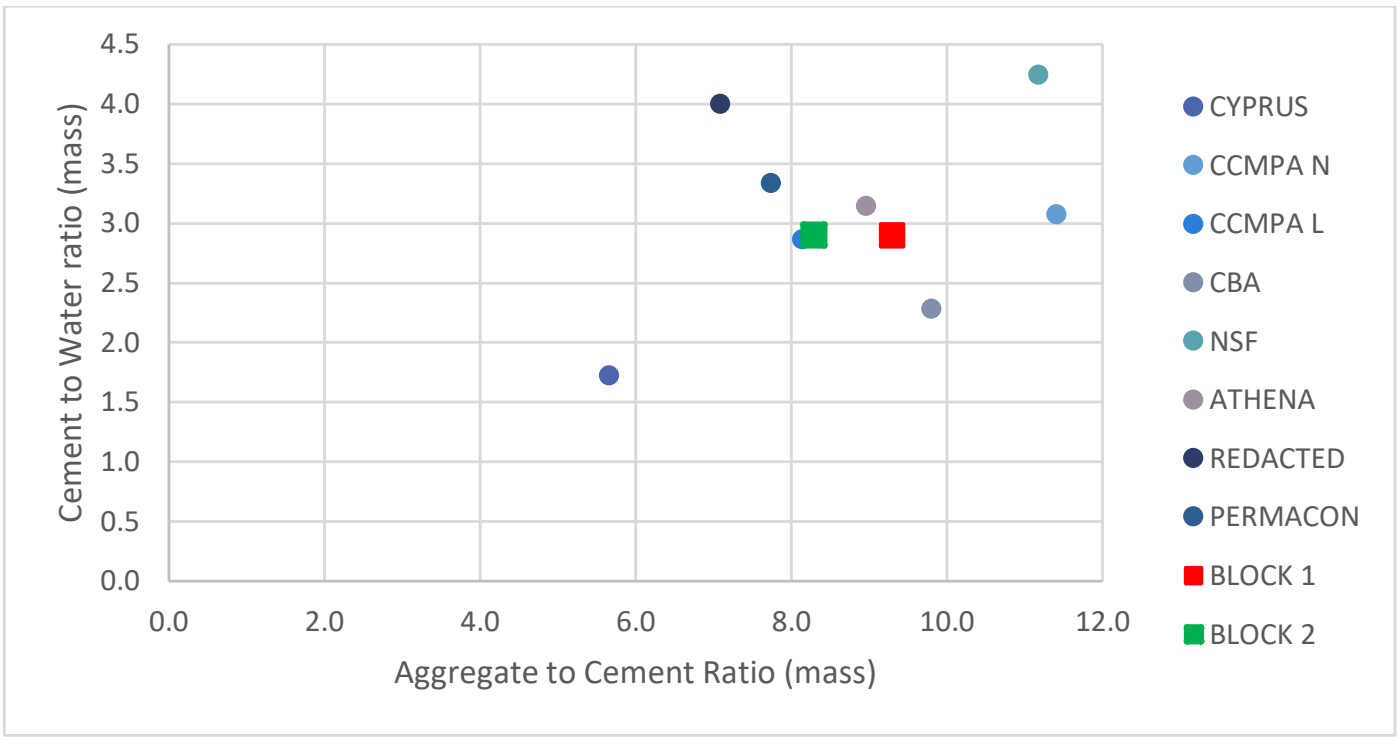

Figure 6.

The scatter plot shows an equal water to cement ratio for the blocks, but a higher aggregate to cement ratio for block 1 . This is due to the difference in the density of C8S aggregate and the natural aggregates it replaces (sand and dolomitic limestone). 


\section{A.5 Reference List}

[1] DEFRA, "Incineration of Municipal solid waste," 2013.

[2] E. EfW, "Emerald EfW - Equipment," 2018. [Online]. Available: http://www.emeraldefw.com/equipment.php.

[3] B. Bahor, M. Van Brunt, K. Weitz, and A. Szurgot, "Life-Cycle Assessment of Waste Management Greenhouse Gas Emissions Using Municipal Waste Combustor Data," vol. 136, no. August, pp. 749-755, 2010.

[4] CONSUTECH, "CONSUMAT Controlled-Air Incinerator," 2004. [Online]. Available: http://www.consutech.com/inciner.htm.

[5] SpiraxSarco, "Steam Tables," 2018. [Online]. Available: http://www.spiraxsarco.com/Resources/Pages/steam-tables.aspx.

[6] T. Lecomte, J. F. F. de la Fuente, F. Neuwahl, M. Canova, A. Pinasseau, I. Jankov, T. Brinkmann, S. Roudier, and L. D. Sancho, Best Available Techniques (BAT) Reference Document for Large Combustion Plants. EU JRC, 2017.

[7] C. L. Chappell and S. L. Willetts, "Some independent assessments of the SEALOSAFE/STABLEX method for toxic waste treatment," J. Hazard. Mater., vol. 3, no. 4, pp. 285-291, 1980.

[8] FCC Environment, "Whisby Landfill: APCr Treatment and Disposal," 2018. [Online]. Available: https://www.fccenvironment.co.uk/apcr.html.

[9] Stablex, "Process Overview," 2018. [Online]. Available:

http://www.stablex.com/en/content/process/5-process.html.

[10] M. J. Quina, J. C. M. Bordado, and R. M. Quinta-Ferreira, "Stabilisation/solidification of APC residues from MSW incineration with hydraulic binders and chemical additives," J. Hazard. Mater., vol. 264, pp. 107-116, 2014.

[11] OSSGA, "The Future of Ontario's Close to Market Aggregate Supply: The 2015 Provincial Plan Review," 2015.

[12] Ontario Geological Survey, ARIP165-REV- Aggregate Resources Inventroy of the Regional Municipality of Peel, southern Ontario. 2009.

[13] Ontario Geological Survey, ARIP179 - Aggregate Resources Inventory of the Regional Municipality of York, Southern Ontario, vol. 9938, no. 416. 2010.

[14] Dufferin Aggregates, "About the Acton Quarry," 2018. [Online]. Available: https://www.dufferinactonquarry.com/en/About-the-Acton-Quarry.asp. .

[15] ASTM International, "Expanded Shale, Clay, and Slate," 2015.

[16] G. Sturgeon, "Physical Properties," 2012.

[17] Mortar Industry Association, "Brick and block production," 2013.

[18] Alphabet Inc., "Google Maps," 2018.

[19] C. Chrysostomou, A. Kylili, D. Nicolaides, and A. Paris, "Life Cycle Assessment of concrete manufacturing in small isolated states : the case of Cyprus Life Cycle Assessment of concrete manufacturing in small isolated," vol. 6451, 2017.

[20] CCMPA, "A Canadian Industry-Average Cradle-to-Gate Life Cycle Assessment of Two Concrete 
Masonry Unit Products," 2015.

[21] Concrete Block Association, "Aggregate Block Sustainability," 2017.

[22] MPA British Precast, "Sustainability Matters 2018," 2018.

[23] D. Green, "Segmental Retaining Wall and Concrete Masonry Units Date of Issue," 2015.

[24] G. Venta, "Life cycle analysis of Brick and Mortar products," 1998.

[25] British Precast Concrete Federation, "UK Manufactured Precast Aerated Concrete Blocks," 2017. 


\section{PART B TEA Worked Example}




\section{Contents}

Table of Contents.

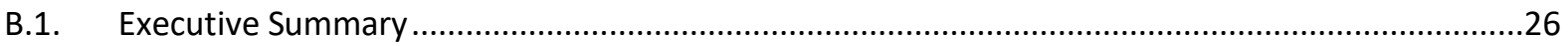

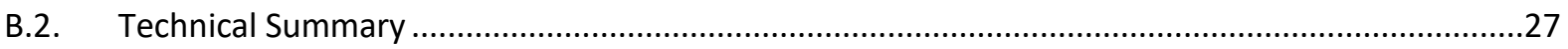

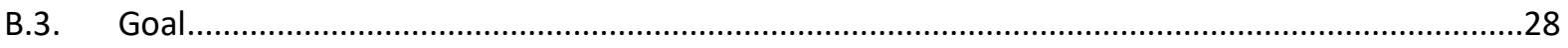

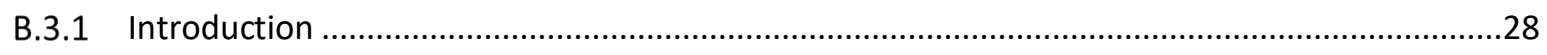

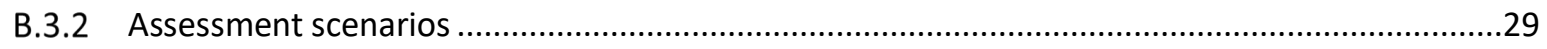

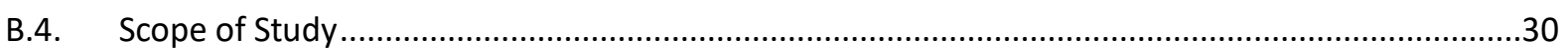

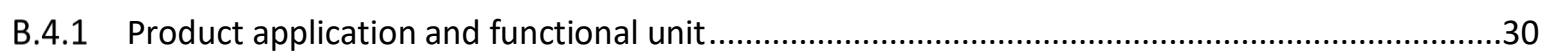

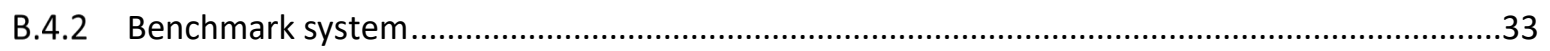

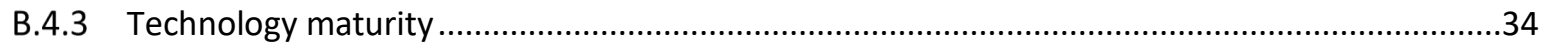

B.4.4 Assessment indicators, consistency and reproducibility ............................................35

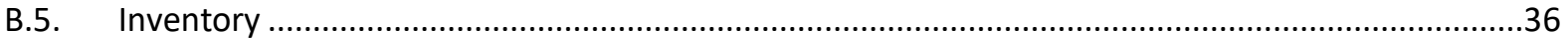

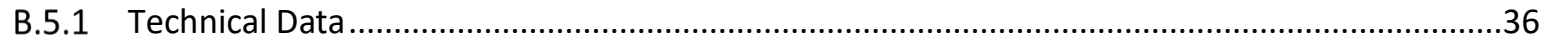

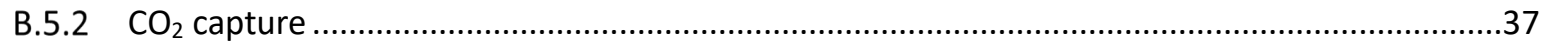

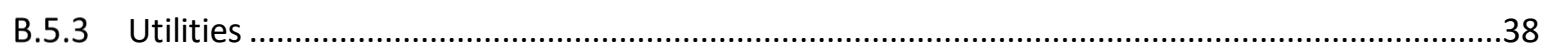

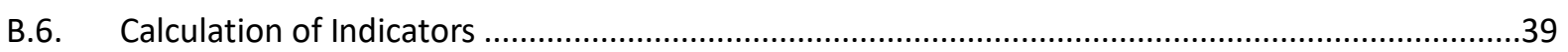

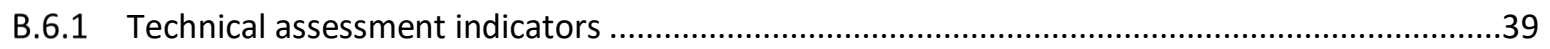

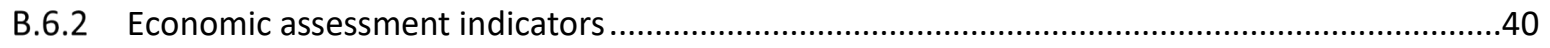

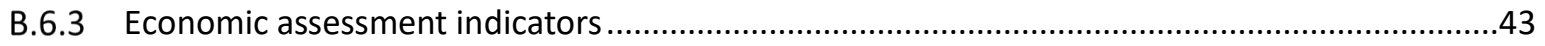

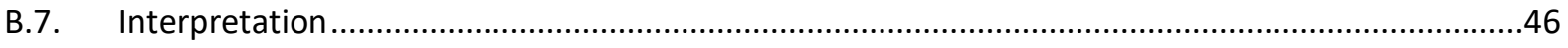

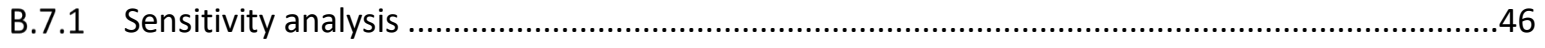

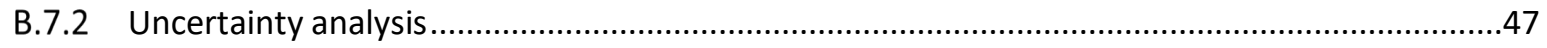

B.7.3 Development of alternative scenarios .........................................................................47

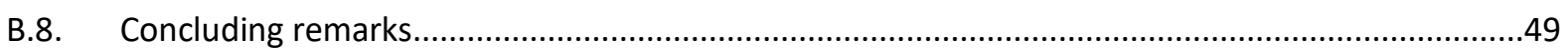

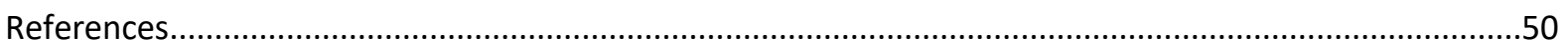




\section{B.1.Executive Summary}

Aggregate has a significant global market with high demand localised around major population centres. Most aggregates used worldwide are from primary sources, however there exists an increasingly large market for secondary and recycled aggregates that offer a reduction in environmental impact.

This report assesses the profitability of the production of secondary aggregate from $\mathrm{APCr}$ and $\mathrm{CO}_{2}$ waste sources. This TEA is designed to be an example of good practice based on the recommendations of the recently published "Techno-Economic Assessment \& Life Cycle Assessment Guidelines for $\mathrm{CO}_{2}$ Utilization".

An overview of the Carbon8 Systems (C8S) process is provided, along with a description of the existing "reference" scenario. A number technical and economic indicators are calculated and reported, with some restrictions to ensure confidentiality and commercial sensitivity are adhered to.

Comparing the production cost of the C8S secondary aggregate (\$CAD 63.26 per tonne) to market prices for crushed stone (\$CAD 14.77) gives a significant cost deficit. Comparing the production cost of $C 8$ aggregate to crushed stone on a functional unit basis gives a price of $\$ C A D 69.59$ per $^{3}$ for C8S aggregate and a market price for crushed stone of $\$ C A D 39.93$ per $\mathrm{m}^{3}$. These figures show that in terms of pure production costs secondary aggregate is not likely to be profitable. The production cost for C8S aggregate is expected to be somewhat stable due to the dominance of the fixed OpEx costs and CapEx.

However, this deficit is overcome by the inclusion of gate fees paid to C8S for the APCr material used resulting in a venture of significant expected profitability. The NPV is calculated to be \$CAD 1,633,606 and the IRR is reported to be $21 \%$.

As would be expected the profitability of the plant is found to be sensitive primarily to the gate fee received, and to a lesser extent the tax rate on profits and the market price for aggregate. Future plants should be located in areas where a significant gate fee is received for aggregate production and in locations where other financial incentives (e.g. tax reductions) for "end of waste" status is provided. 


\section{B.2.Technical Summary}

\begin{tabular}{|c|c|c|c|}
\hline & CCU product & \multicolumn{2}{|c|}{ Secondary aggregate for CMU production } \\
\hline & $\begin{array}{l}\text { Intended application and } \\
\text { reasons for study }\end{array}$ & \multicolumn{2}{|c|}{$\begin{array}{l}\text { What is the economic outlook of utilising air pollution control residue and } \mathrm{CO}_{2} \text { to } \\
\text { produce secondary aggregate material for the construction sector }\end{array}$} \\
\hline 它 & Brief description & \multicolumn{2}{|c|}{$\begin{array}{l}\text { APCr produced from incineration of MSW is currently shipped across Canada for } \\
\text { treatment. An alternative system is to be investigated, where APCr is to be } \\
\text { reacted with } \mathrm{CO}_{2} \text { and mixed with other materials to produce a secondary } \\
\text { aggregate material }\end{array}$} \\
\hline & Intended audience & \multicolumn{2}{|c|}{ TEA practitioners, waste-to-energy sector, aggregate producers } \\
\hline & \multicolumn{3}{|l|}{$\begin{array}{l}\text { Commissioners and } \\
\text { assessors }\end{array}$} \\
\hline & Limitations of study & \multicolumn{2}{|c|}{$\begin{array}{l}\text { Limited data on incinerator conditions } \\
\text { Limitations on reporting commercially sensitive information }\end{array}$} \\
\hline & $\begin{array}{l}\text { System boundary } \\
\text { (e.g. cradle to gate) }\end{array}$ & \multicolumn{2}{|c|}{ Cradle to gate } \\
\hline & Benchmark system & \multicolumn{2}{|c|}{ Production of local primary aggregate material } \\
\hline & Plant size & \multicolumn{2}{|c|}{4500 metric tonnes per year } \\
\hline 芯 & Functional Unit & \multicolumn{2}{|c|}{$\begin{array}{l}\text { Metres cubed of aggregate capable of use in a } 7.6 \mathrm{~N} / \mathrm{mm}^{2} \mathrm{CMU} \text { (primary or } \\
\text { secondary) }\end{array}$} \\
\hline & $\begin{array}{l}\text { System elements and } \\
\text { technology maturity }\end{array}$ & \multicolumn{2}{|c|}{$\begin{array}{l}\text { C8S process: TRL } 9 \\
\text { Primary aggregate production: TRL } 9\end{array}$} \\
\hline & Assessment indicators & \multicolumn{2}{|c|}{ NPV, IRR, CapEx, OpEx, Total production cost } \\
\hline \multirow{8}{*}{ 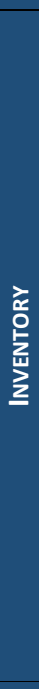 } & Data Source & $\begin{array}{l}\text { \Primary sources } \\
\bigotimes \text { Secondary sources } \\
\square \text { Stoichiometric data }\end{array}$ & $\begin{array}{l}\square \text { Process modelling based data } \\
\square \text { Mixed sources } \\
\square \text { Other (please specify) }\end{array}$ \\
\hline & $\begin{array}{l}\text { Energy sources } \\
\text { (select all that apply) }\end{array}$ & $\begin{array}{l}\square \text { Grid mix } \\
\square \text { Power station with Carbon Capture } \\
\square \text { Wind } \\
\square \text { Solar }\end{array}$ & $\begin{array}{l}\square \text { Nuclear } \\
\square \text { Hydro } \\
\square \text { Future (see timeframes) } \\
\text { \Other (please specify) } \\
\text { Electricity from waste to energy } \\
\text { process..................................... }\end{array}$ \\
\hline & Base year & \multicolumn{2}{|r|}{ 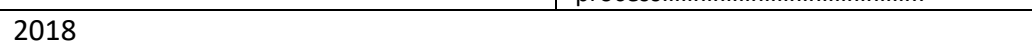 } \\
\hline & Currency & \multicolumn{2}{|l|}{ Canadian Dollars (\$CAD) } \\
\hline & Location & \multicolumn{2}{|l|}{ Canada } \\
\hline & Plant life time & \multicolumn{2}{|c|}{20 years } \\
\hline & $\begin{array}{l}\mathrm{CO}_{2} \text { sources and price } \\
\text { (if applicable) }\end{array}$ & \multicolumn{2}{|c|}{ Not applicable - capture and utilisation are in-situ } \\
\hline & $\begin{array}{l}\mathrm{H}_{2} \text { sources and prices } \\
\text { (if applicable) }\end{array}$ & \multicolumn{2}{|l|}{ Not applicable } \\
\hline zo & $\begin{array}{l}\text { Energy consumption } \\
\text { per functional unit }\end{array}$ & \multicolumn{2}{|l|}{ Confidential } \\
\hline 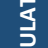 & CAPEX per functional unit & \multicolumn{2}{|l|}{$\$ C A D 20.60$} \\
\hline$\frac{\vec{U}}{4}$ & OPEX per functional unit & \multicolumn{2}{|l|}{ \$CAD 48.99} \\
\hline U & Price per functional unit & \\
\hline 兴 & $\begin{array}{l}\text { Sensitivity analysis main } \\
\text { factors }\end{array}$ & \multicolumn{2}{|c|}{ Market price of aggregate, Gate fee for APCr, Tax rate } \\
\hline 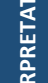 & $\begin{array}{l}\text { Uncertainty manipulated } \\
\text { variables }\end{array}$ & \multicolumn{2}{|c|}{$\begin{array}{l}\text { Electricity price, electrolyser efficiency, electrolyser cost, tax rate and CapEx of } \\
\text { the } \mathrm{CO}_{2} \text { capture unit. }\end{array}$} \\
\hline 兽 & Main Conclusions & \multicolumn{2}{|c|}{$\begin{array}{l}\text { - Production cost is higher for CCU route } \\
\text { - Plant is profitable due to payment of gate fees for APCr treatment }\end{array}$} \\
\hline
\end{tabular}




\section{B.3.Goal}

\section{Reference to Guidelines}

A checklist of items to be included in each section of the report is included in Chapter B.8 Reporting of the guidelines, which for the goal is as follows:

\section{Goal of the study}

State goal - the intended application of the study and the reasons for the study

$\square$ State the target audience for the study

State commissioner and authors of the study

- State limitations in the usability from assumptions or methods

$\square$ State the base case with current conditions

\section{B.3.1 Introduction}

The goal of this study is to investigate the economic outlook of producing secondary aggregate material from air pollution control residue (APCr) and $\mathrm{CO}_{2}$ in an effort to produce a usable product from two waste streams. The scenario investigated is based on a C8S aggregate test facility based in Ontario, Canada. The newly commissioned plant is expected to produce 4500 tonnes of aggregate a year for 20 years beginning in 2018.

This study conducts a TEA from the perspective of a consultant; with the goal to analyse the production costs and potential profitability of the plant through the calculating of economic performance indicators specifically the net present value (NPV) of the initial capital investment and the internal rate of return (IRR).

As covered in the process overview (Part A of this report), APCr is currently classified as a hazardous waste in Canada and as such needs to be transported to a location for stabilisation before being landfilled/stored. The C8S process allows for the utilisation of this waste as a feedstock in the production of aggregate material through carbonation of the APCr (with flue gas $\mathrm{CO}_{2}$ ) to produce a chemically stable aggregate material. Such a process also allows for the offsetting of the production of fresh primary crushed stone aggregate. The process analysis undertaken within this worked example combines data provided from C8S and data available in public domain literature to assess the C8S process in comparison to the production of crushed stone primary aggregate (deemed here as the "reference process"). Due to the confidential nature of some of the data utilised, some data values (such as the debt to equity ratio and the rates applied to these) have been changed and some outputs are only reported in aggregate form or as an indexed value.

This TEA is designed to be an example of good practice based on the recommendations of the recently published "Techno-Economic Assessment \& Life Cycle Assessment Guidelines for $\mathrm{CO}_{2}$ Utilization".

\section{Reference to Guidelines}

This goal definition is described in Guideline B.1. The present report conducts a TEA from the perspective of a consultant. This is reflected in the scenarios considered, where the specification of these scenarios is clear and reflect real-world operating conditions tested during plant demonstration.

The report serves to provide information and showcase good practices to a potential CCU assessor in a similar situation. In order to raise awareness, the report is publicly available. As stated in Guideline B.1, data derives from up to date conditions, and assumptions and results are location and time dependent. 


\section{B.3.2 Assessment scenarios}

The assessment scenarios investigated in this study represent are derived from the process description found in Part A. The assessment scenarios were made in accordance to financial hotspots identified in the sensitivity analysis.

Approaching this as a consultant the assessment scenarios investigated have been chosen to be

those most use/interest to the company who owns the technology

The carbonation plant is to operate in Ontario, Canada, on the site of an incinerator combusting MSW to recover energy in the form of electricity and heat. Due to the relatively low power consumption and the on-site electricity generation (allowing the C8S process to be powered parasitically) it is of little use to vary the electricity source (from status quo to low/high/fully decarbonised). As the process needs a source of APCr and a point-source emission of $\mathrm{CO}_{2}$ it is of limited value to consider a scenario in which the utilisation process would not be undertaken locally with some degree of integration.

Of much more interest is to consider the impact on varying the gate fee received for treating APCr material, as this is a principle factor in defining whether the process is profitable or not. This gate fee is also likely to vary from location to location - depending on existing treatment processes and legislation (both local and national).

Other scenarios considered include:

- Variation of the aggregate market price - what is the impact if carbon-negative secondary is in high demand due to its carbon negativity? What if the demand is low due to a mistrust of nonprimary aggregates

- The introduction of a carbon price - Canada is expected to add a "carbon price" (tax) to $\mathrm{CO}_{2}$ emitters, scenarios are derived investigating the impact on profitability due to this tax.

\section{Reference to Guidelines}

Guideline B.2 presents possible ways to conduct scenario analysis. In this worked example scenarios are derived mainly from hotspots that affect profitability, to align with the goal of the study. 


\section{B.4.Scope of Study}

\section{Reference to Guidelines}

A checklist of items to be included in each section of the report is included in Chapter B.8 Reporting of the guidelines, which for the goal is as follows:

\section{Scope of the study}

State product application(s) and functional unit, including consistency with goal and scope and reference flow

- State elements and boundaries of product system in a graphical scheme

State the benchmark process

State the selected indicator and methods, and including consistency with study goal and data availability associated with technology maturity

\section{B.4.1 Product application and functional unit}

Aggregate refers to a broad range of materials that have a wide range of uses, as shown in figure 1, with the applications taken from a British Geological Society publication [1]. Annual aggregate production and usage is measured in billions of tonnes, for example: in 2016 Europe produced a total of 2.28 billion tonnes of crushed rock, sand and gravel aggregates [2]. For a more localised picture of aggregate use - between 2000 and 2015 Ontario produced on average 164 million tonnes of aggregate per year [3]. As discussed in Part A: process overview, aggregate can be defined as primary (virgin mined), secondary (produced from wastes) or recycled.

The secondary aggregate produced by $\mathrm{C} 8 \mathrm{~S}$ is to be utilised as concrete aggregate (highlighted in figure 1) and thus the most useful comparisons are against other aggregates commonly utilised in this way-crushed stone (e.g. dolomite, limestone), sand and gravel.

For the TEA undertaken the functional unit is metres cubed $\left(\mathrm{m}^{3}\right)$ of aggregate material capable of utilisation in the production of $7.6 \mathrm{~N} / \mathrm{mm}^{2}$ compressive strength CMUs. This is a reasonable functional unit as market prices for aggregates are commonly reported in per tonne values, but this does not account for the variable densities of products that can deliver equal functionality. The composition of any CMU (a product sold on a volume basis, not mass) is highly variable, each CMU production company typically offers multiple products each with a different specification, composition and density - but often these products can provide identical functionality.

\section{Reference to Guidelines}

As described in Guideline B.3, the product application must be included in the Scope of the study; in this worked example aggregate for use in the production of CMUs is considered. The functional unit definition is in accordance with Guideline B.3 where the product must offer the same function. In this worked example defining explicitly in terms of function is required due to the large variety of different aggregate materials and their end uses. 


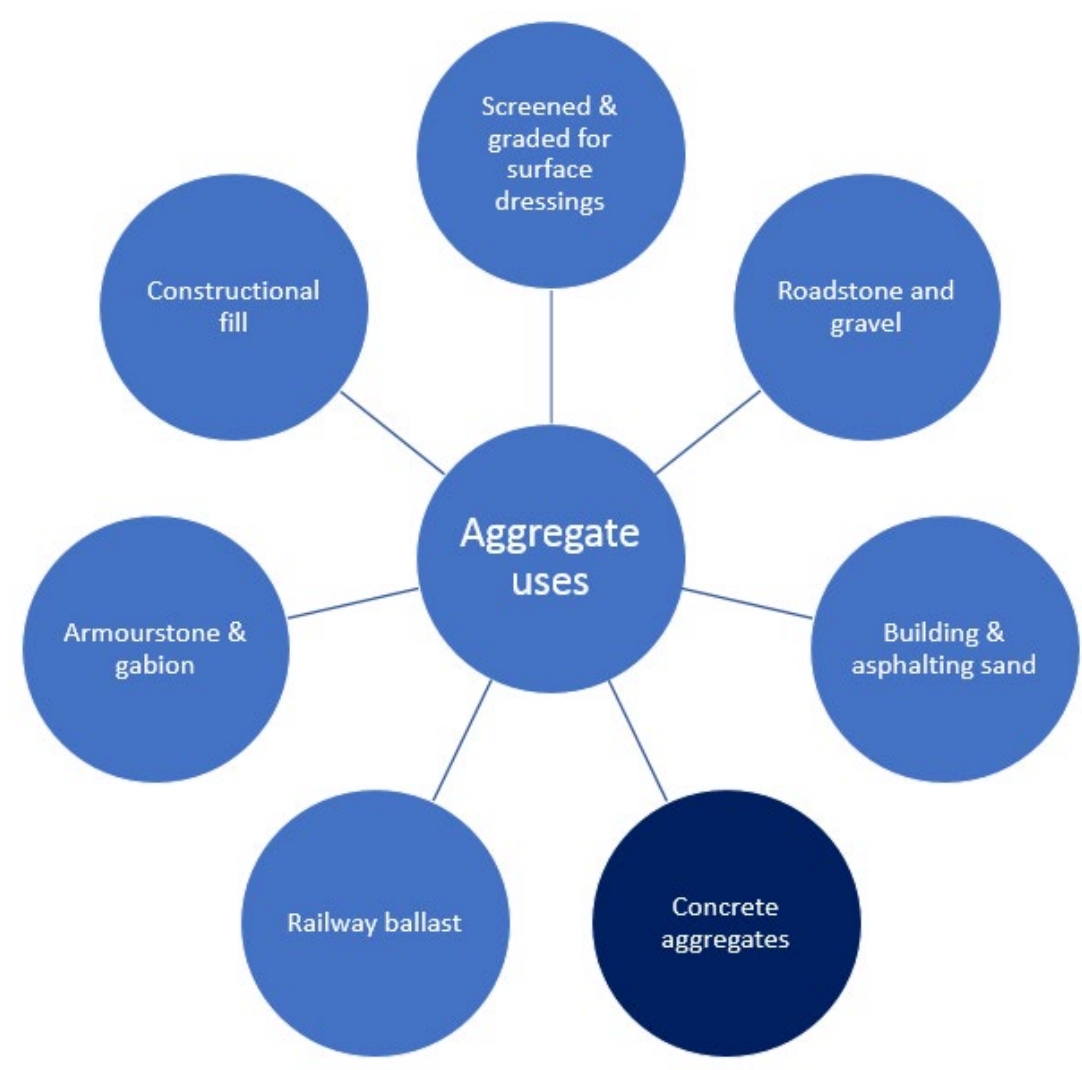

Figure 1. Application of aggregates

The C8S aggregate production process is one element within a larger system investigated. The larger system is of interest for the accompanying LCA and partially integrated study but does not necessarily assess the profitability for the aggregate producer which is the goal of this TEA study.

This larger system can be seen in figure 2, where $\mathrm{APCr}$ and $\mathrm{CO}_{2}$ are produced in an energy from waste (EfW) plant. The APCr and $\mathrm{CO}_{2}$ are fed into the $\mathrm{C} 8 \mathrm{~S}$ system along with sand, cement and water to produce a secondary aggregate. This aggregate is then sold in competition with primary aggregate produced locally and across the wider region (see Part A for more details). The aggregate is then expected to be utilised in the production of medium-weight concrete masonry units (CMUs).

This is a "cradle to gate" analysis. Table 1 below highlights the main inputs and outputs in the process.

Table 1. Process inputs and outputs

\begin{tabular}{l|l} 
Process Inputs & Process Outputs \\
\hline APCr & Secondary Aggregate \\
\hline Sand & Water \\
\hline Cement & Flue gas (returned to stack) \\
\hline Water & \\
\hline $\mathrm{CO}_{2}$ (flue gas) & \\
\hline
\end{tabular}




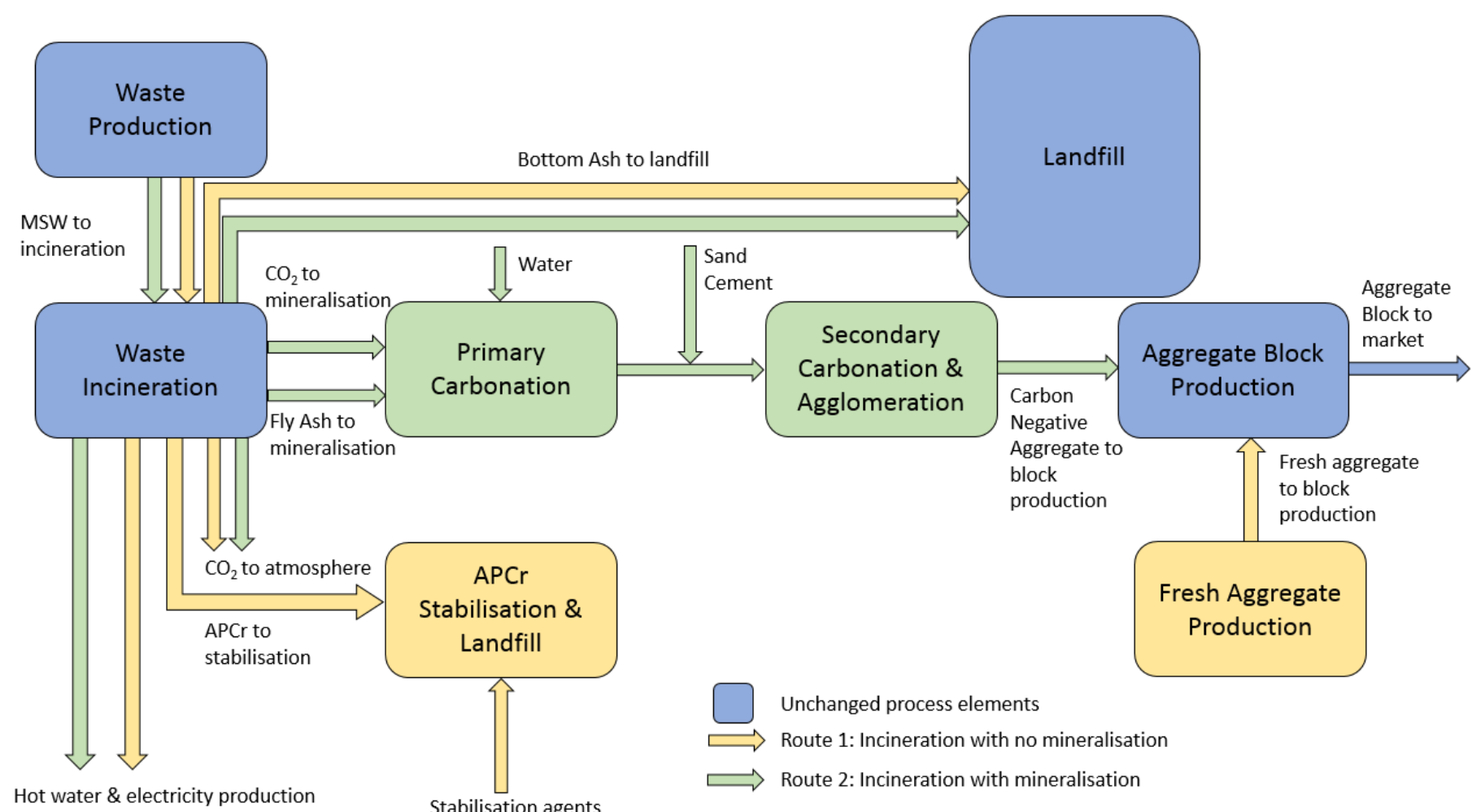

Figure 2. Process flow diagram of whole system

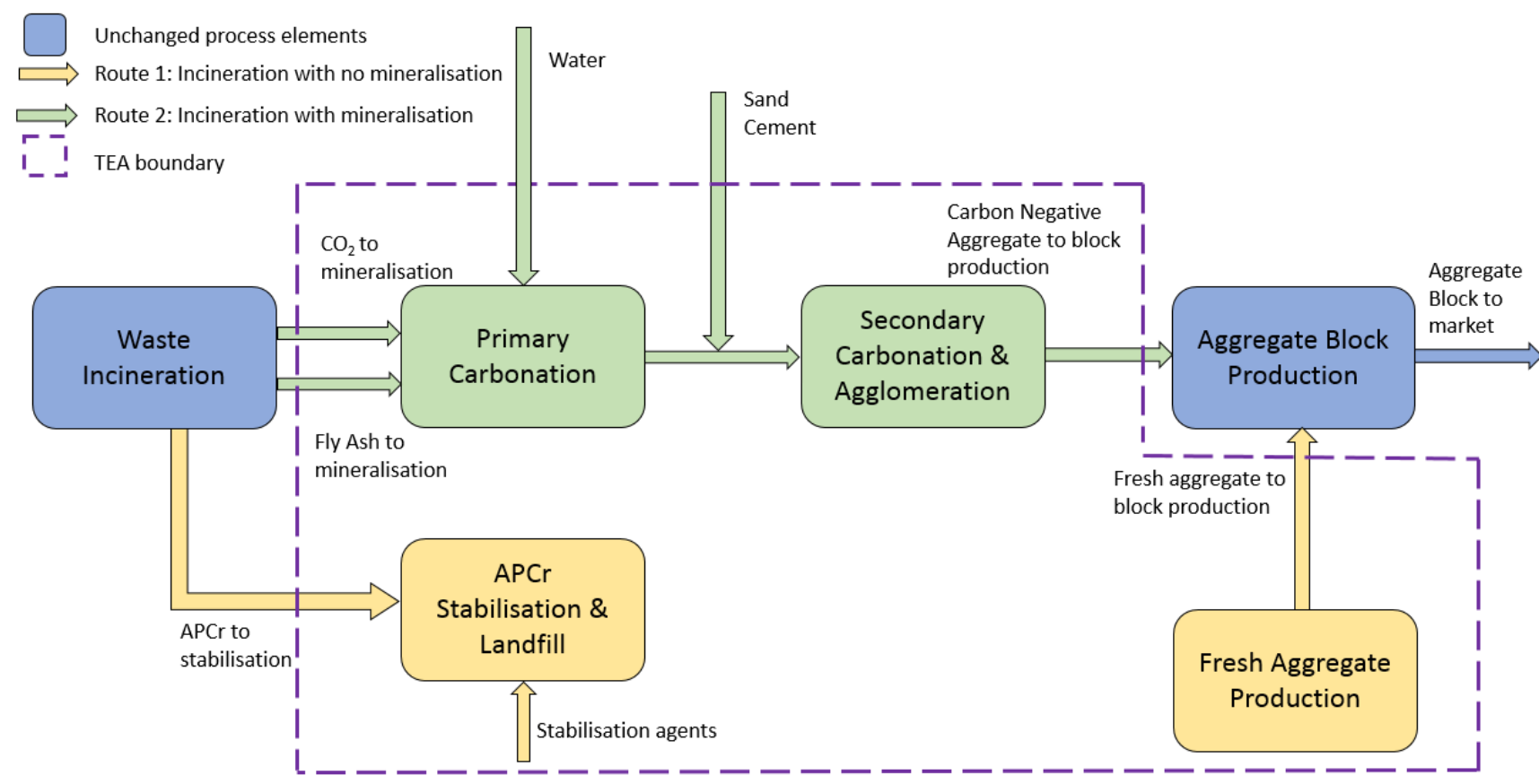

Figure 3. Process flow diagram of boundary used in analysis 
For the TEA undertaken in this worked example the following boundary observed is shown in figure 3 . As figure 3 shows the boundary for this study incorporates the processes of secondary aggregate production (C8S process), primary aggregate production and APCr stabilisation and landfill. The latter two elements being the existing "benchmark" or reference system. The boundary is drawn to allow for the inclusion of relevant market costs when viewed from the position of the secondary aggregate producer (in this case, C8S). Further details on the C8S system are given in Part A.

- For this work, the C8S system consists of three main process units: a first stage reactor where APCr is reacted with $\mathrm{CO}_{2}$, a second stage mixer where carbonated material is mixed along with sand, cement and water and a pelletiser where further $\mathrm{CO}_{2}$ is added, to form pellets of secondary aggregate

- Ancillary equipment such as conveyors, pumps and stirrers are also utilised

- The mechanical equipment is powered entirely with electricity (no other fuel sources are used)

- The process occurs at a slightly elevated pressure (just above atmospheric pressure)

- The process occurs at a moderately elevated temperature as a result of the exothermic reaction (slightly above atmospheric temperature)

\section{Reference to Guidelines}

In this section, both unit processes and system elements are thoroughly presented as recommended in Guideline B.4. System boundaries are set to account for information made available to the reporter and to meet the specified goal. Expanding the boundaries to include the block maker or the EfW plant is feasible but by including other stakeholders assessing the profitability of the CCU technology becomes convoluted.

\section{B.4.2 Benchmark system}

The bench mark system comprises of two elements - stabilisation and primary aggregate production.

Stabilisation is required for the treatment of hazardous wastes such as $\mathrm{APCr}$, the process consists of binding hazardous wastes with cementitious materials. Further details on this process can be found in Part A of this report. For APCr, this treatment entails mixing with cement (and likely other wastes and additives) before being stored in a secure landfill site. In this worked example, Emerald Energy from Waste pay a total price of \$CAD 300 for transport and treatment of the waste. The waste is treated at a facility owned by Stablex in the neighbouring state of Blaineville, Quebec - approximately $580 \mathrm{~km}$ away from the EfW site in Brampton, Ontario. This price is expected to continue to rise due to increasing transport costs [4].

Aggregate production is an umbrella term used here as a reference to the production of any aggregate capable of being utilised to fit the functional unit set in section B.4.1 above. Details on aggregate production can be found in Part A of this report.

As described in Part A: Process Overview, local aggregate in Ontario is found in the form of sand, dolomitic limestone (also referred to as dolostone or dolomite) and gravel. The market price of crushed stone is relatively stable, likely due to the high fixed costs (capital and labour) and relatively low energy consumption (in comparison to energetic commodities such as ammonia and methanol where market price is known to fluctuate significantly with natural gas cost for example). The prices in figure 4 below are taken 
from a USGS survey [5] showing the FOB price for crushed stone in North America/the USA (converted to $\$ C A D$ at a rate of $\$$ USD 1 to $\$ C A D 1.29$ ).

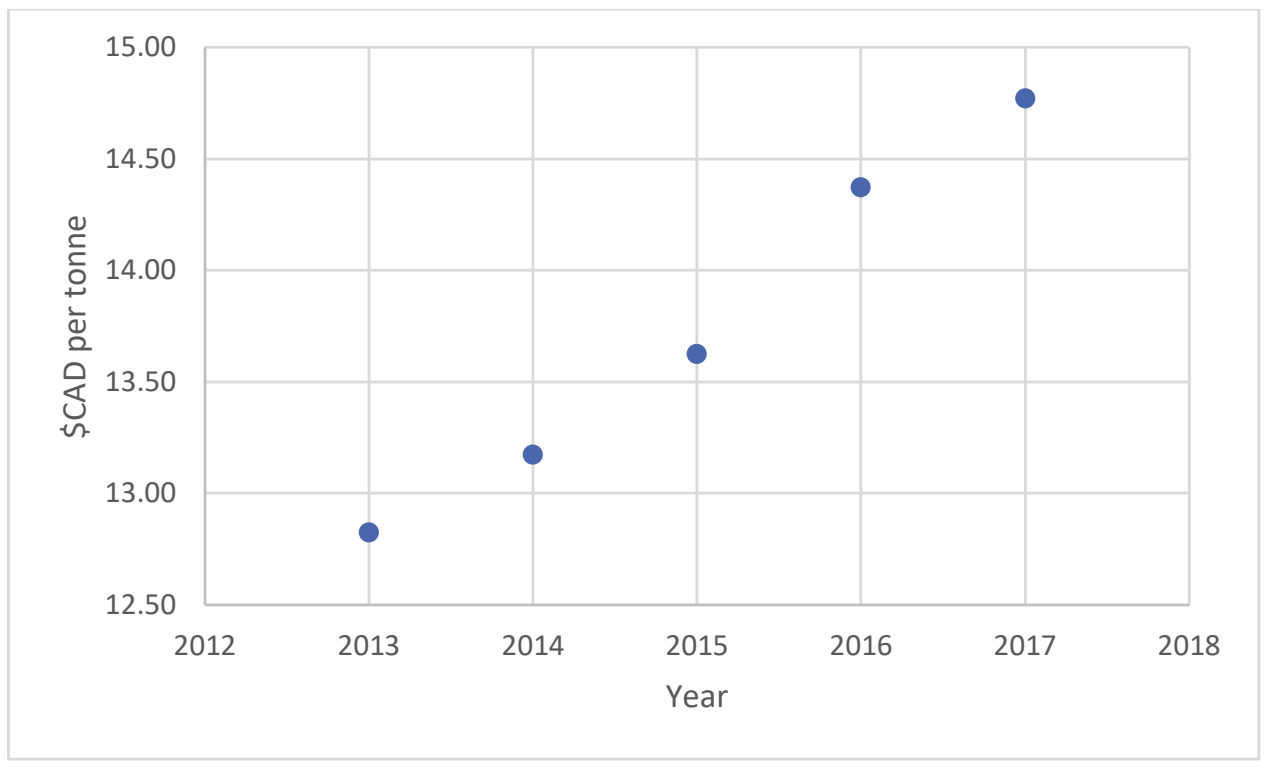

Figure 4. Average FOB crushed stone prices

The graph shows a year on year increase in FOB price. The price shown in figure 4 reflect US prices, however the price for stone in north-eastern states is known to be consistent with FOB prices in Ontario [4]. The price for dolomitic limestone is approximately equal to that of the generic crushed stone described by USGS, as shown in the "Aggregates by state and end use" data set which can be found at [5].

The cost of sand is known to be \$CAD 10 and this price is quoted as being relatively stable [4]. Other aggregate materials such as gravel and expanded shale clay have not been considered in this worked example.

\section{Reference to Guidelines}

Consistent with Guideline B.5, the benchmark system reflects the existing situation described in the scenario. Efforts have been made in both Parts $A$ and $B$ of this report to identify the most likely sources of primary aggregate - which should be seen as "best in class" products due to their market dominance.

\section{B.4.3 Technology maturity}

The TRL-concept from the US DoE was used to identify the technology maturity of the C8S process.

In the United Kingdom C8S have licenced the technology to Carbon8 Aggregates Ltd. who operate a number of large-scale, fixed "waste to aggregate" plants. These plants are capable of producing significant amounts of secondary aggregate per year (for example the plant in Leeds is capable of producing 110,000 tonnes of secondary aggregate annually [6]) and are assumed to be TRL 9. 
The containerised, mobile plant used in Canada utilises similar technology to the existing plants in the UK albeit on a smaller scale. The containerised plant utilises direct flue gas $\mathrm{CO}_{2}$ instead of pure $\mathrm{CO}_{2}$ with this being the major change in process conditions. The plant is therefore assumed to be TRL 7 , with the step down from TRL 9 being due to the "first of a kind" nature of the final plant and the slight modifications in the operation of the plant.

\section{Reference to Guidelines}

The importance of identifying the technology maturity of the investigated configuration is highlighted in this section. The TRL-concept was adapted and as described in Guideline A.1.

\section{B.4.4 Assessment indicators, consistency and reproducibility}

The assessment indicators of choice reflect the desire to investigate the plants potential profitability, as opposed to any need to investigate the plants operational abilities. The technology used is relatively mature, with the technology owners/stakeholders having a comprehensive understanding of both plant capabilities and technical feasibilities. As such the process elements of the worked example are modelled on a "grey box" basis. The assessment indicators utilised are:

- Conversion of APCr to aggregate (as a percentage of total mass)

- Total annual $\mathrm{CO}_{2}$ capture rate

- Capital Expenditure (CapEx) and Operational Expenditure (OpEx): used to give an estimation of expected costs for the production of aggregate

- Net Present Value (NPV): used to investigate the profitability of the plant over its lifespan

- Internal Rate of Return (IRR): used to investigate the profitability of the plant and in the sensitivity analysis

For consistency and reproducibility, all data sources are given in the reference list. Data is preferentially selected from peer-reviewed sources and from government agencies. It should be noted that due to confidentiality agreements not all data used in this worked example has been made available.

\section{Reference to Guidelines}

As stated in Guideline B.6, both economic and technical indicators were considered with the aim of providing robust answers to the assessment goal question. Due to the nature of this study, economic indicators are of more importance and can be more openly reported than most technical indicators that could be considered. Guideline B.7 acknowledges the importance of providing consistent and reproducible ways/methods. To meet this guideline descriptions of each indicator are provided (where necessary). This report contains calculations made using confidential data, causing issues for reproducibility but where possible details have been reported openly to give some indication of reliability. 


\section{B.5.Inventory}

\section{Reference to Guidelines}

A checklist of items to be included in each section of the report is included in Chapter B.8 Reporting of the guidelines, which for the goal is as follows:

\section{Inventory of the study}

State types and sources of the data including the quality

State the technical in SI units a technical parameter list

$\square$ State economic data in an economic parameter list

口 State all economic decisions and assumption made

\section{B.5.1 Technical Data}

This section presents an overview of the process design for the secondary aggregate production plant. Due to the confidential nature of the technology in this study only a limited amount of operational data will be provided.

The containerised plant is constructed to a standard size and thus the limiting factor is the availability of APCr. The following

- The plant is to be utilised for 3000 hours annually - this equates to 12 hours a day, 5 days a week (60 hours) operation to treat 3000 tonnes of APCr.

- If the plant was to operate at the maximum capacity stated by C8S then 6000 tonnes of APCr could be treated annually on a schedule of 24 hours per day, 5 days per week (120 hours).

- Should it be feasible to expand operation to 168 hours per week, annual APCr treatment for the containerised plant could potentially reach 8400 tonnes. This however does not account for any down time for maintenance or repair.

APCr is transported from storage to the primary mixer via a conveyor belt. Here it is mixed with water and treated with the $\mathrm{CO}_{2}$ containing flue gas for a specified period of time. The carbonated APCr is then transported to a second stage mixer whilst the depleted flue gas is returned to the stack. In the second stage the carbonated APCr powder is mixed with sand and cement before being transported to a pelletiser. Further $\mathrm{CO}_{2}$ is added in the pelletiser to form aggregate pellets of varying size grades.

The size of each of the components above is not specified in this worked example, nor is the residence time of the APCr in any stage.

The secondary aggregate can then be stored ready onsite ready for shipment to a customer.

\section{Reference to Guidelines}

The current subchapter provides insight into the process and key aspects of the plants design. Guideline B.8 refers to quality control of data, as the data used in the assessment is provided by the technology stakeholders a high level of confidence can be placed in its accuracy. Guideline B.9 details good practice on how to collect data, as mentioned previously the data used in this report is provided by C8S where relevant and taken from established sources elsewhere (reputable textbooks and government agencies). 


\section{B.5.2 $\mathrm{CO}_{2}$ capture}

$\mathrm{CO}_{2}$ capture in plant takes place "in-situ" with capture and utilisation being a singular step. Flue gas is diverted from the stack and fed to the carbonation stages of the process. The APCr produced consists of a combination of fly ash produced from MSW combustion and activated carbon and calcium oxide (lime) used in the scrubbing of acid gases. The composition of MSW fly ash varies dependent on the makeup/source of the MSW, however a good indication on its composition can be found in journal papers published by C8S [7]. As the source shows the dominant species capable of carbonation is calcium oxide, with a smaller amount of magnesium oxide also present. Combined with the addition of the lime used in acid gas removal it is reasonable to assume that the majority of the carbon capture is as a result of carbonation of calcium oxide. The expected reaction scheme is shown below:

$$
\begin{array}{lr}
\mathrm{CaO}+\mathrm{H}_{2} \mathrm{O}_{(I)} \rightarrow \mathrm{Ca}(\mathrm{OH})_{2} & \Delta \mathrm{H}=-65 \mathrm{~kJ} / \mathrm{mol} \\
\mathrm{Ca}(\mathrm{OH})_{2}+\mathrm{CO}_{2} \rightarrow \mathrm{CaCO}_{3}+\mathrm{H}_{2} \mathrm{O}_{(\mathrm{I})} & \Delta \mathrm{H}=-113 \mathrm{~kJ} / \mathrm{mol}
\end{array}
$$

A similar scheme can be drawn for other group 1 and 2 metals commonly found in similar waste streams (i.e. potassium and magnesium).

As the equations show, carbonation $/ \mathrm{CO}_{2}$ capture takes place in two stages: hydration of the calcium oxide followed by carbonation of the hydrated metal oxide.

The kinetics of these reactions have been modelled as a "shrinking core" mechanism, where the reactant "core" of $\mathrm{CaO}$ is assumed to shrink over time as it reacts initially with water and then $\mathrm{CO}_{2}$ to form $\mathrm{CaCO}_{3}$. The surface of the unreacted core is typically assumed to be the only area where reaction take place. Figure 5 shows a simplified reaction schematic for the shrinking core model (SCM).

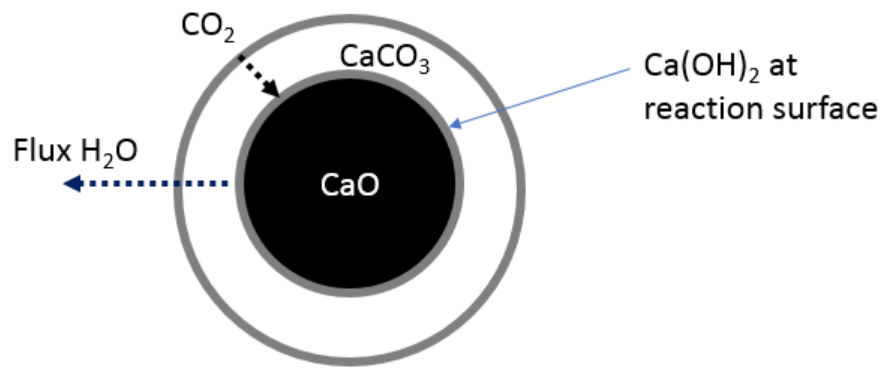

Figure 5. Shrinking core schematic

As expected a range of properties affect the estimated reaction rate in carbonation SCM [8][9][10], including gas partial pressures and particle porosity.

As discussed above, in the existing Carbon8 Aggregates Ltd. plants the $\mathrm{CO}_{2}$ used in the carbonation stage has been a pure source, purchased at a significant price. The impact of reducing $\mathrm{CO}_{2}$ purity has an unknown impact on the reaction the kinetics although the SCM would suggest that the reaction rate is likely to be 
slower. It is assumed in this worked example that this has no discernible impact on the profitability of the plant operated in this scenario.

\section{Reference to Guidelines}

Guideline B.10 refers to the derivation of a $\mathrm{CO}_{2}$ price, this guideline was considered and consulted in this worked example, however it was deemed unnecessary to assign a price in this specific worked example.

A similar result could be expected for other in-situ utilisation systems, particularly those where metal carbonation is the major process step - however in these cases it's more likely that the capture material will need to be purchased rather than it being an opportune use of existing waste.

Considering such inputs is covered in Guideline B.11, where other elements such as establishing an electricity price are covered (the electricity price used in this worked example is discussed in section B.6.2).

A brief reference to Guideline B.12 is also made here, where the cost of $\mathrm{H}_{2}$ is discussed - this is not relevant in this worked example.

\section{B.5.3 Utilities}

The process does not generate an excess of amount of energy that can be recovered as electricity or heat. The utilities used in the plant are:

- Electricity sourced from the energy to waste plant

- Treated water sourced from a mains supply 


\section{B.6. Calculation of Indicators}

\section{Reference to Guidelines}

A checklist of items to be included in each section of the report is included in Chapter B8 Reporting of the guidelines, which for the goal is as follows:

\section{Inventory of the study}

- State calculation procedures

Explain methodology of financial analysis

- Include results of technical assessment

Include results of economic assessment

The goal of this study is to investigate the profitability of the scenario investigated, to do this a number of indicators need to be calculated. Whilst the section above provides details on the data and assumptions used to calculate these it does not provide any details on the indicators or why they have been chosen. This section will provide these details, for both the technical and economical assessment indicators. The indicators used have been selected with the goal in mind, with consideration also paid to the need to protect intellectual property and commercial confidentiality.

\section{B.6.1 Technical assessment indicators}

Part A5 above provides insight into the C8S technology. Due to the nature of this report only a limited number of technical indicators are given. No equations are reported in this section as there are no relevant calculations. The following technical indicators are reported:

- Conversion of APCr to aggregate: $100 \%$

- Total $\mathrm{CO}_{2}$ captured: 300 tonnes per year

- Energy consumption: confidential

\section{Reference to Guidelines}

As suggested in Guideline B.13 indicators are presented in SI units. No formulas are presented due to the nature of the technical elements of the worked example. References to inputs and outputs for the process are made throughout section $\mathrm{B} 5$ and $\mathrm{B} 6$ in this worked example, but to ensure confidentiality scalar values have been removed for most of parameters. 


\section{B.6.2 Economic assessment indicators}

This section provides an overview on the methodology used to estimate both the capital expenditure (CapEx) and the operational expenditure (OpEx).

The plant is based in Ontario, Canada and thus all costs are presented in Canadian Dollars (\$CAD) unless explicitly stated. The following exchanges rates were used where relevant:

- USD to CAD: 1 USD to 1.29 CAD

- GBP to CAD: 1 GBP to 1.68 CAD

The mobile containerised plant was constructed in the UK and shipped to Ontario. Future plants could feasibly be constructed in the country of installation to eliminate the need for shipping costs. As discussed in section B5 above, the plant design is of a specified size; with each plant capable of treating up to 6000 tonnes of APCr annually on a $24 / 5$ operation schedule. Should less APCr than this be available, the plant is run on a reduced schedule (as is the case in this study). Increasing the size of the plant is something not considered within the scope of this worked example (due to the restricted nature of the full plant layout). It is assumed that should a larger plant be required a scaling exponent would satisfy initial cost estimates. The plant has an estimated lifespan of 1.2 million operating hours (equal to 10 years of operation on the $24 / 5$ schedule, or 20 years on the expected schedule in this worked example).

The cost of the unit was provided by $\mathrm{C} 8 \mathrm{~S}$, giving high confidence in its accuracy. As the unit is to be placed on the site of the incinerator no land purchase costs have been included. The unit cost is assumed to not include:

- Shipping costs (provided by C8S)

- Final installation costs

- Indirect project costs

- Contingency costs

- Working capital

Aside from shipping costs which were provided by C8S, each of the other costs are estimated with details on each given below. These estimations are determined from a mixture of discussion with C8S [4] and literature sources [11][12][13].

Final installation costs account for on-site installation; this includes but is not limited to yard improvements, local installation and wiring (electrical systems, piping, instrumentation) and the cost for buildings/services used during installation. These elements would normally be costed separately, but due to the nature of the plant and its installation they've been aggregated as one. After discussing these costs with C8S it was decided that $3 \%$ of the modular plants cost is a reasonable approximation for the cost incurred.

Indirect project costs account for all costs not attributed to any single aspect of the project. These include but are not limited to elements such as plant design, managing the project, the development of operating procedures and other tasks. A value equal to $50 \%$ of the inside battery limit cost has been assigned. It is expected that for future modular plants this cost will be significantly lower.

Contingency costs are estimated to be low. This is primarily due to the containerised plant being tested before shipping and the final installation of the plant being relatively straight-forward. Total contingency is estimated at $5 \%$.

An estimate for Working capital was made based on two months of OpEx costs. 
To be consistent with the first worked example produced (methanol synthesis via $\mathrm{CO}_{2}$ hydrogenation) the same debt-equity split is assumed, along with the same debt interest rate (6\%) and cost of equity (12\%).

It is important to state that this debt-equity assumption does not reflect the true financing of this project, with this being included purely as an example for this study.

The weighted average cost of capital (WACC) is calculated as follows:

$$
W A C C=D R \times i_{d}+\left[(1-D R) \times i_{e}\right]
$$

Where: $D R$ is the debt ratio, $i_{d}$ interest rate due on debt and $i_{e}$ cost of equity. The WACC provides indication on the cost of capital for the project, whilst providing a value for the minimum return required satisfying the demands of all creditors, owners and other source of capital.

Depreciation is assumed to occur over a 10-year period, to align with the expected lifespan at maximum annual operation. Straight-line depreciation is assumed. All capital investment is assumed to occur in the year prior to operation beginning, it is expected that during this time construction, shipping and installation of the plant will be completed.

It is expected that the cost for decommissioning should be relatively low due to the modular nature and simple installation of the plant. The salvage value of the plant is also not known with a high confidence. The salvage value included below is based on selling the entire plant as scrap metal at current prices. Source [14] provides a local scrap price of $\$ C A D 0.45$ per lb of stainless steel, the plant is known to weigh 15 tonnes [4] and all of this is assumed to be stainless steel. For this worked example, the scrap value is assumed to cover the costs of decommissioning the plant.

Table 2 gives an overview of the parameters and assumptions made in calculating the capital investment of the plant.

Table 2 Reported CapEx parameters and assumptions

\begin{tabular}{|l|r|}
\hline Parameter & Value \\
\hline Location & Ontario, Canada \\
\hline Base year & 2018 \\
\hline Project lifetime (years) & 20 \\
\hline Construction period (years) & 1 \\
\hline Plant availability (hours/year) & 6000 \\
\hline Plant utilisation (hours/year) & 3000 \\
\hline Tax rate (\%) & 26.5 \\
\hline Equity/Debt (\%/\%) & $50 / 50$ \\
\hline Debt interest (\%) & 6 \\
\hline Cost of equity (\%) & 12 \\
\hline WACC (\%) & 9 \\
\hline Depreciation method & Straight-line \\
\hline Depreciation period (years) & 10 \\
\hline Salvage value (\$CAD) & 14882 \\
\hline
\end{tabular}


Operational costs are calculated by considering fixed and variable cost elements. A summary of the assumptions made for the variable cost elements is given below.

Raw material costs include the cost for cement, water and sand. A per tonne cost for each is given in table 3. The cost for cement and sand were provided by C8S and are stated to be relatively stable [4]. The cost for water is taken from source [15]. Due to the reliability of the sources used a high level of confidence in these unit costs.

The electricity cost used can be found in source [16], the cost used is the wholesale market cost for electricity. This cost has been used as the existing scenario sees the EfW plant selling electricity to the market at what is assumed to be wholesale prices.

Taxable income is taxed at the rates given in source [17] with the corporate rate for Ontario totalling $26.5 \%$ (15\% federal, $11.5 \%$ provincial).

The fixed elements of the OpEx are detailed below.

Operational labour costs are calculated based on the number of operator hours required per year and the average operator wage for Ontario. C8S state that only 1 operator hour is required per hour of plant operation, so in this worked example 3000 annual operator hours are required. The average wage of a chemical plant operator in Ontario can be found in source [18], as this is a governmental department source a high level of confidence can be placed in the figure.

Supervision costs are assumed to be $15 \%$ of the total operational labour cost. Direct overhead is assumed to be equal to $25 \%$ of total labour costs (operator and supervisor). General overhead costs are assumed to be $6 \%$ of total sales value of the aggregate (this does not include other incomes such as the gate fee received for the APCr) and maintenance and repair costs are assumed to be $1 \%$ of the inside battery limit cost of the plant. Insurance and misc. taxes are assumed to equal $1.5 \%$ of fixed capital costs. The basis of these cost assumptions is based on the ranges given in various established textbooks, see sources [11][12][13]. The percentages used reflect those on the lower end of the ranges reported, however the general overhead is smaller than the range suggested in each source. This was reduced to account for the conditions of this case (the plant is simple to operate, it operates under mild process conditions and is relatively small), this reduction is based on information provided by C8S but was done at the discretion of the authors of this worked example.

Debt interest has also been factored into the OpEx calculation. The debt is assumed to paid over the depreciation period (10 years) in equal repayments. The interest accrued is assumed to be paid in the same year it accrues.

Table 3. Reported OpEx parameters

\begin{tabular}{|l|r|}
\hline Parameter & Value \\
\hline Cost of cement (\$CAD/tonne) & 150 \\
\hline Cost of sand (\$CAD/tonne) & 10 \\
\hline Cost of treated water (\$CAD/tonne) & 2.66 \\
\hline Cost of electricity (\$CAD/MWh & 19.64 \\
\hline Operator wage cost $(\$ C A D /$ hour) & 21.63 \\
\hline
\end{tabular}




\section{Reference to Guidelines}

This section along is aligned with Guidelines B.14 and B15. Methods for calculating various factors within the chosen indicators were chosen from reputable sources and are detailed in the text. For both the CapEx and OpEx, the components, methodology and results were discussed with the stakeholders C8S to ensure accuracy in the figures presented. The high maturity level of the technology and the primary sources of data minimise the need to consider significant variance in data inputs, any assumptions made are clearly stated and identified. The indicators described are selected for their relevance in achieving the goal of the study.

\section{B.6.3 Economic assessment indicators}

The goal is to evaluate profitability of the C8S plant. As identified previously this has been done by considering both the NPV and the IRR of the process under expected operating conditions and realistic market conditions. However, before this it is necessary to calculate the CapEx and OpEx using the method detailed above.

Table 4. Reported OpEx and CapEx indicator values

\begin{tabular}{|l|rr|}
\hline \multicolumn{1}{|c}{ Indicator } & & \multicolumn{1}{c|}{ Value } \\
\hline CapEx $(\$ C A D)$ & $\$$ & $1,685,508$ \\
\hline Average OpEx (\$CAD/year) & $\$$ & 186,499 \\
\hline CapEx per tonne of aggregate $(\$ C A D /$ tonne) & $\$$ & 18.73 \\
\hline CapEx per functional unit $\left(\$ C A D / \mathrm{m}^{3}\right)$ & $\$$ & 20.60 \\
\hline Average OpEx per tonne of aggregate $(\$ C A D /$ tonne) & $\$$ & 44.53 \\
\hline Average OpEx per functional unit $\left(\$ C A D / \mathrm{m}^{3}\right)$ & $\$$ & 48.99 \\
\hline Average production cost $(\$ C A D /$ tonne) & $\$$ & 63.26 \\
\hline Average production cost per functional unit $\left(\$ C A D / \mathrm{m}^{3}\right)$ & $\$$ & 69.59 \\
\hline
\end{tabular}

No breakdown of the CapEx or OpEx costs are provided to protect confidentiality. Although it can be stated that the bulk of the OpEx is attributed to fixed costs. A cumulative net positive cash flow is calculated to begin in year 7 of the 20 year lifespan of the plant.

The costs are given on a per tonne basis, the basis in which they were calculated, and in a per volume basis to satisfy the functional unit. The density of C8S aggregate is taken to $1100 \mathrm{~kg} / \mathrm{m}^{3}$ with this figure being used as the basis for the mass to volume calculation. 


\section{Reference to Guidelines}

As suggested in Guideline B.3, economic results are presented on a functional unit basis, i.e. metres cubed of aggregate. The methodology, equations and assumptions to conduct an NPV analysis is presented here as recommended in Guideline B.16, however a breakdown of the cash flows is not given nor discussed in detail.

The total average production cost does not account for any changes in labour costs, price changes for electricity, sand or cement and overheads. Comparing the production cost of the C8S secondary aggregate ( $\$ C A D 63.26$ per tonne) to market prices for crushed stone (\$CAD 14.77) gives a significant cost deficit.

To compare on a functional unit basis a density for crushed stone needs to be specified, a density of 2500 $\mathrm{kg} / \mathrm{m}^{3}$ is used as this value falls within the reported range for limestone and dolomitic limestone. Comparing the production cost of $\mathrm{C} 8$ aggregate to crushed stone on a functional unit basis gives a price of $\$ C A D 69.59$ per $^{3}$ for C8S aggregate and a market price of \$CAD 39.93 per $\mathrm{m}^{3}$.

Considering both the functional unit and the per tonne market basis, the production cost of C8S aggregate is too high to be profitable on a standalone basis. The majority of the $\mathrm{C} 8 \mathrm{~S}$ production cost can be attributed to the fixed cost elements of the OpEx and to a lesser extent the CapEx of the plant. Whilst the CapEx is likely to be lower for $\mathrm{n}^{\text {th }}$ of a kind plants (due to the expected decrease in indirect costs) the fixed cost elements of the OpEx are unlikely to decrease significantly in the given scenario - for example: operator wages are unlikely to decrease in Ontario, the only viable way of reducing this expense would be to locate the plant somewhere with a lower average wage. This location would still need a source of APCr (or carbonation material) and $\mathrm{CO}_{2}$, but exploring other locations is feasible (yet not covered in this worked example).

However, before profitability can be truly assessed other factors need to be considered. As mentioned in the process description in Part A of this report a gate fee is paid for the processing of APCr. In the existing logistical chain, Emerald EfW pay a gate fee and a fee to transport APCr to an ash stabilisation process located in the neighbouring state of Quebec (approximately $580 \mathrm{~km}$ away). With the installation of the C8S plant this is no longer required and a fraction of the total expenditure for ash stabilisation is paid to C8S, with the remainder of the savings being kept by Emerald EfW. This figure is not factored into production costs but is accounted for in the cash flows used for calculating profitability metrics.

A final note of importance is that in this scenario it is expected that C8S aggregate will be sold at a discounted rate for the first three years of plant operation. This was decision was made to reflect the approach that is to be undertaken by $\mathrm{C} 8 \mathrm{~S}$ and is done due to the local aggregate market being dominated by established primary aggregate sources. C8S secondary aggregate is expected to be sold at a price of \$CAD 10 per tonne initially, before being sold at the market price of \$CAD 14.77 per tonne beyond year 3.

The NPV and the IRR are widely used metrics to assess whether an investment is worthwhile. The NPV and IRR are calculated using the following equations:

$$
\begin{gathered}
N P V=-T C I+\sum_{n=1}^{20} \frac{C F}{(1+\text { discount rate })^{t}} \\
\sum_{n=1}^{20} \frac{C F}{(1+I R R)^{n}}=0 \\
C F=P(1-t)+D t
\end{gathered}
$$


Where the $C F$ values are the after-tax cash flow for each year, $P$ are gross profits, $t$ is the tax rate and $D$ the depreciation. The NPV was calculated with the WACC used as the discount rate.

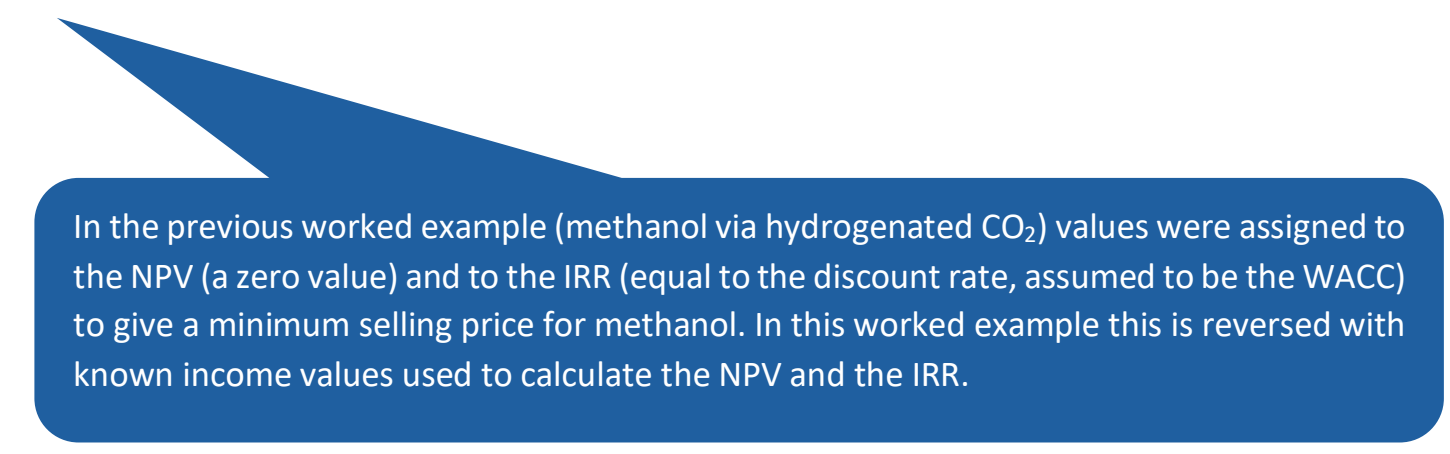

For the scenario considered in the worked example the following values were calculated.

- An NPV of $\$ C A D 1,633,606$

- An IRR of $\mathbf{2 1 \%}$

Both of these figures suggest that this investment is worthwhile and will generate a profit in the given scenario.

\section{Reference to Guidelines}

A checklist of items to be included in each section of the report is included in Chapter B8 Reporting of the guidelines, which for the goal is as follows:

\section{Interpretation of the study}

Include and describe the results

Include and describe uncertainty and sensitivity analysis

- State assumptions and limitation associated with the assumptions, methods and interpretation of results

Include conclusions

Include recommendations, if any 


\section{B.7.Interpretation}

\section{B.7.1 Sensitivity analysis}

A local sensitivity analysis was undertaken to investigate the sensitivity of the profitability of the scenario. Multiple parameters have been varied and their impact on the NPV is the metric that has been used to determine the sensitivity of profitability on each. The parameters varied are:

- Cost of raw materials: the price of cement, sand and water are all varied by $\pm 50 \%$. Varying the price also gives a de facto estimation for the impact of varying masses of each raw material used per tonne

- Cost of utilities: the cost of electricity was varied with a high value of \$CAD 89 per MWh considered and a low of \$CAD $0 \mathrm{MWh}$ considered. The high value reflects the current tariff paid by industrial customers in Ontario from source [19], the low value considers the possibility that the electricity produced on-site from the EfW plant is given for zero cost (either due to grid balancing or due to the partnership between Emerald EfW and C8S).

- Sale price of C8S aggregate: The price of C8S aggregate is varied by $\pm 50 \%$. For simplicity, only the market price of \$CAD 14.77 is considered in the sensitivity analysis.

- Gate fee received for APCr: The gate fee received per tonne of APCr is varied by $\pm 50 \%$.

- Tax rate: A minimum tax rate of $0 \%$ on profits is applied to simulate a situation where government incentives are proposed to stimulate "end of waste" products. A maximum tax rate of $49.5 \%$ is considered, where this accounts for the removal of all federal abatement and rate reductions that are shown in source [17].

- Interest rate: The interest rate is varied by $\pm 50 \%$.

The sensitivity results are shown in figure 6 where an indexed value is plotted against the percentage of the original input value. Indexed values are derived by dividing the newly calculated NPV by the original NPV reported in section B6 above.

Figure 6 can be interpreted as follows:

- A line with a positive gradient sees an increase in NPV as the parameter increases

- A line with a negative gradient sees a decrease in NPV as the parameter increases

- The scale of the gradient indicates sensitivity, a steeper gradient shows that the NPV calculation is more sensitive to changes in the input

- The lines are of variable length dependent on the range of values considered

- A negative value shows a

Figure 6 shows that the gate fee received has the largest impact on profitability, as would be expected from the production costs and known market prices of aggregate.

This clearly shows that for future scenarios and installations, locations where a high gate fee for treating the hazardous APCr should be considered. The market price also shows some effect on NPV; however, this should ultimately be a secondary consideration. The tax rate (on profits) is also shown to have a significant impact on the final profitability (as would be expected), more so than the market price of the aggregate itself. Figure 6 shows that any form of tax rebate for utilising wastes and generating an "end of waste" 
product should be pursued; future plants may be more profitable in locations where such tax breaks are offered.

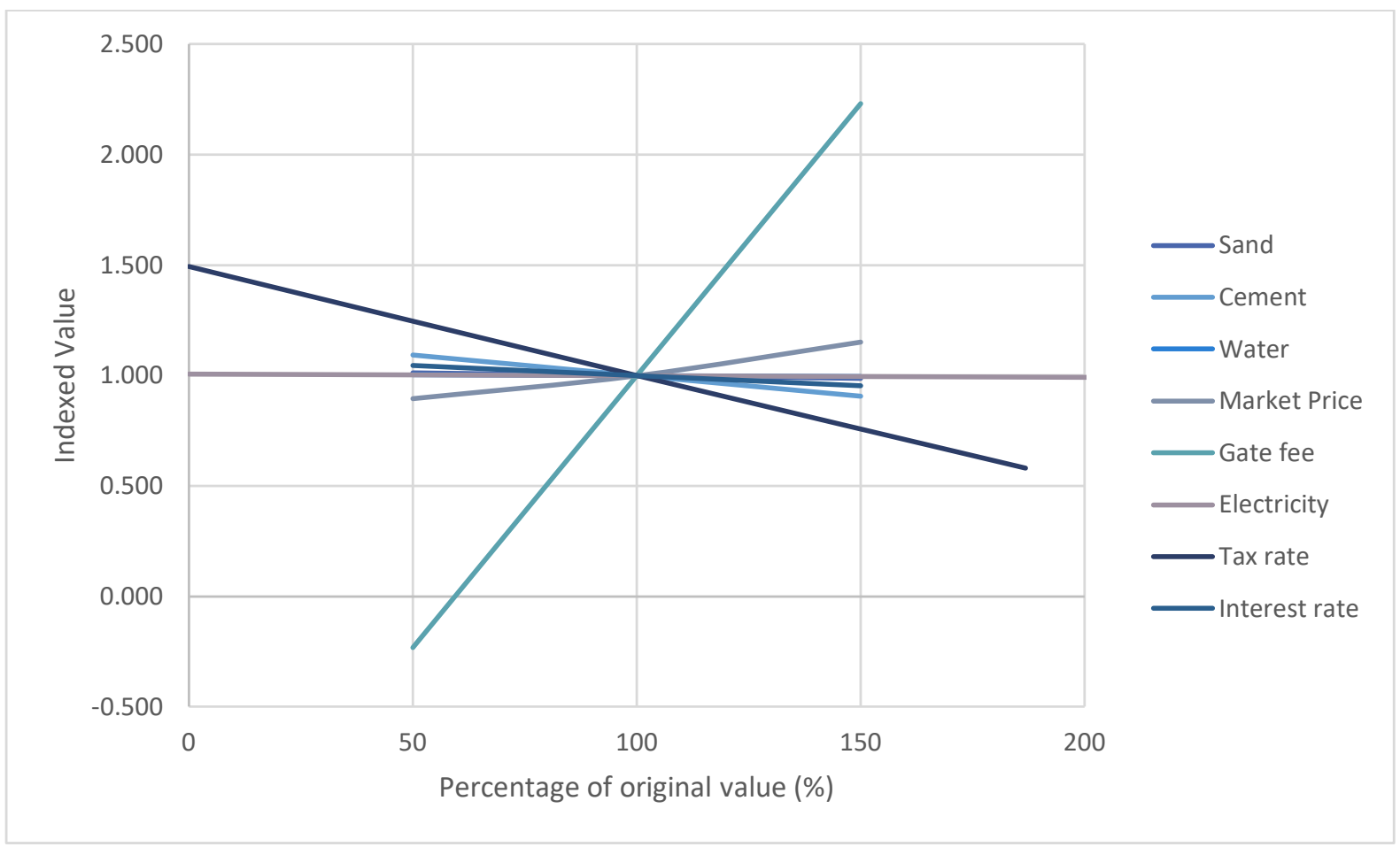

Figure 6. Sensitivity of the NPV

\section{B.7.2 Uncertainty analysis}

No uncertainty analysis was conducted during this worked example.

\section{B.7.3 Development of alternative scenarios}

Three alternative scenarios are considered in this section. The first and most obvious scenario considered follows on from the sensitivity analysis above and that is to consider variation of the gate fee received by C8S for treating APCr. The sensitivity analysis identifies this as the dominating "hotspot" in profitability determination. No further calculations or analysis are required for this scenario, it's clear that the higher the fee per tonne received for treating APCr, the greater the profitability.

A second scenario to consider is the implications of the addition of a carbon tax to emitters. A plan was originally formalised in 2016/17 that would see a conveyor type increase on carbon dioxide emissions, starting at \$CAD 10 per tonne in 2018 and rising by \$CAD 10 per year until 2022 when a final value of \$CAD 50 per tonne would be reached [20]. This plan has since been altered and its future remains uncertain, but it is used here as a reasonable estimate for what this tax could look like. By utilising $\mathrm{CO}_{2}$ in the $\mathrm{C} 8 \mathrm{~S}$ process 
a saving against this tax will be made and, in this scenario, it is assumed that the saving will be split equally between C8S and Emerald EfW. On the full 2022 rate this would see C8S receive \$CAD 25 per tonne of $\mathrm{CO}_{2}$ used. Factoring this in a similar way to the results from the sensitivity analysis an index of 1.032 is returned, suggesting only a minor improvement to the NPV of the project.

A third scenario would be to consider a scenario in which the C8S aggregate sees a high demand allowing for a raise above crushed stone market price. As the C8S aggregate is a carbon-negative product it holds a unique position in the local market which is dominated by primary aggregate sources. This scenario assumes that the assumptions made previously hold, specifically that for the first three years of plant operation aggregate is sold at a reduced price. However, after this period the price of sale for the aggregate is assumed to increase. The results of this are shown in figure 7 below.

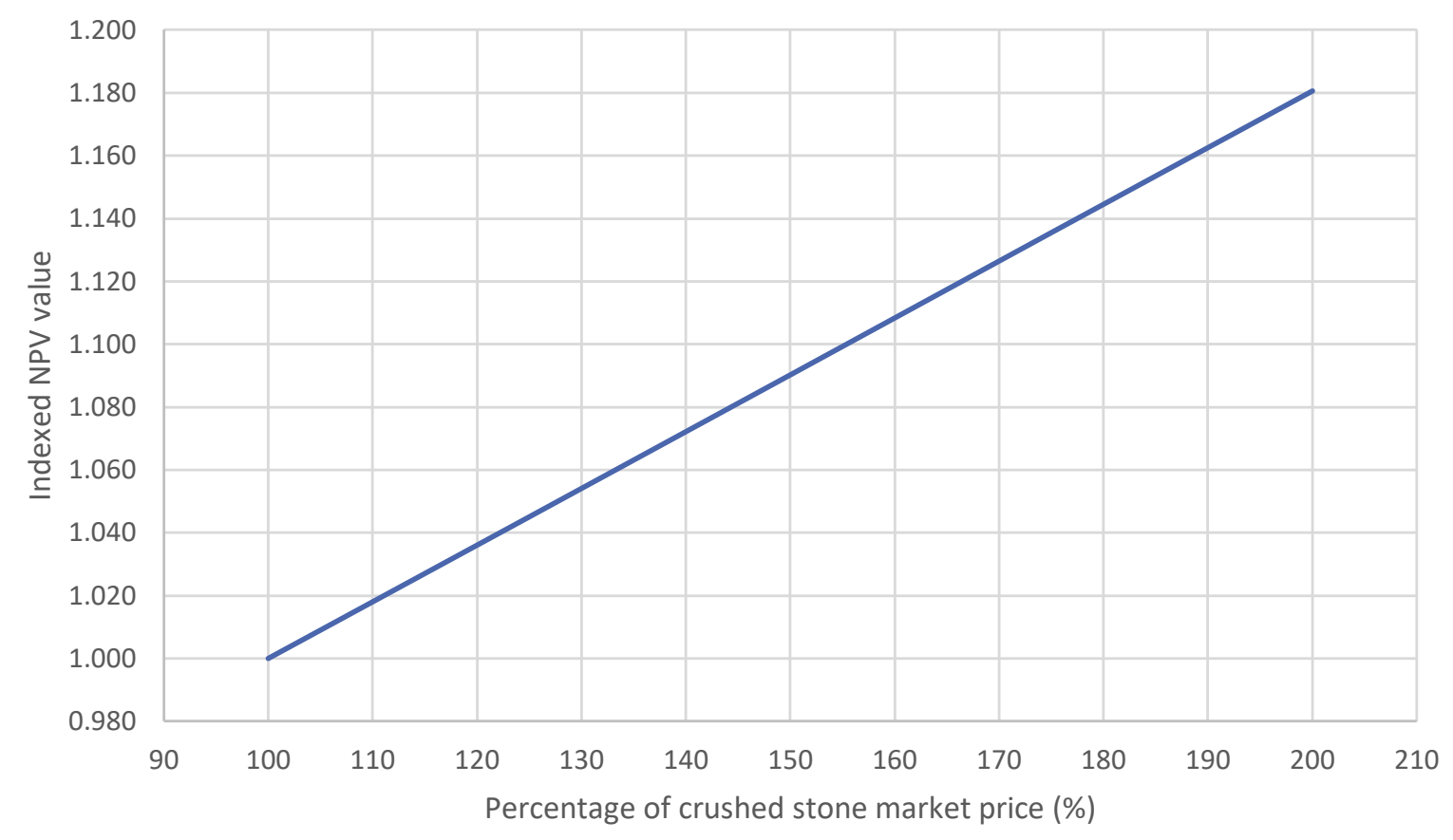

Figure 7. Indexed NPV value for increasing secondary aggregate market price

\section{Reference to Guidelines}

As suggested in Guideline B.2, scenario analysis was conducted based on hot spot identification. The impact of the gate fee on profitability makes it the most obvious element to consider when discussing potential future scenarios, but the impact of tax and market price for secondary aggregate are also considered due to their own impact. 


\section{B.8.Concluding remarks}

This report assessed the profitability of the production of secondary aggregate from $\mathrm{APCr}$ and $\mathrm{CO}_{2}$ waste sources. Comparing the production cost of the C8S secondary aggregate (\$CAD 63.26 per tonne) to market prices for crushed stone ( $\$ C A D 14.77)$ gives a significant cost deficit. Comparing the production cost of $C 8$ aggregate to crushed stone on a functional unit basis gives a price of $\$ C A D 69.59$ per $\mathrm{m}^{3}$ for C8S aggregate and a market price for crushed stone of $\$ C A D 39.93$ per $\mathrm{m}^{3}$. These figures show that in terms of pure production costs secondary aggregate is not likely to be profitable. The production cost for C8S aggregate is expected to be somewhat stable due to the dominance of the fixed OpEx costs and CapEx.

However, this deficit is overcome by the inclusion of gate fees paid to C8S for the APCr material used resulting in a venture of significant expected profitability. The NPV is calculated to be $\$ C A D 1,633,606$ and the IRR is reported to be $21 \%$.

As would be expected the profitability of the plant is found to be sensitive primarily to the gate fee received, and to a lesser extent the tax rate on profits and the market price for aggregate. Future plants should be located in areas where a significant gate fee is received for aggregate production and in locations where other financial incentives (e.g. tax reductions) for "end of waste" status is provided.

\section{Reference to Guidelines}

Following the directives in Guideline B.21, the report states and analyses the entire spectrum of elements of the checklist. 


\section{References}

[1] British Geological Survey, "Construction aggregates," 2013.

[2] T. Brown, N. Idoine, E. Raycraft, R. Shaw, S. Hobbs, P. Everett, E. Deady, and T. Bide, World Mineral Production 2012-16. British Geological Survey, 2016.

[3] OSSGA, "The Future of Ontario's Close to Market Aggregate Supply: The 2015 Provincial Plan Review," 2015.

[4] Carbon8 Systems, "Private Communication." 2018.

[5] USGS, "USGS Minerals Information," 2018. [Online]. Available: https://minerals.usgs.gov/minerals/pubs/commodity/aggregates/.

[6] Carbon8 Aggregates, “Carbon8 wins approval to build new plant in Leeds," 2016. [Online]. Available: https://c8a.co.uk/Carbon8-wins-approval-to-build-new-plant-in-leeds/.

[7] P. J. Gunning, C. D. Hills, and P. J. Carey, "Accelerated carbonation treatment of industrial wastes," Waste Manag., vol. 30, no. 6, pp. 1081-1090, 2010.

[8] J. Blamey, M. Zhao, V. Manovic, E. J. Anthony, D. R. Dugwell, and P. S. Fennell, “A Shrinking Core Model for Steam Hydration of CaO-Based Sorbents Cycled for CO2 Capture A shrinking core model for steam hydration of CaO-based sorbents cycled for CO 2 capture," Chem. Eng. J., vol. 291, no. February, pp. 298-305, 2016.

[9] L. Ji, H. Yu, B. Yu, R. Zhang, D. French, M. Grigore, X. Wang, Z. Chen, and S. Zhao, "Insights into Carbonation Kinetics of Fly Ash from Victorian Lignite for CO 2 Sequestration," 2018.

[10] C. Zhao, X. Chen, and C. Zhao, "Carbonation Behavior and the Reaction Kinetic of a New Dry PotassiumBased Sorbent for CO 2 Capture," 2012.

[11] D. Green and R. Perry, Perry's Chemical Engineers' Handbook. McGraw-Hill, 2008.

[12] R. Turton, R. Bailie, W. Wallace, and J. Shaeiwitz, Analysis, Synthesis, and Design of Chemical Processes, Third. Boston, 2009.

[13] M. Peters and K. Timmerhaus, Plant Design and Economics for Chemical Engineers. McGraw-Hill, 1991.

[14] Premier Recycling, "Scrap metal Prices Ontario," 2018. [Online]. Available: http://www.premierrecycling.ca/contact/premier-recycling-mississauga-ltd/pricing/.

[15] Toronto Local Authority, “Water Rates \& Fees," 2018. [Online]. Available: https://www.toronto.ca/services-payments/property-taxes-utilities/utility-bill/water-rates-and-fees/.

[16] P. A. Llc, “Ontario Wholesale Electricity Market Price Forecast,” 2019.

[17] KPMG, “Corporate Tax Rates,” pp. 80-82, 2018.

[18] Department of Employment \& Social Development Canada, "Chemical Process Operator Average Wage Ontario," 2018. [Online]. Available: https://www.jobbank.gc.ca/marketreport/wagesoccupation/20513/ON.

[19] Ontario Energy Board, “Ontario Electricity Rates,” 2018. [Online]. Available: https://www.oeb.ca/ratesand-your-bill/electricity-rates.

[20] Government of Canada, "Pricing carbon pollution in Canada: how it will work," 2017. [Online]. Available: https://www.canada.ca/en/environment-climatechange/news/2017/05/pricing_carbon_pollutionincanadahowitwillwork.html. 


\section{PART C LCA Worked Example}


THIS LCA WORKED EXAMPLE USES A MODEL PRODUCED SOLELY TO ASSIST IN THE USE AND INTERPRETATION OF THE ACCOMPANYING LCA GUIDELINES. THE FOLLOWING LCA WORKED EXAMPLE HAS THEREFORE NOT UNDERGONE AN EXTERNAL REVIEW IN ACCORDANCE WITH ISO 14040/14044 AND CONSEQUENTLY IT SHOULD NOT BE USED IN COMPARISONS OF OTHER LIFE CYCLE ASSESSMENTS OF CCU AND/OR CONCRETE BLOCK PRODUCTION TECHNOLOGIES. 


\section{Contents}

Contents

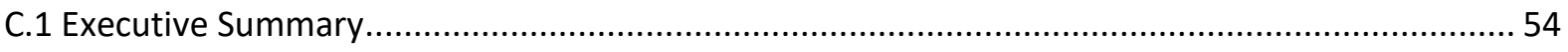

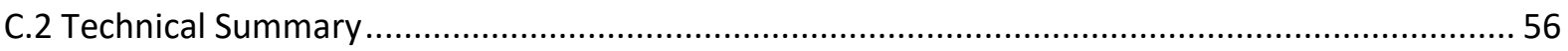

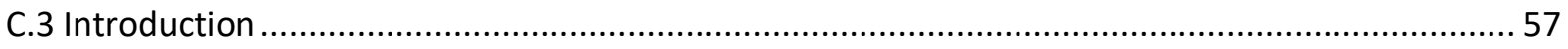

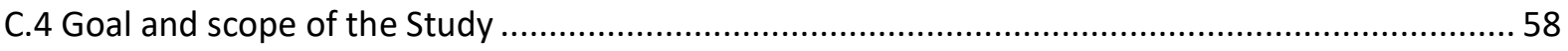

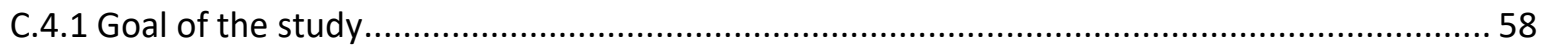

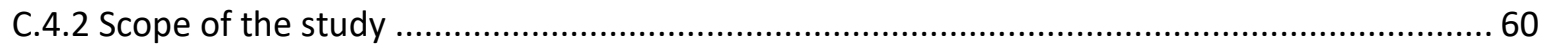

C.4.2.1 Product characteristics and classification......................................................6 60

C.4.2.2 Study limitations, completeness requirements and related cut-offs ......................63 63

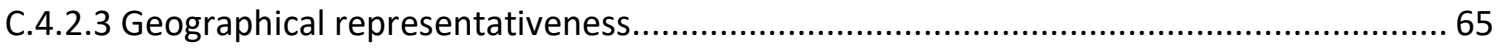

C.4.2.4 Solving multi-functionality and defining the functional unit ................................65

C.5 Inventory data sets for the main process inputs...................................................... 70

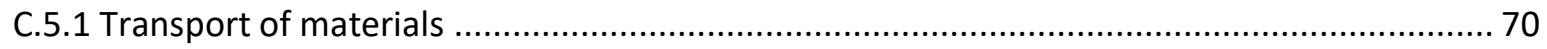

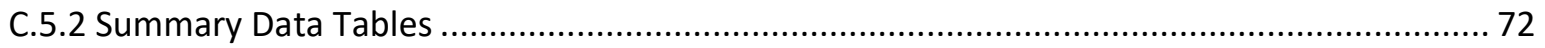

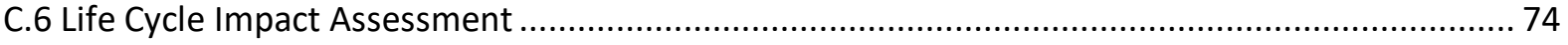

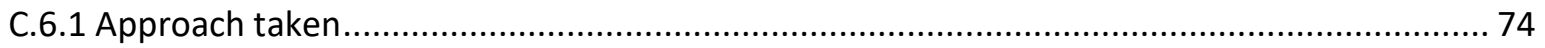

C.6.2 Results of concrete block production impact assessment ...................................... 76

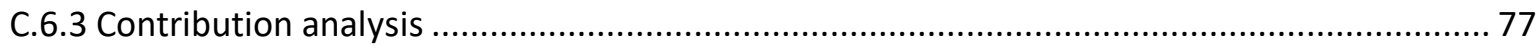

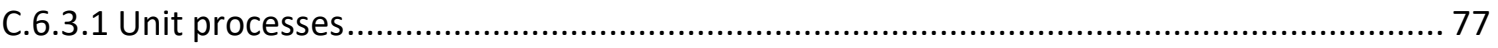

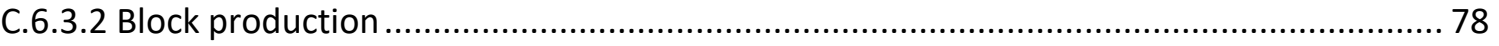

C.6.3.3 APCr stabilization/solidification ............................................................... 80

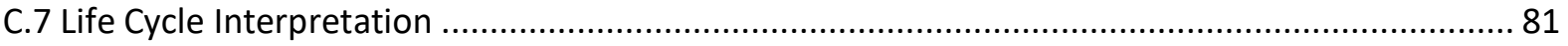

C.7.1 Sensitivity analysis - block composition .......................................................... 81

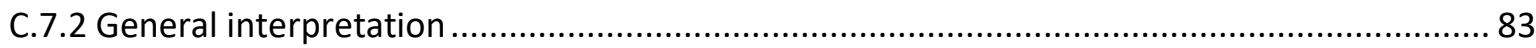

C.7.3 Subsequent approach to the analysis ................................................................. 84

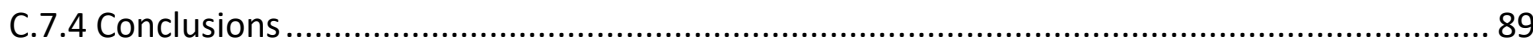

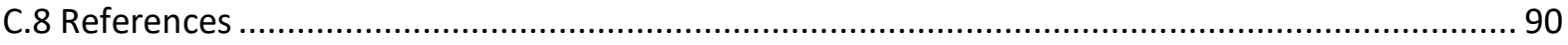




\section{C.1 Executive Summary}

\section{$\square$ Reference to Guidelines}

The LCA guidelines do not have a specific section covering what should be included within the executive summary, because this is not particular to CCU. However, a checklist of items to be included in the executive summary is included in Section C.8 Reporting of the guidelines, which is as follows:

\section{Checklist - Executive summary}

\section{Goal of the study}

State the intended application of the study

State the reasons for carrying out the study

- State the intended audience of the study

- State whether the results are to be used in comparative assertions disclosed to public

State unambiguously the research question(s)

State the classification of the assessed CCU technology

\section{Scope of the study}

- State functional unit clearly and unambiguously according to guideline and report changes due to solving of multi-functionality

State system boundaries according to guideline

- State relevant issues with data quality and assumptions

State technology readiness level (TRL) of processes and sub-processes

Report production or storage capacity

Report geographical scope

State software system (and version) and data library (and version) used

- State type of review and provide additional information about reviewers

\section{Life cycle inventory and Life cycle impact assessment}

- State main results of life-cycle inventory and life-cycle impact assessment

If results are reported on a relative basis, report basis

Describe uncertainty and sensitivity analysis and report results separately

\section{Interpretation}

- State any conclusions, recommendation and limitations

Whilst the executive summary of an LCA report on CCU technologies does not really differ from an executive summary from any other LCA report, this section has been provided as an example. 
This study has the goal to assess the environmental impacts of producing concrete blocks containing aggregate manufactured from air pollution control residues (APCr) and flue gas $\mathrm{CO}_{2}$ arising from a municipal solid waste (MSW) energy from waste (EfW) plant, compared to the stabilization \& landfilling of the APCr and the production of conventional concrete blocks from naturally-derived aggregate.

The results are intended to be used to compare the environmental impacts of producing concrete blocks using CCU technology to treat the APCr waste, versus conventional technology to produce blocks and to stabilize and landfill the APCr waste. It is expected that this study will be of interest to the technology developer Carbon8 Systems, so it is possible that the results will be used for marketing purposes or to make comparisons between products.

The carbonated aggregate has a different chemical structure and composition to its conventional counterpart and it also has a slightly lower density than natural aggregate and so results in blocks with a slightly lower density. For this reason, a cradle-to-grave assessment is conducted. System expansion is used to include the impacts arising from the source of the $\mathrm{CO}_{2}$ utilised in the process, as well as the block production, use and end-of life. The functional unit reflects this multi-functionality and comprises the blocks required to build $1 \mathrm{~m}^{2}$ of wall, plus the $372 \mathrm{kWh}$ of electricity produced and $13.7 \mathrm{~kg} \mathrm{APCr}$ treated.

The study is limited by the modelling of the EfW plant used in the assessment. Data specific to the facility is used where possible, but some data from GaBi (v8.7.0.18) and ecoinvent 3.4 is used. The focus of the analysis is to compare an existing EfW facility to the same facility with an on-site carbonated aggregate production plant, rather than to assess the impacts of the EfW processes itself. Consequently, the potential toxicity impacts of the EfW plant and APCr re-use were not evaluated.

The modelled production plant has a production capacity of 4,500 t carbonated aggregate/year. The mineralization sub-process utilising $\mathrm{CO}_{2}$ which has not been separated from the flue gas is at demonstration scale. For this reason, a technology readiness level of 7 is assigned to the overall process, despite the fact that EfW plants and block-making utilising mineralized APCr-derived aggregate are well-established commercial processes at TRL 9. The geographical scope of the study is limited to Ontario, Canada. The study was commissioned by The Global $\mathrm{CO}_{2}$ Initiative $/ \mathrm{CO}_{2}$ Sciences and was conducted by the University of Sheffield with data provided by Carbon8 Systems.

A contribution analysis of the results arising from the system expansion model identified that the EfW plant dominated in terms of GHG emissions. To enable product specific assessment of the block-making and APCr treatment processes, substitution was conducted to focus the analysis upon the processes of interest.

When using system expansion, the Carbon8 Systems (C8S) process is shown to reduce the GHG emissions of the entire process system by $5 \%$ compared to the reference process. Most of these reductions arose from the avoidance of the reference APCr treatment process and the aggregate/block-making process. However, additional small emissions reductions were additionally achieved when transporting the blocks to market and in their end-of-life treatment, largely due to the reduced mass of the C8S blocks compared to the conventional blocks. The system is dominated by GHG emissions from the EfW plant, so by using substitution to give credit for the avoided burden of an unabated EfW plant, it removes electricity from the functional unit and effectively removes the EfW plant from the system boundary. Using this approach allows us to calculate that the $\mathrm{C} 8 \mathrm{~S}$ process leads to a reduction in $\mathrm{GHG}$ emissions of the reduced system by approximately $22 \%$ over the reference method. Focusing upon the APCr treatment and block production processes alone, the reduction in GHG emissions achieved by switching to the C8S process rises to $34 \%$. Cement use makes the largest contribution to the impacts from both block production processes and the reference APCr stabilization process. The latter impacts were significantly larger than from transporting the APCr long distances to the treatment site. 


\section{C.2 Technical Summary}

\begin{tabular}{|c|c|c|c|}
\hline & CCU Product & \multicolumn{2}{|l|}{ Concrete building blocks. } \\
\hline & Goal & \multicolumn{2}{|c|}{$\begin{array}{l}\text { To assess the environmental impacts of producing concrete blocks containing aggregate manufactured } \\
\text { from } \mathrm{APCr} \text { and flue gas } \mathrm{CO}_{2} \text { arising from an MSW EfW plant, compared to the stabilization \& landfilling } \\
\text { of the APCr and the production of conventional concrete blocks from naturally-derived aggregate. }\end{array}$} \\
\hline- & Brief description & \multicolumn{2}{|c|}{$\begin{array}{l}\mathrm{CO}_{2} \text {-containing flue gas is used directly from an MSW energy-from-waste plant to carbonate the APCr } \\
\text { arising from the same plant. The resulting solid aggregate is used to produce building blocks. }\end{array}$} \\
\hline 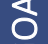 & Intended audience & \multicolumn{2}{|c|}{ LCA practitioners } \\
\hline & Functional Unit & \multicolumn{2}{|c|}{$\begin{array}{l}\text { The production of blocks to build } 1 \mathrm{~m}^{2} \text { of wall, the production of } 372 \mathrm{KWh} \text { electricity and the treatment } \\
\text { of } 13.7 \mathrm{~kg} \mathrm{APCr} \text {. }\end{array}$} \\
\hline & $\begin{array}{l}\text { Limitations and } \\
\text { Assumptions }\end{array}$ & \multicolumn{2}{|c|}{$\begin{array}{l}\text { - MSW collection was not included within the system boundary. } \\
\text { - } \quad \text { Waste steam from the EfW plant was not included within the system boundary. } \\
\text { - } \quad \text { The same type of road freight was used to transport all aggregates and products. } \\
\text { - End-of-life treatment was assumed to be the same process for both blocks. }\end{array}$} \\
\hline \multirow{4}{*}{$\frac{u}{\text { 岁 }}$} & $\begin{array}{l}\text { Boundary } \\
\text { (i.e. cradle to gate) }\end{array}$ & \multicolumn{2}{|c|}{$\begin{array}{l}\text { Cradle to grave - due to the blocks composed of carbonated material being slightly lighter than } \\
\text { conventional blocks }\end{array}$} \\
\hline & Location & \multicolumn{2}{|l|}{ Ontario, Canada } \\
\hline & Time frames & \multicolumn{2}{|l|}{ Current } \\
\hline & $\begin{array}{l}\text { Multi-functional } \\
\text { approach }\end{array}$ & $\begin{array}{l}\square \text { Sub-division } \\
\text { \System expansion } \\
\text { \System expansion via substitution } \\
\square \text { Virtual sub-division } \\
\square \text { Mass allocation }\end{array}$ & $\begin{array}{l}\square \text { Energy allocation } \\
\square \text { Economic allocation } \\
\square \text { Closed loop scenarios } \\
\square \text { Other (specify)............................................. }\end{array}$ \\
\hline & Data Source & $\begin{array}{l}\text { 囚Primary sources } \\
\text { 囚Secondary sources } \\
\square \text { Stoichiometric data }\end{array}$ & $\begin{array}{l}\text { 囚Process modelling based data } \\
\square \text { Mixes sources } \\
\square \text { Other (specify) }\end{array}$ \\
\hline 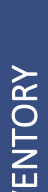 & $\begin{array}{l}\text { Energy sources } \\
\text { (select all that apply) }\end{array}$ & $\begin{array}{l}\square \text { Grid mix } \\
\square \text { Power station with Carbon Capture } \\
\square \text { Wind } \\
\square \text { Solar }\end{array}$ & $\begin{array}{l}\square \text { Nuclear } \\
\square \text { Hydro } \\
\square \text { Future (see timeframes) } \\
\text { 冈Other (specify)...electricity directly from the energy-from- } \\
\text { waste plant }\end{array}$ \\
\hline 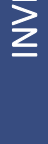 & $\begin{array}{l}\text { Main Sub- } \\
\text { Processes and } \\
\text { TRLS }\end{array}$ & $\begin{array}{l}\text { SUB-PROCESS } \\
\text { MSW Energy from Waste } \\
\text { Carbonated aggregate production } \\
\text { Block making }\end{array}$ & $\begin{array}{r}\text { TRL } \\
\text { TRL } 9 \\
\text { TRL 7 } \\
\text { TRL } 9\end{array}$ \\
\hline & $\begin{array}{l}\text { Database \& } \\
\text { Software }\end{array}$ & \multicolumn{2}{|l|}{ ecoinvent v3.4 and GaBi v8.7.0.18 } \\
\hline \multirow{2}{*}{ 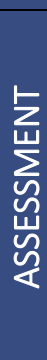 } & LCIA Method & $\begin{array}{l}\text { 区 CML } \\
\text { ILCD 1.09a } \\
\square \text { ReCiPe } \\
\text { OTHER IMPACT METHODS }\end{array}$ & $\begin{array}{l}\text { SINGLE CATEGORIES: } \\
\square \text { Global warming } \\
\square \text { CED } \\
\square \text { use TOX }\end{array}$ \\
\hline & $\begin{array}{l}\text { Highlighted } \\
\text { Results } \\
\text { (graphical, text or } \\
\text { tabular format) }\end{array}$ & \multicolumn{2}{|c|}{$\begin{array}{l}\text { Using system expansion, the production of blocks using the C8S process leads to GHG emissions of } 185.1 \\
\mathrm{Kg} \mathrm{CO}_{2} \text { eq. per } 1 \mathrm{~m}^{2} \text { wall, } 372 \mathrm{KWh} \text { electricity produced and } 13.7 \mathrm{Kg} \mathrm{APCr} \text { treated compared to } 195 \mathrm{Kg} \\
\mathrm{CO}_{2} \text { eq. when the reference process is used. }\end{array}$} \\
\hline \multirow[t]{2}{*}{ 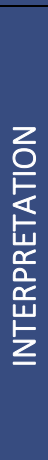 } & Main Conclusions & \multicolumn{2}{|c|}{$\begin{array}{l}\text { - Using system expansion, the C8S process is shown to reduce the GHG emissions of the entire } \\
\text { process system by } 5 \% \text { compared to the reference process. } \\
\text { Using substitution to remove the EfW impacts from the system boundary, the C8S process } \\
\text { leads to a reduction in GHG emissions of } 22 \% \text { and this rises to } 34 \% \text { if just the impacts arising } \\
\text { from the APCr treatment and block production process are evaluated. } \\
\text { - Small emissions reductions were additionally achieved when transporting the blocks to } \\
\text { market and in their end-of-life treatment, largely due to the reduced mass of the C8S blocks } \\
\text { compared to the conventional blocks. } \\
\text { Cement makes the largest contribution to the impacts of the C8S and the reference block } \\
\text { production processes; and cement has a significantly larger impact upon the reference APCr } \\
\text { treatment process than transport. }\end{array}$} \\
\hline & Sensitivity Analysis & \multicolumn{2}{|c|}{$\begin{array}{l}\text { 区 Yes (please specify below) } \\
\text { Block composition }\end{array}$} \\
\hline
\end{tabular}




\section{C.3 Introduction}

Aggregates are used directly as fill, ballast or road stone in construction projects and they are also manufactured into concrete masonry units/aggregate blocks (hereafter referred to as concrete blocks) used for building. Concrete blocks are generally produced from naturally-derived aggregate which is quarried, crushed/processed to the required grade and then mixed with sand and cement to produce blocks. Bottom ash arising from combustion processes and fly ash from coal power stations can be added to natural aggregates during the block production process in order to divert these wastes from landfill. Air Pollution Control residue (APCr) is the term given to the material collected from flue gases passing up smoke stacks and flues in order to limit the air pollution. The APCr arising from municipal solid waste (MSW) incineration is contaminated with heavy metals and persistent organic pollutants such as dioxins and furans, so most countries require such material to be disposed of as a hazardous waste or treated to stabilize it before it can be landfilled as a non-hazardous waste.

The process described and modelled in the following assessment mixes the flue gas arising from an MSW Energy from Waste (EfW) plant with the APCr from the same plant. The carbon dioxide $\left(\mathrm{CO}_{2}\right)$ within the flue gas reacts with the alkaline metal oxides ( $\mathrm{CaO}$ and some $\mathrm{MgO}$ and calcium/magnesium silicates) within the APCr to form mineral carbonates - equivalent to natural limestone. This mineralization of the $\mathrm{CO}_{2}$ from the flue gas not only chemically transforms the $\mathrm{CO}_{2}$ into a solid material which can no-longer contribute to climate change, but the solid limestone matrix locks-up the heavy metals and persistent organic pollutants and prevents them from causing harm. The pelleting process forms an aggregate which can be used as a loose fill or subsequently made into concrete blocks.

By producing blocks from waste $\mathrm{CO}_{2}$ combined with waste $\mathrm{APCr}$, it becomes possible to substitute a proportion of the natural aggregates used to produce conventional blocks with mineral carbonates derived from $\mathrm{CO}_{2}$. This mineralization process provides essentially permanent sequestration of the waste carbon within the blocks, since even if the blocks are ground to a fine powder at their end-of-life, the carbon remains in the form of mineral carbonates rather than returning to $\mathrm{CO}_{2}$.

This report assesses the environmental impacts of an APCr aggregate demonstration plant capable of producing around 4,500 tonnes of aggregate per year.

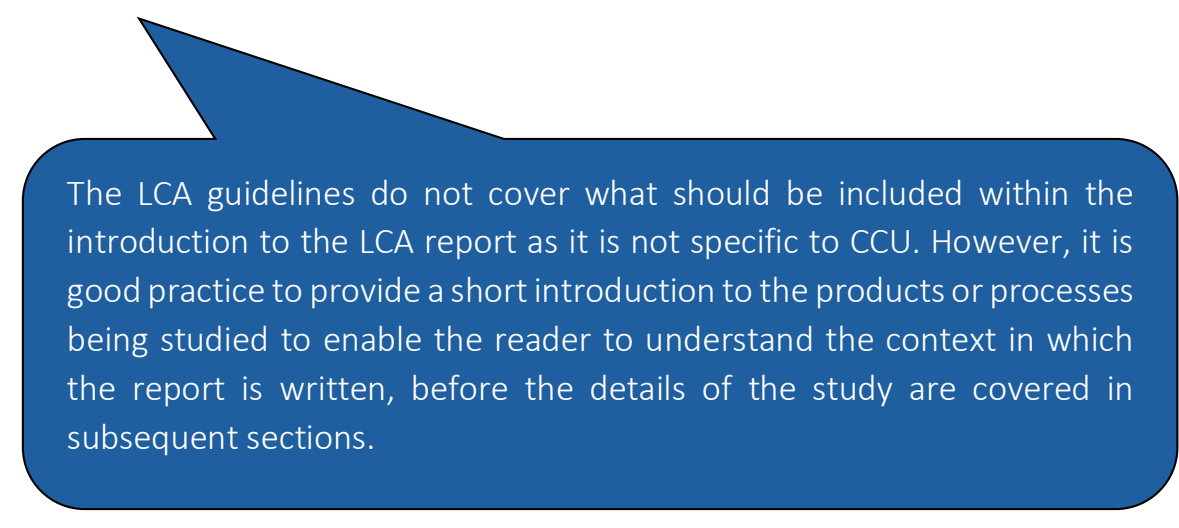




\section{C.4 Goal and scope of the Study}

\section{C.4.1 Goal of the study}

\section{$\square$ Reference to Guidelines}

A description of what should be included within the Goals section of an LCA report is provided in Section C.3 Goal definition of the guidelines. Specific guidelines of what shall or should be included are listed in Section C.3.1.1.

In addition, a checklist of items to be included in each section of the report is included in Section C.8 Reporting of the guidelines, which for the goal is as follows:

\section{Goal of the study}

- State the intended application of the study

- State the reasons for carrying out the study

- State the intended audience of the study

State whether the results are to be used in comparative assertions disclosed to public

State unambiguous research question(s)

State the classification of the assessed CCU technology

State limitations due to the assumptions and methods, e.g. if study is preliminary

- State the commissioner of the study and other influential actors

State technology readiness level (TRL) of processes and sub-processes

Report production or storage capacity

$\square$ State review process and review experts, if any

The following study has the goal:

To assess the environmental impacts of producing concrete blocks containing aggregate manufactured from $\mathrm{APCr}$ and flue gas $\mathrm{CO}_{2}$ arising from an MSW EfW plant, compared to the stabilization \& landfilling of the APCr and the production of conventional concrete blocks from naturally-derived aggregate.

The results are intended to be used to compare the environmental impacts of producing concrete blocks using CCU technology versus conventional technology, together with the APCr treatment service of utilizing the APCr rather than it being stabilized prior to being landfilled.

The carbonated aggregate has a slightly lower density than conventionally-derived natural aggregate and when used to make building blocks it results in blocks with a slightly lower density than conventional blocks. The modelled plant has a production capacity of 4,500 $\mathrm{t}$ carbonated aggregate/year.

The study is limited by the municipal solid waste (MSW) Energy from Waste (EfW) facility being modelled using a mixture of data arising from published plant-specific data, literature data relating to energy from waste plants in general and data arising from GaBi/ecoinvent. Further limitations are imposed by the use of 
aggregated data for the block-making process and the quarrying of the natural aggregate and sand and the production of the cement.

The mineralization sub-process utilising $\mathrm{CO}_{2}$ which has not been separated from the flue gas is at demonstration scale, therefore a technology readiness level 7 has been assigned to the overall process, despite the fact that EfW plants and block-making utilising mineralized APCr-derived aggregate are wellestablished commercial processes at TRL 9.

\section{Reference to Guidelines}

Using the lowest TRL process to define the TRL of the overall process is explained in Section A.4.2 and the specific guideline of what shall or should be included is provided as Guideline A.1.

The aim of this study is to assess whether or not the Carbon8 technology can reduce system-wide environmental impacts and to compare the impacts of producing blocks using Carbon8 aggregate with blocks made using conventional aggregate. The results will be of interest to the technology developer Carbon8 Systems (C8S), so it is possible that the study will be used for marketing purposes or to make comparisons between products by the companies involved.

This study was commissioned by The Global $\mathrm{CO}_{2}$ Initiative $/ \mathrm{CO}_{2}$ Sciences and was conducted by the University of Sheffield.

As mentioned in the overall introduction to this set of worked examples in Part A and in the preface to Part $\mathrm{C}$, this document is a worked example produced to help in the use and interpretation of the guidelines. Therefore, the true goal of this study is slightly different to that described above and the report has not undergone external review as would be required by a published LCA report according to ISO $14040 / 14044$. 


\section{.4.2 Scope of the study}

\section{Reference to Guidelines}

A description of what should be included within the Scope section of an LCA report is provided in Section C.4 Scope definition of the guidelines. The specific guidelines of what shall, should or may be included are provided as Guidelines C.2 to C.6.

In addition, a checklist of items to be included in each section of the report is included in Section C.8 Reporting of the guidelines, which for the scope is as follows:

\section{Scope of the study:}

- State functional unit clearly and unambiguously according to the guideline, report changes due to solving of multi-functionality

- State performance characteristics, any omission of additional function in comparison and how performance is measured (might apply for products different in chemical structure and composition to their conventional counterparts)

- State system boundaries according to guideline and cut-off criteria including a system boundaries diagram

- State omitted life cycle stages and processes (might apply for products different in chemical structure and composition to their conventional counterparts)

- State relevant issues with data quality and assumptions

- State method(s) to solve multi-functionality

- State impact assessment methods

- State data quality needs and how energy and material inputs and outputs are quantified

- State software system (and version) and data library (and version) used

- State type of review and provide additional information about reviewers

\section{C.4.2.1 Product characteristics and classification}

The product under assessment is concrete blocks manufactured using the mineralization of $\mathrm{CO}_{2}$ and $\mathrm{APCr}$ obtained from an MSW (municipal solid waste) Energy from Waste plant. The plant in question has some characteristics of an incinerator and some more like a gasifier, so to avoid miss-classifying the technology it is referred to as an Energy from Waste plant. The blocks are not identical in chemical structure and composition to their conventional counterpart and their physical characteristics differ in that the mineralized- $\mathrm{CO}_{2}$ blocks are slightly less dense than conventional concrete blocks. 
The product classification is important as it influences not only the positioning of the boundaries of the study, but also the nature of the functional unit. For instance, chemicals produced by CCU generally have an identical chemical structure and composition to those produced by conventional techniques. They can therefore be compared by mass with the functional unit in Kg. However, CCU fuels such as synthetic gasoline or diesel may have different energy contents than the conventional equivalents, in which case the functional unit needs to reflect the energy service that it provides. Fuels with identical chemical structure and composition would be compared using energy content in the functional unit. More information is available in the LCA Guidelines.

All processes in this study are assessed from cradle-to-grave as shown diagrammatically in Figures 1 and 2. Block flow diagrams are presented for both the conventional (reference) route and the CCU route to enable comparison.

\section{Reference to Guidelines}

The use of a cradle-to-grave boundary is in line with the recommendation in Section C.4.2.1 of the LCA guidelines when the chemical structure and composition of the $\mathrm{CO}_{2}$-derived product differs from that of the conventionally-derived product. In this case, it is known that the $\mathrm{CO}_{2}$-derived aggregate blocks have differing chemical and physical characteristics to conventional blocks. Therefore, potentially the impacts arising from the use phase and end-of-life treatment could differ.

In practice, carbonated APCr aggregate which is produced commercially by Carbon 8 Aggregates from $\mathrm{APCr}$ and purified $\mathrm{CO}_{2}$ (rather than flue gas) have been shown to perform in the same way during usage and end-of-life as conventional aggregate.

The process routes considered for this assessment are:

a. Blocks manufactured from natural/primary aggregate - referred to as the conventional process in Figure 1 and the subsequent assessment.

b. Blocks manufactured from aggregate produced from carbonated APCr - referred to as the CCU process in Figure 2 and the subsequent assessment. 


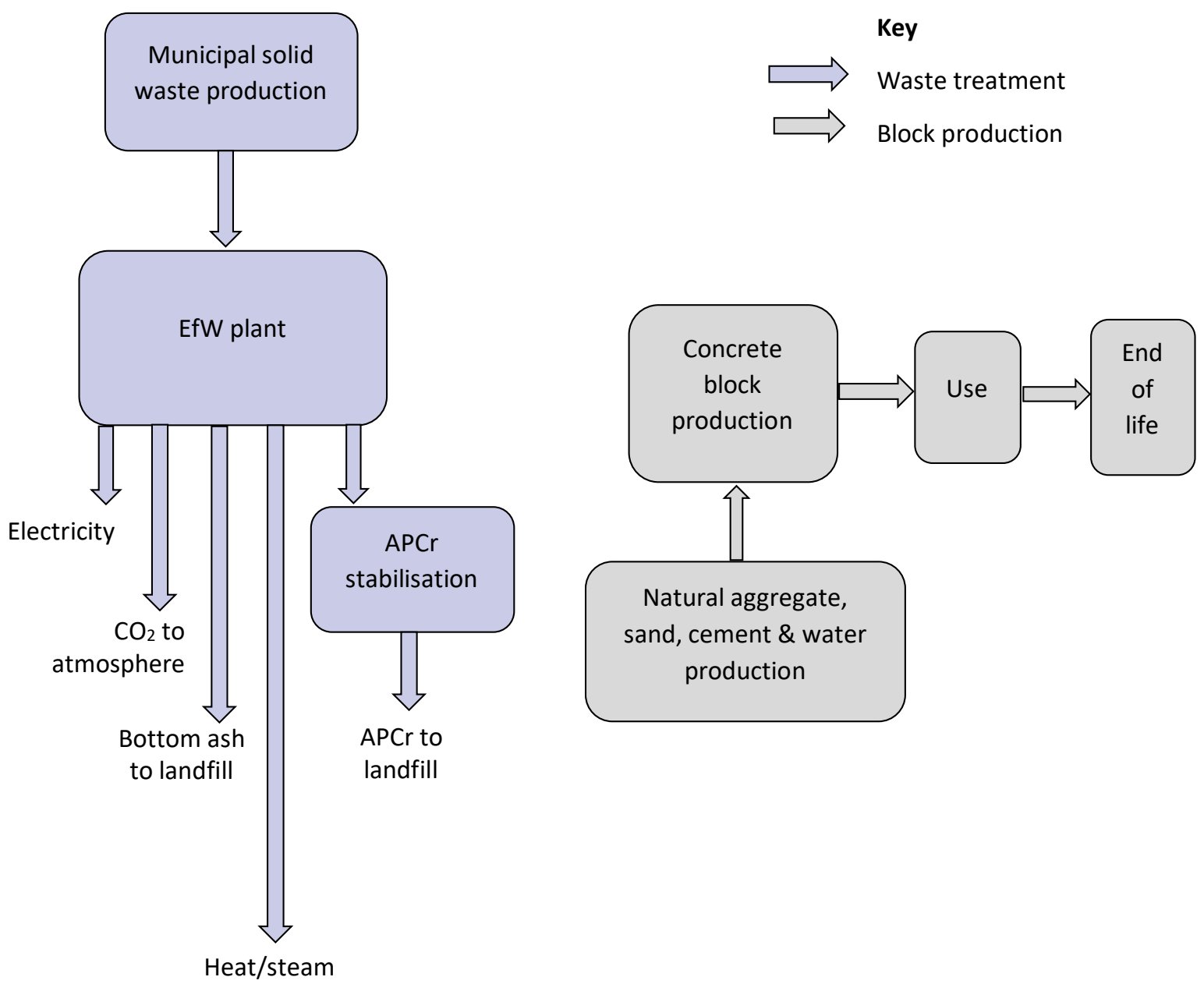

Figure 1. Block flow diagram of the conventional process.

\section{Reference to Guidelines}

The description of the reference process is included as recommended in Section C.4.2 of the guidelines. This ensures that the avoided impacts of the conventional (reference) process are transparent and measurable. Section C.4.2 of the guidelines suggests that the $\mathrm{CO}_{2}$ source, $\mathrm{CO}_{2}$ purification and transport are included for the $\mathrm{CCU}$ process and are shown within the system boundaries of the process. Figure 2 includes the $\mathrm{CO}_{2}$ source, but $\mathrm{CO}_{2}$ purification and transport are not relevant to the process under assessment here which utilises $\mathrm{CO}_{2}$ contained within the flue gas. 


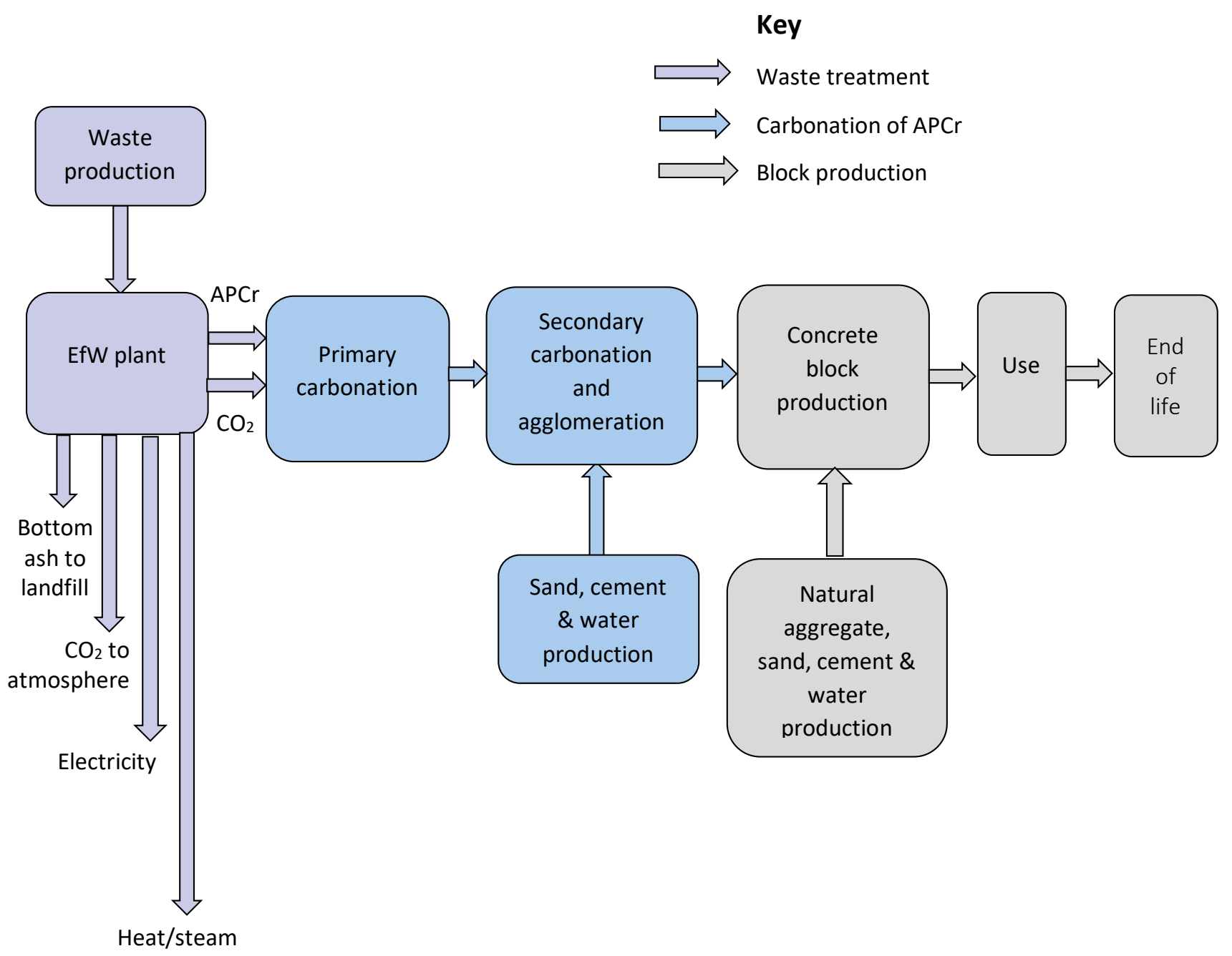

Figure 2. Block flow diagram of the CCU process.

\section{C.4.2.2 Study limitations, completeness requirements and related cut-offs}

The limitations of the study, including data cut-offs, data availability and other uncertainties are summarized below.

\section{EfW plant}

The main limitation of the study is the modelled EfW plant used in the assessment. Data specific to the facility was used where possible [1], but in addition, data from Gabi and ecoinvent 3.4 was also used and sense-checked against data published in the literature. An assumption was made that the composition of the APCr (by weight) was 50\% fly ash and 50\% slaked lime used by Emerald Waste to Energy in their venture scrubber. This was deemed acceptable in this instance as the focus of this analysis is to compare an existing EfW facility to the same facility with an on-site carbonated aggregate production plant, rather than to assess the impacts of the EfW processes itself. 


\section{APCr toxicity}

Following on from the above reasoning, the incinerator model created for the purposes of this worked example did not include persistent organic pollutants such as dioxins and furans associated with EfW emissions as outputs. As a consequence of this, the potential toxicity impacts of MSW incineration and APCr re-use could not be evaluated in this study. As before, this was considered acceptable in this instance because the incineration process is not affected in any way by the process under evaluation - which is simply a treatment option for the waste APCr produced. Therefore, the incinerator outputs do not differ between the conventional reference process and the CCU aggregate process. The purpose of creating the incinerator model was to enable the environmental impacts of the carbonation and block-making processes to be placed into context against the impacts of the incinerator.

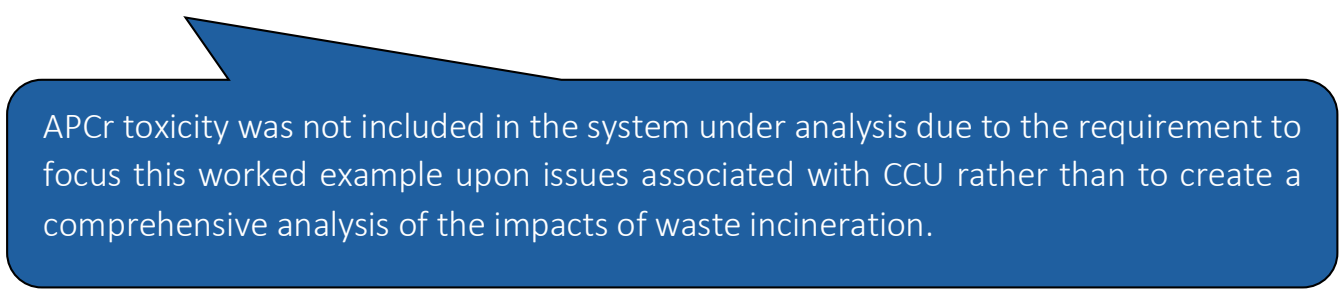

\section{Other limitations/cut-offs:}

- Waste heat in the form of steam from the EfW plant is piped to a neighbouring paper mill, but little data was available. As this heat is identical in both processes and so does not need to be included in the comparison between the two, it was not included within the system boundary.

- Some datasets used from ecoinvent version 3.4 are several years out of date.

- In the absence of specific information, the same type of road freight was used for all movements of aggregates, cement, blocks etc. to enable a fair comparison. However, the actual transport impacts may differ from those modelled.

- The end-of-life treatment of the blocks was assumed to be the same for both types of blocks. Consequently, the only differences in impacts arising from the transportation and end-of-life treatment can be ascribed to the differences in mass between the two types of blocks.

- MSW collection was not included within the system boundary as it is identical for both processes and therefore does not need to be considered during the comparison.

\section{End of life \& $\mathrm{CO}_{2}$ storage}

Calcium carbonate is a very stable compound and only thermally decomposes back to Calcium oxide and carbon dioxide $\left(\mathrm{CaCO}_{3} \rightarrow \mathrm{CaO}+\mathrm{CO}_{2}\right)$ at temperatures between $800{ }^{\circ} \mathrm{C}$ and $950{ }^{\circ} \mathrm{C}$ [2]. The end-of-life treatment of the blocks is likely to result in crushing the blocks to form a loose aggregate, but even if the aggregate was further processed to form a fine powder, the carbon would remain bound as calcium carbonate and not be re-emitted as $\mathrm{CO}_{2}$. It is therefore deemed unlikely that end-of-life treatment of the concrete blocks would result in the re-release of the $\mathrm{CO}_{2}$ utilised in its production. For this reason, the $\mathrm{CO}_{2}$ captured and utilised in the process is not treated as being temporary storage but a permanent sequestration. This study makes no attempt to assess the stability of any entrapped or encapsulated persistent organic pollutants during end-of-life processing. 


\section{C.4.2.3 Geographical representativeness}

The main location assessed in this study is Ontario, Canada. Energy and other inventories were adapted to the conditions of this location as closely as possible. When data for the specific state was not available, data for the country was used and if this was not available then global average (GLO) data was used. Whilst this limits the regional representativeness of the data, the technology representativeness can still be achieved through the use of such secondary data as proxy data.

Tables showing the location (and date) of each database inventory used have not been provided as part of this worked example as that is an issue common to most LCA rather than being specific to LCA of CCU.

\section{Reference to Guidelines}

Section C.4.4 of the guidelines covers data quality. Complete data availability may be limited to full LCA studies, so clarity and transparency in explaining the sources of data used is important. Guideline C.9 in Section C.5.3 explains that the reference (conventional) process should use the current best available technology because the conventional technologies in future when CCU is implemented is likely to be unknown. In this way, the perception of bias is avoided.

\section{C.4.2.4 Solving multi-functionality and defining the functional unit}

\section{Solving multi-functionality}

In the system under investigation, flue gas is diverted from an MSW EfW plant and the $\mathrm{CO}_{2}$ from the flue gas becomes a feedstock for carbonation of the APCr to produce an aggregate. This aggregate is then used to produce concrete blocks for the building trade. The whole system produces multiple products as shown in Figure 2. 
To allow all of the associated environmental impacts of producing carbonated aggregate to be included in the assessment, the MSW EfW plant and the block manufacturing plant have to be included in the analysis. This results in the overall system being multi-functional in that multiple products are produced. To enable comparison of the conventional route and the CCU route under equal conditions, this multi-functionality needs to be solved. Depending upon where the system boundaries are drawn, solving the multi-functionality can lead to having a single product or multiple products within the functional unit.

As explained in the Guidelines, sub-division should be the first approach to solving multifunctionality, but in this instance the impacts of producing the electricity from MSW cannot be separated from the impacts of producing the $\mathrm{CO}_{2}$, because electricity cannot be produced from MSW without producing $\mathrm{CO}_{2}$. Since $\mathrm{CO}_{2}$ is an essential feedstock of the carbonated aggregate, it is therefore impossible to separate the impacts of MSW incineration from those of block production in this way.

The multi-functionality of the system is solved by using system expansion to include both the EfW plant and the block-making plant within the system boundary of both the CCU process and the conventional process. This is represented diagrammatically in the figures below.

\section{Reference to Guidelines}

Section C.4.3.2 Solving multi-functionality describes a hierarchy of methods for solving multifunctionality. System expansion is the method that should be used to solve multi-functionality in this instance. For this reason, both the EfW plant and the block manufacture are included along with the carbonated aggregate production process within the system boundary of the conventional block production process. 


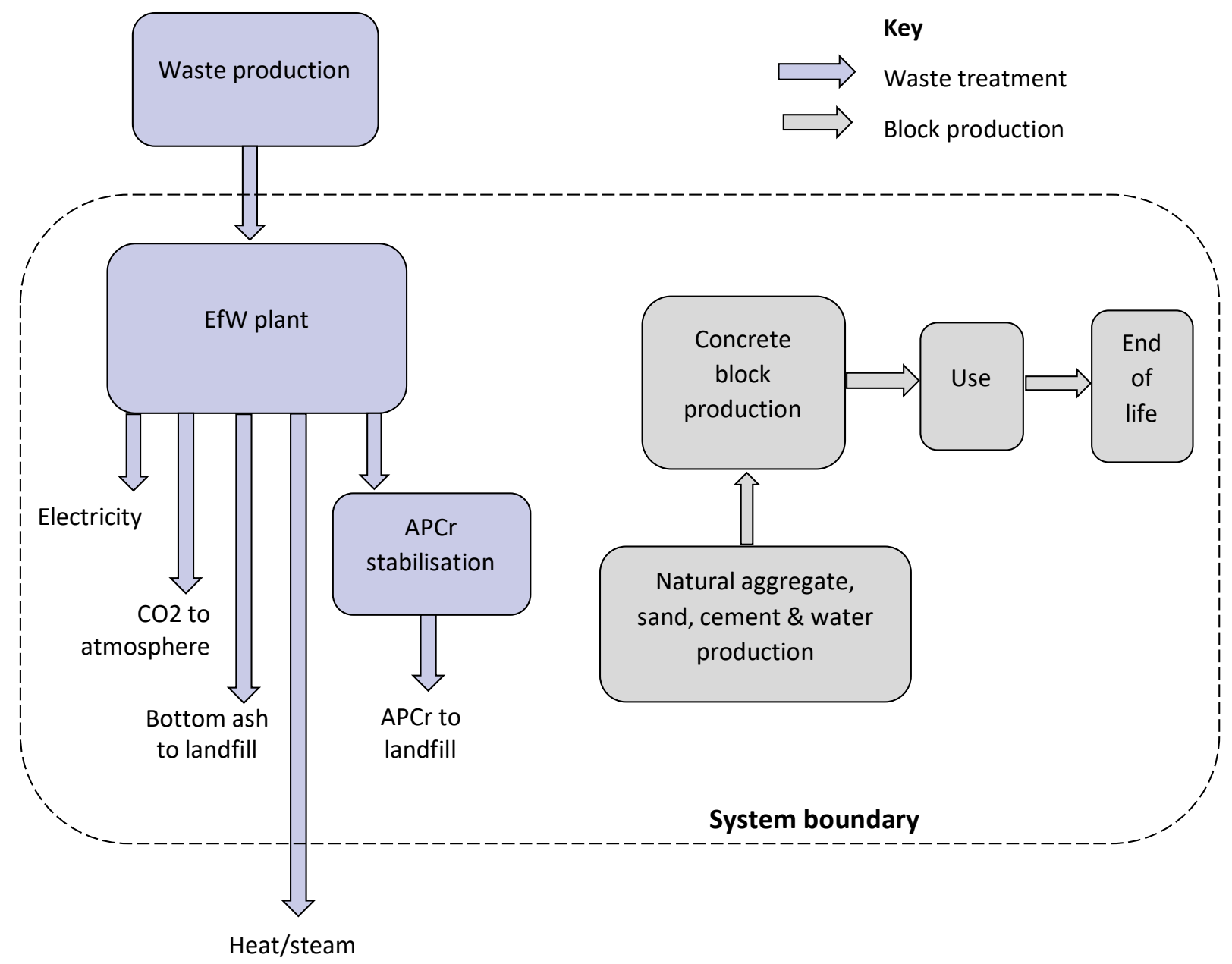

Figure 3. Using system expansion to enable comparison between the conventional process (shown here) and the CCU process (shown in Figure 4), with the system boundary represented by the dotted line.

By including the MSW EfW plant which disposes of its APCr by stabilization and landfill within the system boundary of the conventional block manufacturing plant, then this approach allows the comparison of the conventional route and the CCU route under equal conditions. 


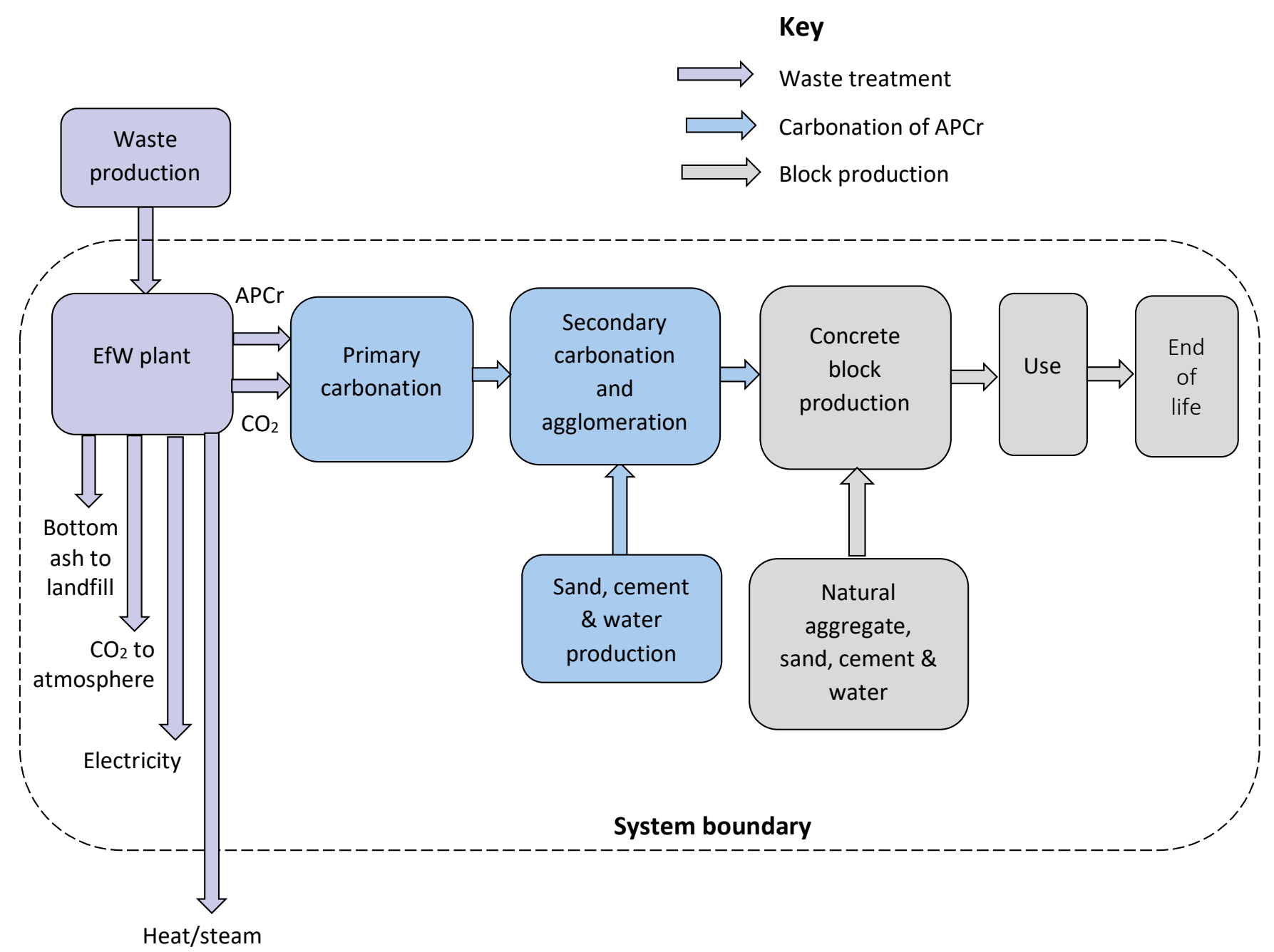

Figure 4. Using system expansion to enable comparison between the conventional process (shown in Figure 3) and the CCU process (shown here), with the system boundary represented by the dotted line.

\section{Defining the functional unit}

In this study, a product-specific assessment is conducted of mineralized aggregates manufactured into concrete blocks which have different characteristics than conventional concrete blocks. In this case, the comparison must consider the technical performance of the product. Therefore, the functional unit for the blocks component is the number of standard dimension blocks (390 mm x $190 \mathrm{~mm} \times 90 \mathrm{~mm}$ ) required to build $1 \mathrm{~m}^{2}$ of wall. As the product system produces both electricity and blocks as well as waste treatment (in that APCr no-longer needs to be transported to be stabilized and landfilled but forms a component of the blocks), a system expansion approach is used, meaning that the functional unit contains all of these products. As mentioned in Section 4.2.2, the waste heat arising from the EfW plant was not modeled, therefore this output is depicted outside the system boundary in Figures 3 and $\mathbf{4}$ and it is not considered as a product of the system under investigation.

In summary, due to the multi-functionality of the system, the functional unit is: 
- The number of standard dimension blocks required to build $1 \mathrm{~m}^{2}$ of wall which is $90 \mathrm{~mm}$ thick (14 blocks).

- $372 \mathrm{kWh}$ electricity from the EfW delivered to the consumer.

- $13.7 \mathrm{~kg}$ of APCr treated.

\section{Reference to Guidelines}

As described in Section C.4.1 Product system, its function, functional unit and reference flow of the guidelines, the functional unit description provided follows the recommendation for $\mathrm{CO}_{2}$-based products with different chemical structure and composition. In this situation, the functional unit needs to define the technical performance of the product, i.e. the blocks required to produce a wall of defined dimensions. Since the defined system serves multiple functions, the functional unit contains multiple functions. In this case, in addition to providing blocks, the system also provides electricity and treats the APCr waste (diverting it from stabilization and subsequent landfill). 


\section{C.5 Inventory data sets for the main process}

\section{inputs}

\section{$\square$ Reference to Guidelines}

A description of what should be included within the inventory section of an LCA report is provided in Section C.5 Life cycle inventory ( $\mathrm{LCl}$ ) of the guidelines, with Guidelines C.7 to C.9 listing the specific items which need to be included.

In addition, a checklist of items to be included in each section of the report is included in Section C.8 Reporting of the guidelines, which for the life cycle inventory is as follows:

\section{Life cycle inventory}

Include flow diagram of assessed process system(s)

State types and sources of required data and information

State calculation procedures

State all assumption made

Describe sensitivity analysis for refining system boundaries

Include calculated full LCl results (if this does not contradict with confidentiality)

- State data representativeness and appropriateness of $\mathrm{LCl}$ data

If results are reported on a relative basis, report basis

- State results obtained from scenario analysis (including scenarios) and threshold values, if any

To avoid repetition between the TEA and LCA sections of these worked examples, the main processes involved in the system under evaluation were described in the first section (Part A). The following inventory section provides an explanation of the transport distances used in the model (as transport in CCU mineralization processes usually has a significant impact) followed by summary data tables. The latter provide just the main inputs and outputs from the unit processes involved in the CCU and conventional processes so as to not distract the reader from CCU-specific issues which these worked examples focus upon.

\section{C.5.1 Transport of materials}

The bottom ash produced by Emerald EfW each year is used as landfill cover [3]. The MSW landfill serving the region is the Halton Regional Landfill at Milton [4], which is located approximately $40 \mathrm{Km}$ from Emerald $\mathrm{EfW}$. Prior to the start of the accelerated carbonation demonstration period, the APCr produced by the facility was sent to Stablex in Blainville, Quebec for stabilization and subsequent landfill - a distance of 582 $\mathrm{km}$. 
The sand and cement inputs required to produce the carbonated aggregate are transported to the aggregate manufacturing location by road freight. The distances to local sand and aggregate quarries were determined from Google Maps and the distance for transportation of the carbonated aggregate to the block manufacturer was determined in the same way, as were the respective distances for transporting sand and natural/primary aggregate to that site.

As a cradle-to-grave system boundary was adopted for this study, the transportation of the blocks to market needed to be estimated. The block manufacturing site at Brampton is $50 \mathrm{Km}$ from the centre of Toronto, so it was assumed that Toronto forms the main market for the blocks produced and so $50 \mathrm{Km}$ was used as the distance to market. A distance of $30 \mathrm{Km}$ was used to cover the transportation of the blocks after their initial use phase to a crushing facility and subsequent use as a loose aggregate fill (the usual end-of-life treatment for such building materials). It is assumed that all materials are transported in loads of 30 tonnes.

Figure 3 provides a map of the main locations identified and Table 3 presents the transport distances used in the assessment.

4,500 tonnes of C8S aggregate is produced per year. This model assumes that this is used to make blocks containing $13.13 \%$ C8S aggregate by mass, so 34,273 t of blocks. The C8S blocks have a density of $1.676 \mathrm{t} / \mathrm{m}^{3}$ so this mass of blocks equates to $20,449 \mathrm{~m}^{3}$ of blocks. The conventional blocks have a density of $1.850 \mathrm{t} / \mathrm{m}^{3}$, therefore the same $20,449 \mathrm{~m}^{3}$ (i.e. producing the same area of wall) would weigh 37,831 tonnes.

Table 1. Assumed block composition

\begin{tabular}{|l|c|c|c|}
\hline Material & $\begin{array}{c}\text { Assumed Density } \\
\left(\mathrm{kg} / \mathrm{m}^{3} \text { material) }\right.\end{array}$ & $\begin{array}{c}\text { Conventional block } \\
\left(\mathrm{kg} \text { material } / \mathrm{m}^{3} \mathrm{CMU}\right)\end{array}$ & $\begin{array}{c}\text { C8S block } \\
\left(\mathrm{kg} \text { material/ } \mathrm{m}^{3} \mathrm{CMU}\right)\end{array}$ \\
\hline Dolomitic limestone & 2500 & 1025 & 775 \\
\hline Sand & 1442 & 591 & 447 \\
\hline C8S aggregate & 1100 & 0 & 220 \\
\hline Cement & 1450 & 174 & 174 \\
\hline Water & 1000 & 60 & 60 \\
\hline TOTAL & & 1850 & 1676 \\
\hline
\end{tabular}

Using the block compositions provided in Table 1, the annual mass of material required to manufacture this volume of blocks are provided in Table 2 below:

Table 2. Annual material requirements to produce the equivalent quantity of blocks.

\begin{tabular}{|l|c|c|}
\hline & \multicolumn{2}{|c|}{ Mass of material required annually (tonnes) } \\
\hline & Conventional block & C8S block \\
\hline Natural primary aggregate & 20,960 & 15,848 \\
\hline Sand & 12,085 & 9,141 \\
\hline Cement & 3,558 & 3,558 \\
\hline Water & 1,227 & 1,227 \\
\hline C8S aggregate & 0 & 4,499 \\
\hline Total & 37,830 & 34,273 \\
\hline
\end{tabular}

Coupling the material requirements presented in Table 2 with the transportation distances described previously leads to the transport distances in tonnes kilometer presented in Table $\mathbf{3}$ which were used in the model. 
Table 3. Transport distances required to produce the same number of bricks using the conventional and C8S processes.

\begin{tabular}{|l|c|c|c|}
\hline Transport requirements & Distance & Conventional & C8S \\
\cline { 3 - 4 } & $(\mathrm{km})$ & $\begin{array}{c}\text { Annual freight } \\
\text { transport (tkm) }\end{array}$ & $\begin{array}{c}\text { Annual freight } \\
\text { transport (tkm) }\end{array}$ \\
\hline $\begin{array}{l}\text { Bottom ash from Emerald EfW to landfill (Halton } \\
\text { Regional Landfill) }\end{array}$ & 40 & $1,200,000$ & $1,200,000$ \\
\hline $\begin{array}{l}\text { APCr from Emerald EfW to stabilization \& landfill } \\
\text { (Stablex, Quebec) }\end{array}$ & 582 & $1,746,000$ & 0 \\
\hline $\begin{array}{l}\text { Sand quarry (Lafarge, Caledon Village) to Emerald } \\
\text { EfW }\end{array}$ & 35 & 0 & 21,000 \\
\hline $\begin{array}{l}\text { Cement production (CRH Mississauga) to Emerald } \\
\text { EfW }\end{array}$ & 35 & 0 & 10,500 \\
\hline $\begin{array}{l}\text { Emerald EfW to block manufacturer (Brampton } \\
\text { Blocks) }\end{array}$ & 16 & 0 & 72,000 \\
\hline $\begin{array}{l}\text { Sand quarry (Lafarge, Caledon Village) to block } \\
\text { manufacturer }\end{array}$ & 21 & 253,785 & 191,961 \\
\hline $\begin{array}{l}\text { Cement production (CRH Mississauga) to block } \\
\text { manufacturer }\end{array}$ & 45 & 160,110 & 160,110 \\
\hline $\begin{array}{l}\text { Aggregate quarry (Dufferin Aggregates, Acton) to } \\
\text { block manufacturer }\end{array}$ & 26 & 544,960 & 412,048 \\
\hline Block manufacturer to market (Toronto City Hall) & 50 & $1,891,550$ & $1,713,650$ \\
\hline Block market to end-of-life & 30 & $1,134,930$ & $1,028,190$ \\
\hline Total transport requirements (tkm) & $6,931,335$ & $4,809,459$ \\
\hline
\end{tabular}

\section{.5.2 Summary Data Tables}

Table 4. The main process inputs and outputs for the involved in the CCU system.

\begin{tabular}{|l|c|c|c|c|}
\hline \multirow{2}{*}{ Parameter } & \multicolumn{2}{|c|}{ Annual plant flows } & \multicolumn{2}{c|}{ Flows per $1 \mathrm{~m}^{2}$ wall } \\
\cline { 2 - 5 } & Value & Unit & Value & Unit \\
\hline EfW plant & 100,000 & tonnes & 456 & $\mathrm{~kg}$ \\
\hline MSW input & 30,000 & tonnes & 137 & $\mathrm{Kg}$ \\
\hline Bottom ash output & 3000 & tonnes & 13.7 & $\mathrm{~kg}$ \\
\hline APCr output & 31,000 & tonnes & 141.5 & $\mathrm{~kg}$ \\
\hline Abiotic (fossil) $\mathrm{CO}_{2}$ stack emissions & 81,556 & MWh & 372 & $\mathrm{kwh}$ \\
\hline Net electricity output & \multicolumn{5}{|l|}{} & $\mathrm{kg}$ \\
\hline Block production & 300 & Tonnes & 1.37 & $\mathrm{~kg}$ \\
\hline Captured CO, 2 & 4,500 & tonnes & 20.5 & $\mathrm{~kg}$ \\
\hline Carbonated aggregate input & 15,848 & tonnes & 72.4 & $\mathrm{~kg}$ \\
\hline Natural/primary aggregate input & 9,141 & tonnes & 41.7 & $\mathrm{~kg}$ \\
\hline Sand input & 3,558 & tonnes & 16.2 & $\mathrm{~kg}$ \\
\hline Cement input & 1,227 & tonnes & 5.6 & $\mathrm{~kg}$ \\
\hline Water input & 34,273 & tonnes & 156.5 & \\
\hline Blocks output &
\end{tabular}


Table 5. The main process inputs and outputs involved in the conventional system.

\begin{tabular}{|l|c|c|c|c|}
\hline \multirow{2}{*}{ Parameter } & \multicolumn{2}{|c|}{ Annual plant flows } & \multicolumn{2}{c|}{ Flows per $1 \mathrm{~m}^{2}$ wall } \\
\cline { 2 - 5 } & Value & Unit & Value & Unit \\
\hline EfW plant & 100,000 & t/year & 456 & $\mathrm{~kg}$ \\
\hline MSW input & 30,000 & t/year & 137 & $\mathrm{~kg}$ \\
\hline Bottom ash output & 3000 & t/year & 13.7 & $\mathrm{~kg}$ \\
\hline APCr output & 31,300 & t/year & 143 & $\mathrm{~kg}$ \\
\hline Abiotic (fossil) CO, emissions & 81,556 & MWh & 372 & $\mathrm{kwh}$ \\
\hline Net electricity output & & & $\mathrm{kg}$ \\
\hline Block production & 20,960 & tonnes & 95.7 & $\mathrm{~kg}$ \\
\hline Natural/primary aggregate input & 12,085 & tonnes & 55.2 & $\mathrm{~kg}$ \\
\hline Sand input & 3,558 & tonnes & 16.2 & $\mathrm{~kg}$ \\
\hline Cement input & 1,227 & tonnes & 5.6 & $\mathrm{~kg}$ \\
\hline Water input & 37,831 & tonnes & 172.7 & \\
\hline Blocks output &
\end{tabular}

Data relating to the use (wall construction) and end-of-life phases of the life cycle were taken from aggregated data from ecoinvent 3.4 and are not provided here. 


\section{C.6 Life Cycle Impact Assessment}

\section{$\square$ Reference to Guidelines}

A description of what should be included within this section of an LCA report is provided in Section C. 6 Life cycle impact assessment of the guidelines, with Guidelines C.10 and C.11 specifying the items which need to be included.

In addition, a checklist of items to be included in each section of the report is included in Section C.8 Reporting of the guidelines, which for the life cycle inventory is as follows:

\section{Life cycle impact assessment}

Include results of life cycle impact assessment

State if impact categories coverage is reduced, e.g. in case of carbon footprinting

If results are reported on a relative basis, report basis

- State if delayed emissions occur and include emission time profile if needed

If applied, state discounting method and discounted results

\section{C.6.1 Approach taken}

GaBi ts software (version 8.7.0.18) from thinkstep was used along with the ecoinvent database version 3.4. A model of a conventional EfW and block making plant was compared to making blocks using aggregate produced from $\mathrm{APCr}$ and mineralized $\mathrm{CO}_{2}$.

When constructing the GaBi model, the input flow of flue gas into the secondary aggregate production was modelled as an elementary flow of $\mathrm{CO}_{2}$ using Carbon dioxide [inorganic emissions to air] from ecoinvent 3.4 so that the impact of capturing these emissions are included in the assessment. If the $\mathrm{CO}_{2}$ was treated as a technical flow by using Carbon dioxide [inorganic intermediate product] the model would not include the impact of avoiding the $\mathrm{CO}_{2}$ emissions captured by the mineralisation process.

The results arising from the life cycle impact assessment were obtained using the CML 2001-Jan.2016 method. While the impacts upon greenhouse gas (GHG) emissions are the main impact category of interest in this study, all CML impact categories at midpoint level are presented for transparency. 


\section{Reference to Guidelines}

Guidance on which impact assessment methodology to employ are provided in Section C.6.1, which explains that CML is the preferred method, but a second method can be applied if it would be more geographically appropriate (i.e. ILCD for studies within Europe and TRACI for those based in the United States). Specific guidelines of what shall, should or may be included are provided as Guideline C.10.

Section C.6.1 also explains that although the impacts upon GHG emissions are the main impact category of interest in many CCU studies (as this is often a driver for implementing such a process), all impact categories should be presented to avoid arriving at misleading conclusions if environmental burdens have shifted from one impact category to another by changing a process technology.

A contribution analysis was conducted to determine the contribution that the different unit processes which make up both the C8S process and the conventional reference process made to the overall impact.

This is especially important when system expansion has been used because one process may dominate a particular impact category but have a limited effect upon other categories. A contribution analysis makes this clear.

\section{Reference to Guidelines}

As described in Section C.7.3 of the guidelines, environmental impacts in CCU can be very sensitive as they are often closely linked to energy requirements. Showing only a dependency on clean feedstocks limits interpretation and can leave to ambiguity. Presenting alternative energy scenarios facilitates comparison between similar assessments and prevents overstating the environmental benefits of $\mathrm{CO}_{2-}$ based products. Standard inventory data-sets for electricity scenarios are introduced in Section C.7.3 and described in greater detail in Appendix C.9.1 of the guidelines.

In this instance, the APCr carbonation process is closely linked to the MSW EfW plant and the fact that it uses both flue gas and APCr means that it is highly likely that this is always going to be an on-site process. For this reason, it is envisaged that the electricity for the carbonation process will always be taken directly from the EfW process rather than from the local electricity grid. This, coupled with the low use of electricity in this process (compared to many other CCU processes) lead to the conclusion that it was not appropriate to utilise alternative electricity scenarios in this instance.

As described in the process description in Part A of this series of worked examples, 9.31 MW electricity is produced by the EfW plant, which relates to an annual production of 81,556 MWh. The APCr carbonation process uses a very small proportion of this output (less than $0.1 \%$ ) and therefore the impacts of this were minor. However, electricity production by the EfW plant forms part of the functional unit and therefore 
needs to be the same for both processes to enable a fair comparison. The shortfall of electricity caused by its usage by the C8S process is therefore assumed to be supplemented by electricity from the Ontario grid (from the Gabi database). Due to the small proportion of supplementary electricity, it was felt unnecessary to model the use of alternative electricity scenarios to fulfill this "top-up" function.

\section{.6.2 Results of concrete block production impact assessment}

Running the LCA model produces the results presented in Table 6.

Table 6. Comparison of all the CML midpoint impact categories obtained for the expanded system for the C8S process and the reference process.

\begin{tabular}{|l|l|l|}
\hline \multirow{2}{*}{ CML2001-Jan. 2016 Impact Categories } & \multicolumn{2}{|c|}{ Process } \\
\cline { 2 - 3 } & Reference & C8S \\
\hline Abiotic Depletion (ADP elements) [kg Sb eq.] & 0.00014 & 0.00012 \\
\hline Abiotic Depletion (ADP fossil) [MJ] & 295 & 241 \\
\hline Acidification Potential (AP) [kg SO2 eq.] & 0.76 & 0.71 \\
\hline Eutrophication Potential (EP) [kg Phosphate eq.] & 0.14 & 0.13 \\
\hline Freshwater Aquatic Ecotoxicity Pot. (FAETP inf.) [kg DCB eq.] & 7.24 & 6.2 \\
\hline Global Warming Potential (GWP 100 years) [kg CO2 eq.] & 421 & 409 \\
\hline Global Warming Potential (GWP 100 years), excl biogenic carbon [kg CO2 eq.] & 195.0 & 185.1 \\
\hline Human Toxicity Potential (HTP inf.) [kg DCB eq.] & 16.2 & 14.2 \\
\hline Marine Aquatic Ecotoxicity Pot. (MAETP inf.) [kg DCB eq.] & $2.04 \mathrm{E}+04$ & $1.7 \mathrm{E}+04$ \\
\hline Ozone Layer Depletion Potential (ODP, steady state) [kg R11 eq.] & $2.10 \mathrm{E}-06$ & $1.7 \mathrm{E}-06$ \\
\hline Photochem. Ozone Creation Potential (POCP) [kg Ethene eq.] & 0.043 & 0.040 \\
\hline Terrestric Ecotoxicity Potential (TETP inf.) [kg DCB eq.] & 0.42 & 0.42 \\
\hline
\end{tabular}

The GHG emissions and fossil depletion impact categories are presented graphically below.

Greenhouse Gas emissions $\left[\mathrm{kg} \mathrm{CO}_{2}\right.$ eq.]

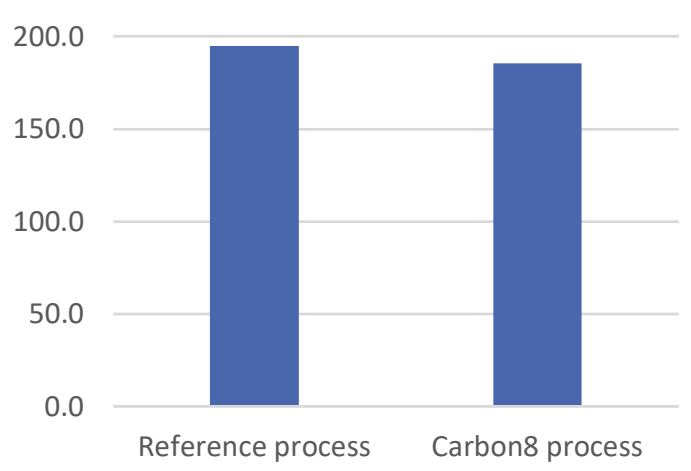

Abiotic Depletion (ADP fossil)

$[\mathrm{MJ}]$

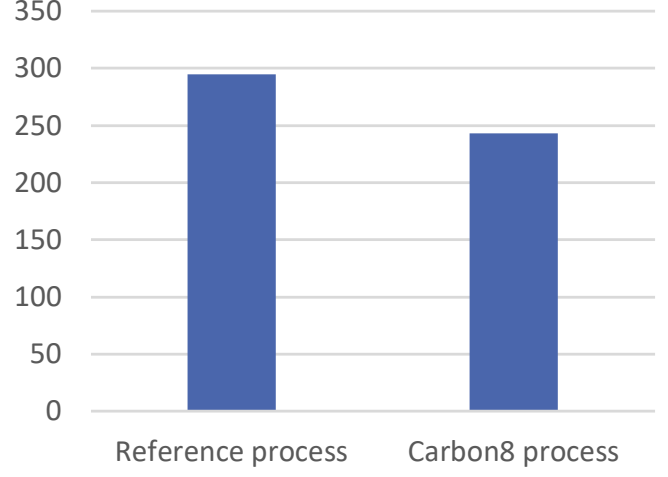

Figure 5. Comparison of the GHG emissions and fossil depletion impact categories obtained for the expanded system for the C8S process and the reference process. 
To prevent the results and interpretation presented in this worked example from being too long, graphs and analysis of just two CML impact categories will be presented - the Global Warming Potential (GWP 100 years), excl. biogenic carbon [kg CO2 eq.] and Abiotic Depletion (ADP fossil) $[\mathrm{MJ}]$.

Evaluation of the two systems reveals the $\mathrm{CML}$ impact category of Global Warming Potential excl. biogenic carbon (hereafter referred to as the GHG emissions) for the C8S system is $185.1 \mathrm{~kg} \mathrm{CO}$ eq. per $1 \mathrm{~m}^{2}$ wall compared to $195.0 \mathrm{~kg} \mathrm{CO} 2$ eq. per $1 \mathrm{~m}^{2}$ wall for the reference system. The proportions of the impacts which arise from the different processes shall be examined in the contribution analysis in the following section.

\section{.6.3 Contribution analysis}

\section{C.6.3.1 Unit processes}

For the purpose of determining the major contributors to the impacts, the expanded system included within the system boundary can be split into five unit-processes:

- EfW plant: including bottom ash transport and disposal, and for the reference process it includes the APCr transport to stabilization and disposal and cement production and transport to the stabilization process.

- Block production: including natural aggregate, sand and cement production, and for the C8S process this includes the production of the aggregate from APCr.

- Transport of blocks to market

- Wall construction: identical for both processes

- End-of life: including transport

Pie charts showing the relative contributions of the above categories are provided below for the GHG emissions and fossil depletion impact categories. When the impact of the five different processes upon GHG emissions are examined (Figure 6), the processes are found to contribute an identical proportion to both the $\mathrm{C} 8 \mathrm{~S}$ and the reference process. The EfW plant had the major role in contributing to this category, with $81 \%$ $\mathrm{CO}_{2}$ eq. coming from this process step. Block production contributed $10 \%$ and wall construction contributed 7\%. Transport of the blocks to market and end-of-life treatment of the blocks (which included transport to end-of-life) had minor contributions. 


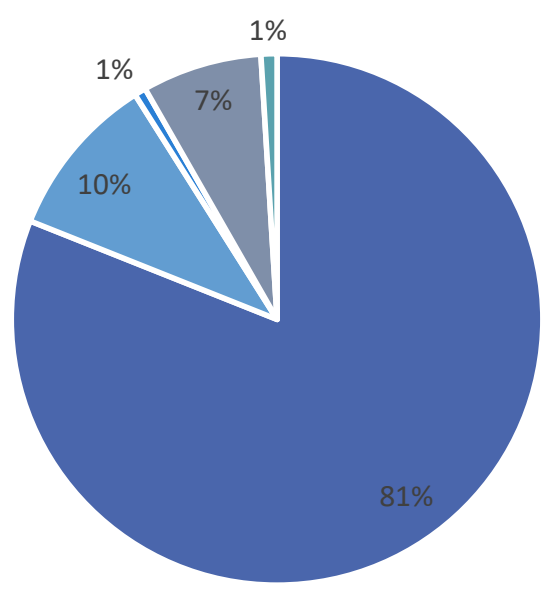

\section{Reference process}

- MSW EfW

- Block

production

- Transport to

market

- Wall

construction

- End of life treatment

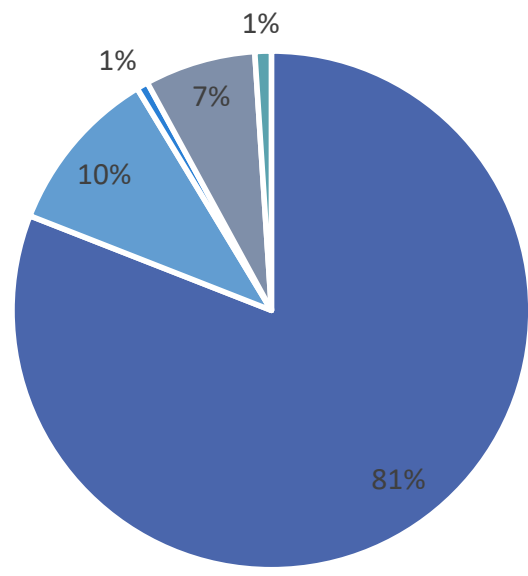

Figure 6. Relative contribution of the five processes to the overall GHG emissions (CML impact category Global Warming Potential (GWP 100 years) excl. biogenic carbon).

The process contributions to fossil resource depletion are presented in Figure 7.

C8S process

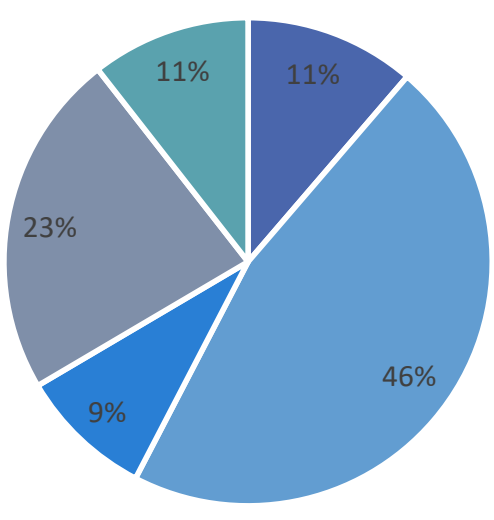

- MSW EfW

- Block production

- Transport to market

- Wall construction

- End of life treatment
Reference process

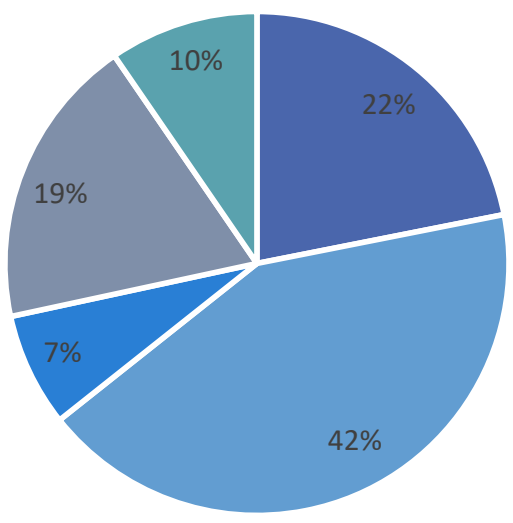

Figure 7. Relative contribution of the five processes to the overall CML impact category for fossil resource depletion.

\section{C.6.3.2 Block production}

The process breakdown above reveals that block production only contributes to around $10 \%$ of the climate change impacts of the entire system being evaluated, but $42-47 \%$ of the fossil depletion impacts of the entire system. A comparison of the full impact data for block production is provided in Table 7 below. 
Table 7. Comparison of the CML impact categories of the block production process.

\begin{tabular}{|l|l|l|}
\hline \multirow{2}{*}{ CML2001-Jan. 2016 Impact Categories } & \multicolumn{2}{|c|}{ Block Production } \\
\cline { 2 - 3 } & Reference & C8S \\
\hline Abiotic Depletion (ADP elements) [kg Sb eq.] & $8.05 \mathrm{E}-05$ & $7.77 \mathrm{E}-05$ \\
\hline Abiotic Depletion (ADP fossil) [MJ] & 125.00 & 111.96 \\
\hline Acidification Potential (AP) [kg SO2 eq.] & 0.120 & 0.117 \\
\hline Eutrophication Potential (EP) [kg Phosphate eq.] & 0.028 & 0.026 \\
\hline Freshwater Aquatic Ecotoxicity Pot. (FAETP inf.) [kg DCB eq.] & 4.63 & 4.24 \\
\hline Global Warming Potential (GWP 100 years) [kg CO2 eq.] & 20.3 & 18.7 \\
\hline Global Warming Potential (GWP 100 years), excl biogenic carbon [kg CO2 eq.] & 20.3 & 18.5 \\
\hline Human Toxicity Potential (HTP inf.) [kg DCB eq.] & 9.2 & 8.7 \\
\hline Marine Aquatic Ecotoxicity Pot. (MAETP inf.) [kg DCB eq.] & $1.34 \mathrm{E}+04$ & $1.18 \mathrm{E}+04$ \\
\hline Ozone Layer Depletion Potential (ODP, steady state) [kg R11 eq.] & $6.83 \mathrm{E}-07$ & $5.76 \mathrm{E}-07$ \\
\hline Photochem. Ozone Creation Potential (POCP) [kg Ethene eq.] & 0.008 & 0.007 \\
\hline Terrestric Ecotoxicity Potential (TETP inf.) [kg DCB eq.] & 0.134 & 0.138 \\
\hline
\end{tabular}

The data in Table 7 reveals that the GHG emissions arising from the $\mathrm{C} 8 \mathrm{~S}$ block production is $18.5 \mathrm{Kg} \mathrm{CO}_{2}$ eq. per $1 \mathrm{~m}^{2}$ wall. This is $10 \%$ of the value reported for the entire system in Table 6, which is consistent with the contribution analysis represented in Figure 6.

By breaking down the block production process further, we can identify the inputs which are major contributors to the observed impacts.
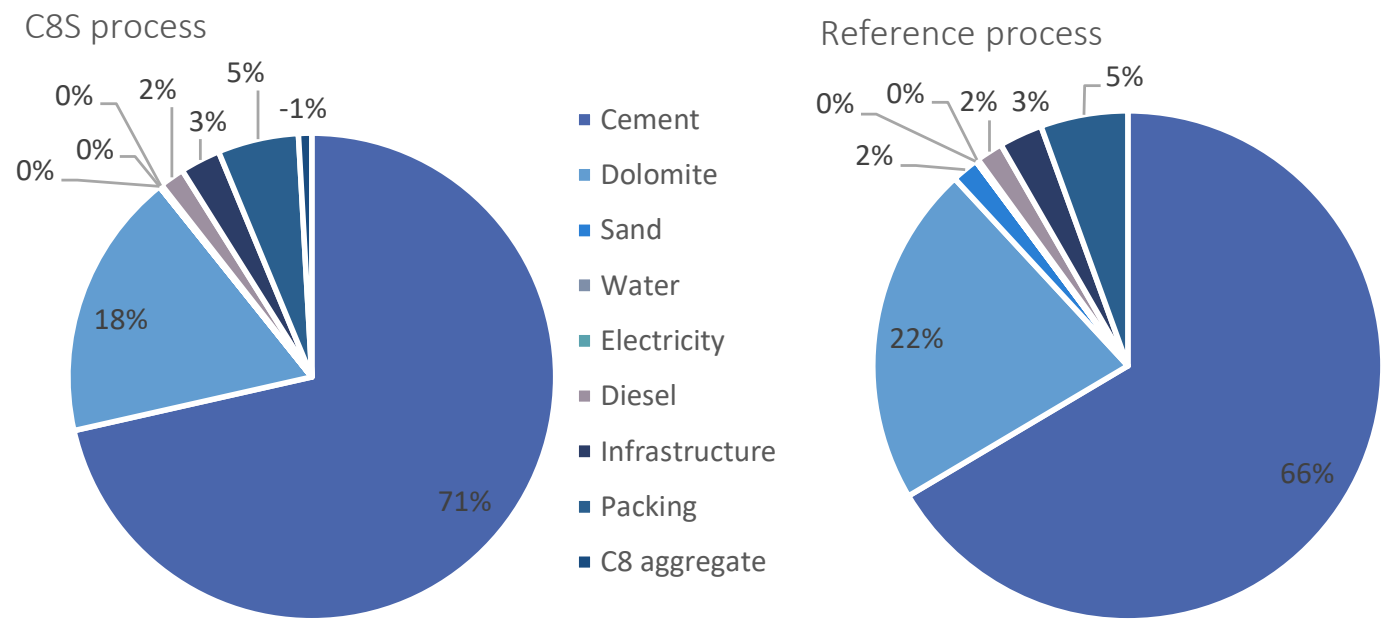

Figure 8. Relative contribution of the inputs into the block making processes to the GHG emissions (CML impact category Global Warming Potential (GWP 100 years) excl. biogenic carbon).

Cement clearly is the major contributor to the climate change impacts of block production, contributing $71 \%$ of the GHG emissions of the C8S block production process and 66\% for the reference conventional block production process. 


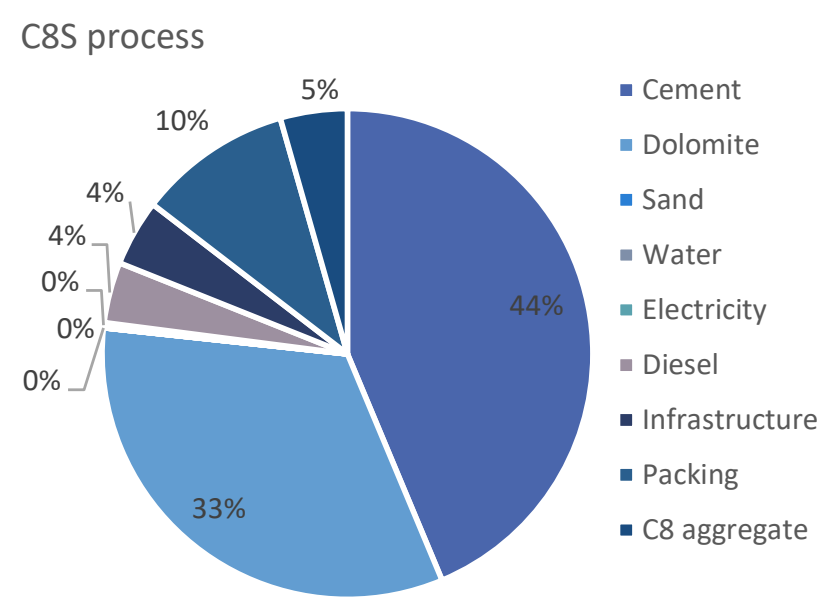

Reference process

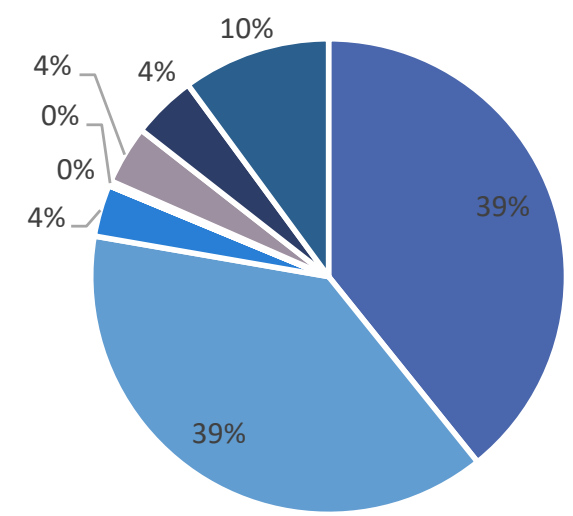

Figure 9. Relative contribution of the inputs into the block making processes to the fossil resource depletion impact category.

When looking at the fossil depletion impact we again see that cement and dolomite aggregate extraction are the main contributors.

\section{C.6.3.3 APCr stabilization/solidification}

The existing (reference) method of APCr disposal used in this instance involves four main inputs:

- $\quad$ producing the cement used

- transporting the APCr to the treatment and disposal site and transporting the cement required in the stabilization/solidification process

- the treatment process itself

- producing the water used

The pie charts below present the relative contributions of these four inputs to the GHG emissions and fossil depletion impact categories.

Global Warming Potential (GWP 100 years), excl biogenic carbon [kg $\mathrm{CO} 2 \mathrm{eq}$.

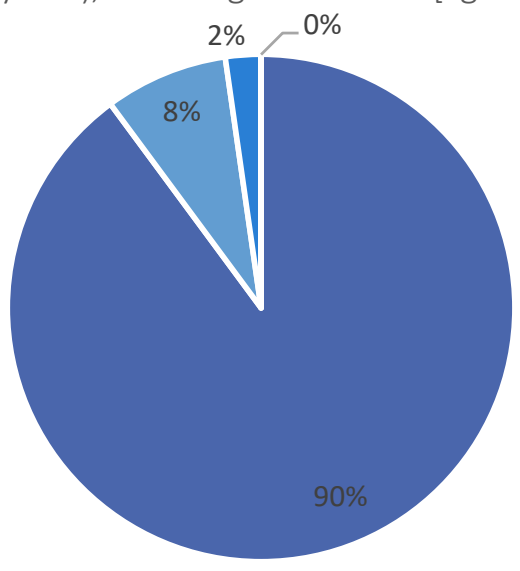

Abiotic Depletion (ADP fossil)

[MJ]

- Cement

- Transport

- Treatment

- Water

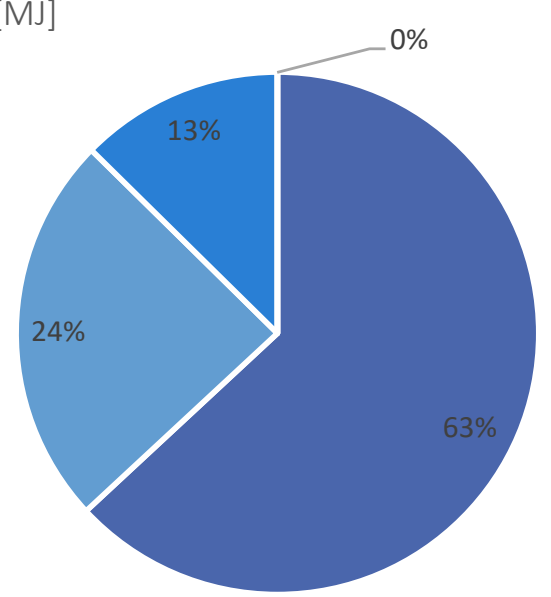

Figure 10. Relative contribution of the different inputs into the conventional treatment process for APCr. 


\section{C.7 Life Cycle Interpretation}

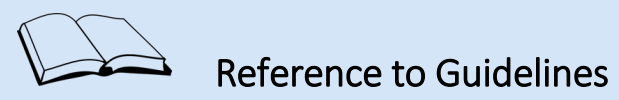

A description of what should be included within this section of an LCA report is provided in Section C.7 Life cycle interpretation of the guidelines, with Guidelines C.12 and C.13 specifying what is required.

In addition, a checklist of items to be included in each section of the report is included in Section C.8 Reporting of the guidelines, which for the life cycle interpretation is as follows:

\section{Life cycle interpretation}

Include and describe the results

- Negative emission in cradle-to gate studies shall not be interpreted as $\mathrm{CO}_{2}$ sinks if life does not end with permanent carbon fixation

- Emission reductions due to substitution effects shall be interpreted as environmental benefits but not as negative emissions

Describe uncertainty and sensitivity analysis and report results separately

Include completeness check

Include consistency check

- State assumptions and limitations associated with the interpretation of results

Include conclusions

Include recommendations, if any

\section{C.7.1 Sensitivity analysis - block composition}

The life cycle impact assessment results presented in Section 6 of this report reveal that the composition of the blocks is an important contributor to the observed impacts, especially in terms of the proportion of cement used. The sensitivity of the CCU process system to changes in the composition of the blocks, in terms of the content of C8S aggregate, natural aggregate and cement, was therefore examined. The content values were varied from $50 \%$ of baseline to $150 \%$ (i.e. a $50 \%$ increase and a $50 \%$ decrease). This was done as a simple change in the amount of C8S aggregate, natural aggregate or cement in the block so that the slope of the linear relationship (reflecting the sensitivity of the process to changes in that single component) could be assessed.

Ten scenarios per parameter were created using GaBi to cover the range from $50 \%$ to $150 \%$, resulting in 11 data points (including the baseline value) which were used to analyses the sensitivity using a graph indexed at the baseline value. The greater the variance of the value from the baseline operational value, the more sensitive the impact category is.

When the chosen parameters are varied, the GHG emissions were found to be one of the least sensitive categories to these changes. This is expected since the system includes the emissions from the EfW plant which are significantly larger than all other $\mathrm{CO}_{2}$ sources. Thus, any variations due to changes in the secondary aggregate and block making process will be negligible. 
Because of the use of system expansion, the sensitivity of the GHG emissions arising from the production of the C8S aggregate and block making cannot be interpreted in detail, i.e. a significant difference is difficult to identify. However, the results give confidence in the $\mathrm{CO}_{2}$ emissions savings of the whole system compared to other impact categories. If further analysis is required, sensitivity can also be applied to other unit processes (such as block making).

For the purpose of this study, sensitivity is applied to the whole system and is not used as a comparative analysis to the reference process but as a sensitivity analysis to test variations in the parameters of the CCU system.

When varying the efficiency of the C8S aggregate production so that the output changes (Figure 11), the impact categories most sensitive to change are: abiotic depletion, ozone depletion, human toxicity and marine ecotoxicity. As more aggregate is produced more material inputs are required (such as cement) leading to higher environmental impacts. The same impact categories are the most sensitive to change if the proportion of C8S aggregate in the blocks is varied (Figure 12). However, when this parameter is varied, the environmental impacts are reduced as the proportion of C8S aggregate used in block making is increased. This is due to the replacement of the natural primary aggregate dolomite for the secondary aggregate produced from APCr.

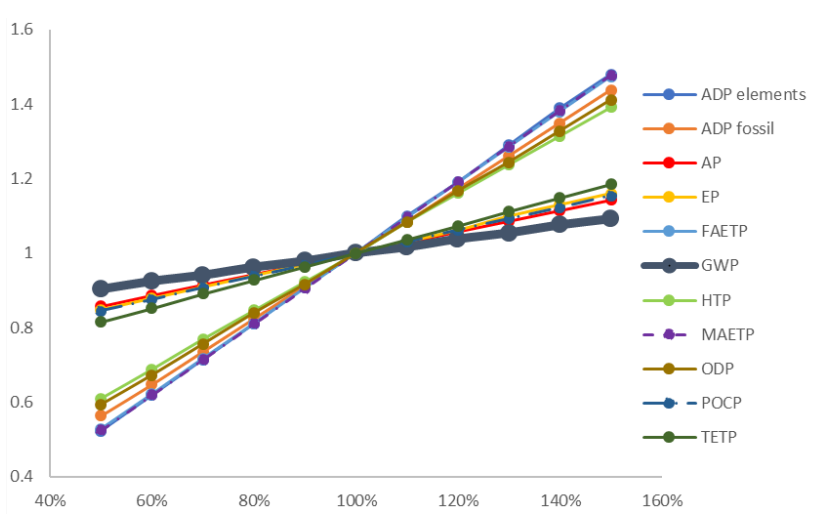

Figure 11. Varying the efficiency of C8S aggregate production.

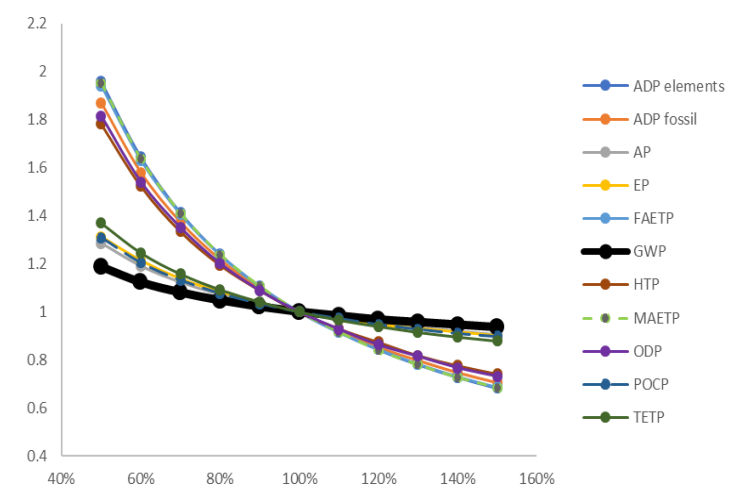

Figure 12. Varying the proportion of C8S aggregate in the blocks

When the proportion of cement and dolomite within the blocks is changed (Figures 13 and 14 respectively), abiotic depletion is found to be one of the most sensitive impact categories to change as more raw materials are used instead of the C8S aggregate. This leads to higher environmental impacts as the ratio of raw materials to C8S aggregate increases. Other sensitive categories include: ozone depletion, human toxicity, freshwater and marine aquatic ecotoxicity. 


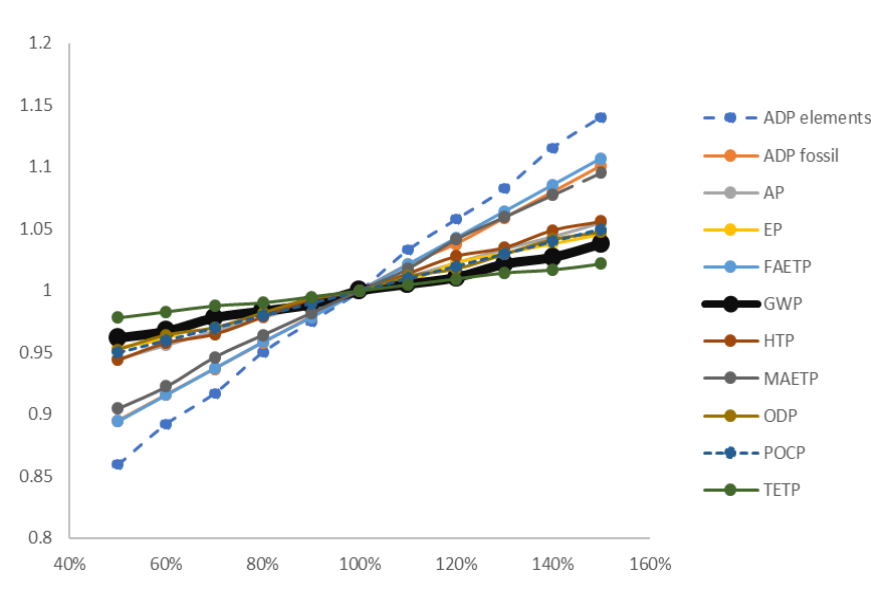

Figure 13. Varying the proportion of cement in the blocks.

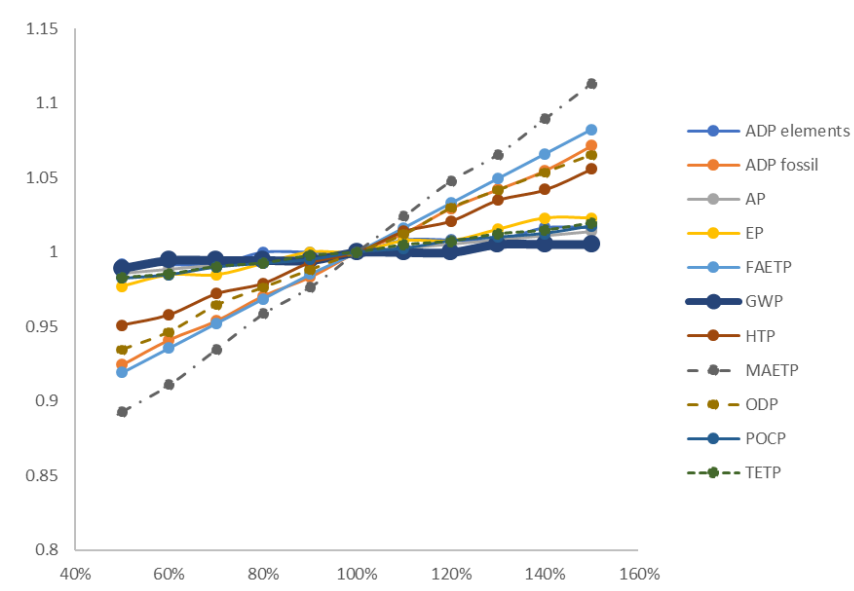

Figure 14. Varying the proportion of dolomite in the blocks.

\section{C.7.2 General interpretation}

The C8S process results in a reduction in the GHG emissions of the entire system of $9.9 \mathrm{~kg} \mathrm{CO} 2$ eq. $/ 1 \mathrm{~m}^{2}$ wall, $372 \mathrm{kWh}$ electricity and $13.7 \mathrm{~kg}$ APCr treated (from $195 \mathrm{~kg} \mathrm{CO} 2$ eq. for the conventional reference process to $185.1 \mathrm{~kg} \mathrm{CO} 2$ eq. for the C8S process). This difference represents a $5 \%$ reduction compared to the reference process, which needs to be considered in the context of the entire system under evaluation, which includes electricity production and APCr treatment as well as block production.

\section{IMPORTANT}

The functional unit used for the blocks in this study is $1 \mathrm{~m}^{2}$ wall, so this unit which must be used to compare the impacts of the two process systems. If we try to analyses the LCIA data by comparing the two systems per $\mathrm{kg}$ of blocks (instead of per $1 \mathrm{~m}^{2}$ wall), then the conclusions drawn are incorrect and misleading. For example, the comparison below is incorrect:

$1 \mathrm{~m}^{2}$ of wall contains 14 blocks. Each C8S block weighs $11.2 \mathrm{~kg}$ while each reference block weighs $12.3 \mathrm{~kg}$, so 14 C8S blocks weigh $156.8 \mathrm{~kg}$ and 14 reference blocks weigh $172.2 \mathrm{~kg}$. Correlating this with the LCIA data shows that C8S blocks result in $\mathrm{GHG}$ emissions of $185 \mathrm{~kg} \mathrm{CO}$ eq. per $156.8 \mathrm{~kg}=1.18 \mathrm{~kg} \mathrm{CO} 2 \mathrm{eq} . / \mathrm{kg}$ whereas the reference blocks result in $\mathrm{GHG}$ emissions of $195 \mathrm{~kg} \mathrm{CO} 2$ eq. per $172.2 \mathrm{~kg}=1.13 \mathrm{~kg} \mathrm{CO} 2$ eq. $/ \mathrm{kg}$.

The above calculation incorrectly concludes that the C8S blocks result in higher GHG emissions than the reference blocks. The approach and conclusion is flawed because it compares the blocks by mass rather than by area of wall. Due to their lower density, the C8S blocks would produce a larger area of wall per kg than the reference blocks, so comparing by mass does not compare like-with-like. The function of the blocks (to produce a wall) therefore must be used in a comparison. 
The contribution analysis presented in Figure 6 reveals that $81 \%$ of the GHG emissions arise from the EfW plant. This includes the transporting and landfilling of the bottom ash and the transport of the APCr to the stabilization/solidification facility and the cement used in this process. The block production process was shown to contribute $10 \%$ of the GHG emissions and wall construction $7 \%$. Although the C8S process causes lower GHG emissions than the reference process, the proportional split between the processes are identical for each.

A different relationship is evident when fossil resource depletion is evaluated. Figure 7 reveals that block production (which includes the production of the mineralized aggregate within the C8S process) has the greatest impact, contributing $46 \%$ to the C8S process and $42 \%$ to the conventional process. The larger impact of the C8S process is likely due to the additional use of cement in this model (as opposed to fully utilizing all waste capable of being carbonated) in the production of the aggregate. The EfW plant contributes a larger proportion of the fossil resource depletion in the reference process $(22 \%)$ than the C8S process $(11 \%)$ due to the transport, stabilization and landfilling of the APCr, which is avoided by the C8S process.

The contribution of inputs to the block-making process presented in Figures 8 and 9 show that cement has the major impact and contributes $71 \%$ to the $\mathrm{C} 8 \mathrm{~S}$ block GHG emissions and $66 \%$ to the reference block. The higher proportion in the Carbon 8 block process reflects the fact that cement is used in the production of the C8S aggregate in addition to the production of the blocks themselves. Dolomite is the second largest contributor to GHG emissions, arising from the quarrying and transportation and crushing/grading of the rock. In terms of the fossil depletion impact, cement is the main contributor again, although dolomite aggregate has the same impact as cement in conventional blocks, but a slightly lower proportional impact when the C8S process is used due to the natural aggregate being replaced with the C8S aggregate. It can therefore be concluded that, due to the proportionally higher impact of cement, the C8S process will benefit more from the future development of low carbon cements.

Finally, the breakdown of the conventional APCr treatment process provided in Figure 10 reveals that despite transporting the APCr $582 \mathrm{~km}$ for treatment, it is the cement use which is contributes $90 \%$ to the GHG emissions and $63 \%$ to the fossil depletion impact categories.

\section{C.7.3 Subsequent approach to the analysis}

Using system expansion to evaluate the entire system composed of multiple processes ensures that impacts originating from processes associated with the product of interest, but not directly caused by it, are included within the assessment. However, one feature of this approach is that an associated process may have greater environmental impacts than the process which is of specific interest. Such is the case here, with the EfW plant contributing $81 \%$ of the GHG emissions of the system, the reductions achieved by adopting the C8S process appear to be relatively small compared to the entire system (just $5 \%$ ). Comparing the reductions achieved relative to fewer processes rather than all processes would be desirable in allowing productspecific reductions to be determined.

To enable such an analysis, the impacts arising from the entire expanded system were separated into the impacts arising from the six distinct unit processes that were modelled in GaBi to produce the overall system. The six processes are: EfW plant, APCr treatment, block production (which includes production of the necessary aggregates and cement), transport of the blocks to market, wall construction (use phase) and endof-life. The contribution of the six processes to the GHG emissions of the entire system are presented in Table 8. The data presented here differs slightly from the previous analysis in that it separates the APCr treatment process from the EfW plant, hence the EfW plant is now seen to contribute around $77 \%$ of the GHG emissions (compared to $81 \%$ when the APCr treatment was included within the EfW plant figure). 
Table 8. Contribution of separate unit processes to the GHG emissions of the system.

\begin{tabular}{|c|c|c|c|}
\hline \multirow{2}{*}{ Unit process } & \multicolumn{3}{|c|}{ GHG emissions $\left[\mathrm{kg} \mathrm{CO} 2\right.$ eq./1 $\mathrm{m}^{2}$ wall $]$} \\
\hline & Reference system & C8S system & Difference \\
\hline EfW plant & 150.0 & 148.63 & -1.37 \\
\hline APCr treatment & 7.78 & 0 & -7.78 \\
\hline $\begin{array}{lll}\text { Block production } & \text { (incl } \\
\text { producing aggregates } & \text { and } \\
\text { cement) } & & \end{array}$ & 20.3 & 19.9 & -0.4 \\
\hline Transport to market & 1.44 & 1.30 & -0.14 \\
\hline Wall construction & 13.5 & 13.5 & 0 \\
\hline $\begin{array}{lll}\text { End-of-life } & \text { (crushing } \quad \& \\
\text { transport) } & & \\
\end{array}$ & 1.93 & 1.75 & -0.18 \\
\hline System total & 195.0 & 185.1 & -9.9 \\
\hline
\end{tabular}

\section{Modelling $\mathrm{CO}_{2}$ flows}

The $\mathrm{GaBi}$ model used to obtain the data in this analysis treated the flue-gas $\mathrm{CO}_{2}$ utilised by the aggregate production process as an input into the block production process rather than as a reduction in the output emissions of the EfW plant. When modelling this system, it felt more appropriate to treat the utilised $\mathrm{CO}_{2}$ in this way because it is this $\mathrm{CO}_{2}$ which is mineralized into the carbonate which forms the aggregate. However, it is important to be aware that the way $\mathrm{CO}_{2}$ flows are modelled has important implications.

By treating the utilised $\mathrm{CO}_{2}$ as an input into block production, it means that the GHG emissions savings achieved by utilising this waste $\mathrm{CO}_{2}$ have effectively been allocated to this block production process. The raw results show that the C8S block production process leads to GHG emissions of $18.5 \mathrm{~kg} \mathrm{CO}$ eq. per functional unit compared to 20.3 using the reference process, with the EfW plant in both cases having identical emissions of $150 \mathrm{~kg} \mathrm{CO}_{2}$ eq. per functional unit.

Whilst the GHG savings must be accounted for somewhere (and they cannot be allocated to both the EfW plant and the block production process without double-counting), in the current assessment approach such unintended allocation needs to be avoided. The data presented in Table 8 is therefore shown after the $1.37 \mathrm{~kg} \mathrm{CO}_{2}$ eq. saving per functional unit has been switched from the block production process to the EfW plant.

System expansion via substitution can be used to give credit for the avoided burden of an unabated EfW plant (i.e. the reference EfW plant). Performing this substitution in practice means subtracting the impacts of the reference EfW plant from the C8S system, which removes electricity from the functional unit and effectively removes the EfW plant from the system boundary. In this way, we have reduced the system boundary to exclude the process which dominated emissions, allowing the impact of switching from the reference system to the C8S system to be observed more clearly. 


\section{As long as only one function (or product) is removed from the system, more than} one process can be removed from the system in this way.

Figure 15 provides a representation of how system expansion via substitution leads to the system boundary excluding the EfW plant, meaning that the only products within the functional unit are $1 \mathrm{~m}^{2}$ wall and 13.7 $\mathrm{kg}$ APCr treated.

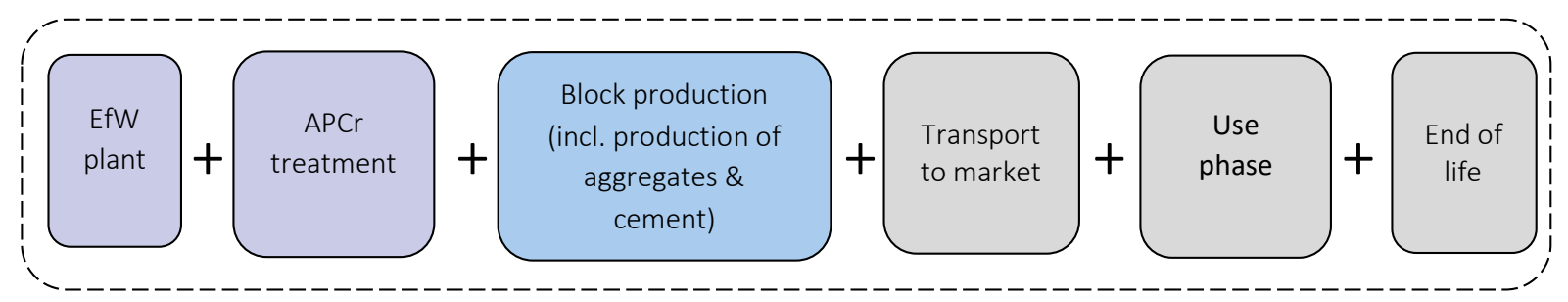

Reference system boundary using system expansion

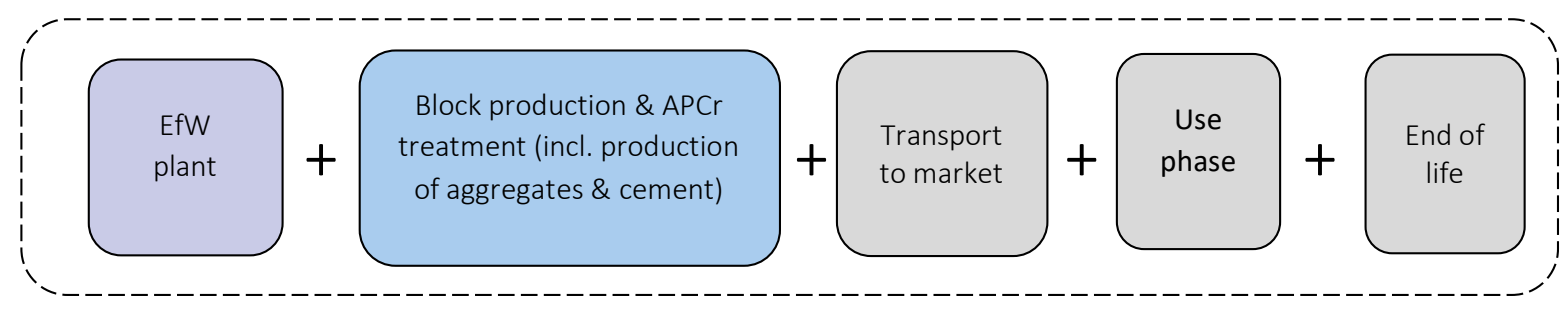

C8S system boundary using system expansion

\section{Substitution of reference EfW plant to give:}

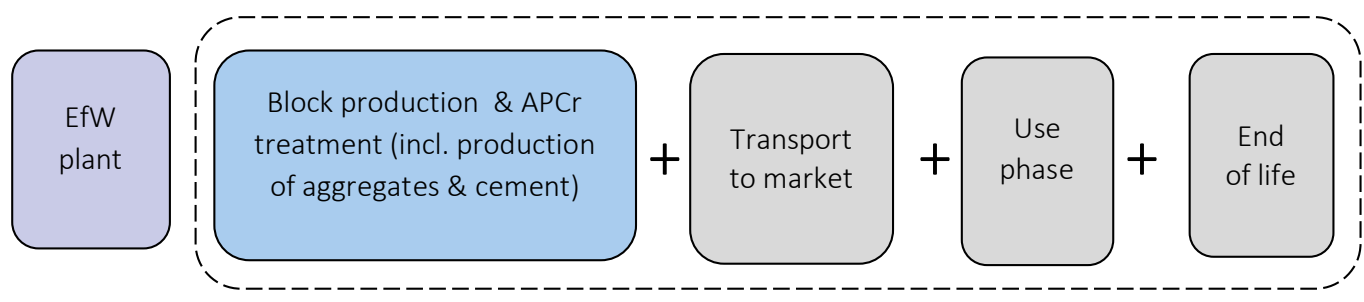

C8S system boundary following substitution

Figure 15. Representation of system expansion with substitution: the reference EfW plant is substituted which removes its impacts from the boundary of the C8S system expansion model. The dotted lines indicate the system boundaries. 


\section{Reference to Guidelines}

Section 4.3 of the Guidelines explains how to solve multi-functionality and within Guideline C.4 it states that system expansion should be applied and if a product-specific assessment is needed to answer the initial research question then this can be applied additionally by utilising substitution or allocation.

Interpretation of $\mathrm{CO}_{2}$ emissions/allocating impacts

Due to the use of system expansion, many LCAs of CCU processes will be multi-functional. It is therefore important that any interpretation of the results is conducted in a manner which enables a fair and equal comparison of all functions within the system.

An overall reduction in the $\mathrm{GHG}$ emissions of $9.9 \mathrm{~kg} \mathrm{CO}_{2} \mathrm{eq} / 1 \mathrm{~m}^{2}$ wall enabled by the C $8 \mathrm{~S}$ process was revealed by this study. When evaluating data from a system expansion model it is crucial to avoid "cherry-picking" results from the contribution analysis and relating this to the process of interest. For example, by ascribing the GHG emissions saving of $9.9 \mathrm{~kg} \mathrm{CO} 2$ eq./ $1 \mathrm{~m}^{2}$ wall and 13.7 $\mathrm{kg}$ APCr treated solely to the block production process, one could incorrectly conclude that the GHG emissions of block production has been almost halved (9.9/20.3). However, Table 8 reveals that the modelled GHG emissions reductions were due to reductions in multiple processes, not just in block production.

Care therefore needs to be taken to avoid allocating emissions savings to processes which did not enable those savings. It would therefore be incorrect to allocate all $9.9 \mathrm{~kg}$ of the system-wide emissions reductions to block production alone.

A product-specific analysis is possible if substitution is utilized to subtract the impacts of processes from the system. However, when there are multiple products produced by the system, only one can be removed in this way.

With reference to the six processes listed in Table 8, the calculation of the GHG emissions impact of switching from the reference system to the C8S system when using system expansion via substitution is as follows:

C8S system using system expansion $=185.1 \mathrm{~kg} \mathrm{CO} 2$ eq. $/ 1 \mathrm{~m}^{2}$ wall, $13.7 \mathrm{~kg}$ APCr treated and $372 \mathrm{kWh}$ electricity

Impacts arising from the reference EfW process being substituted $=150.0 \mathrm{~kg} \mathrm{CO} 2 \mathrm{eq} . / 372 \mathrm{kWh}$ electricity

$185.1-150.0=35.1 \mathrm{~kg} \mathrm{CO}$ eq. $/ 1 \mathrm{~m}^{2}$ wall and $13.7 \mathrm{~kg} \mathrm{APCr}$ treated

The reduction in GHG emissions achieved by switching from the reference to the C8S system remains the same as when calculated previously using the system-wide perspective of system expansion $\left(9.9 \mathrm{~kg} \mathrm{CO}_{2} \mathrm{eq}\right.$. 
per functional unit, so reduction from 45 to $35.1 \mathrm{~kg} \mathrm{CO}_{2}$ eq. $/ 1 \mathrm{~m}^{2}$ wall and $13.7 \mathrm{~kg}$ APCR treated). However, system expansion via substitution allows us to better appreciate the scale of the reduction in GHG emissions achieved as this is now relative to the system without the EfW plant. Rather than being $5 \%$ when viewed system-wide, the reduction is $22 \%$ when the EfW plant has been substituted (reduction of $9.9 \div 45$ (reference system impacts without EfW)).

If we were attempting to determine only the difference in impacts between the reference system and the C8S system, the analysis could be simplified by ignoring any processes which have the same impacts in both systems (e.g. the use phase in this worked example gave rise to $13.5 \mathrm{~kg} \mathrm{CO} 2$ eq. in both systems) as this would not contribute to any difference between the two. This was not done in this example because we were calculating the absolute impacts arising from each system and then determining the difference from those.

The calculations above using system expansion via substitution determined the impacts arising from APCr treatment, block production, transport to market and the end-of-life. However, the processes of direct interest to the process developer are just the APCr treatment and block production. To determine the impacts of just these processes when switching to the C8S system, the data presented in Table 8 reveals:

GHG emissions of the reference APCr treatment and block production processes $=7.78+20.3=28.1 \mathrm{~kg} \mathrm{CO} 2$ eq. $/ 1 \mathrm{~m}^{2}$ wall and $13.7 \mathrm{~kg}$ APCr treated.

GHG emissions of the C8S block production process (which includes $\mathrm{APCr}$ treatment) $=19.9 \mathrm{~kg} \mathrm{CO} 2 \mathrm{eq} . / 1 \mathrm{~m}^{2}$ wall and $13.7 \mathrm{~kg}$ APCr treated.

$$
28.1-19.9=\text { GHG saving of } 8.2 \text {, so reduction achieved is } 8.2 / 28.1=29 \% \text {. }
$$

Note: when using this approach, the GHG saving calculated by this method are lower than the $9.9 \mathrm{~kg} \mathrm{CO} 2$ eq. used previously. This is because the 8.2 value used only includes the savings achieved in the APCr treatment and block production processes and does not include the savings achieved in the $\mathrm{CO}_{2}$ utilisation step or in transporting the blocks to market and during their end-of-life treatment. The $1.37 \mathrm{~kg}$ of $\mathrm{CO}_{2}$ utilised per functional unit was included within the EfW data in Table $\mathbf{8}$ and so this was accounted for in the system expansion model and the substitution approach, but not if we simply look at individual processes of interest.

If the $1.37 \mathrm{~kg}$ of $\mathrm{CO}_{2}$ utilised by the mineralization process per functional unit is allocating to the block production process, then the GHG emissions savings achieved in APCr treatment and block production by switching from the reference process to the C8S process are $9.6 / 28.1=34 \%$. 
Again it will be noted that the $9.6 \mathrm{~kg} \mathrm{CO} 2 \mathrm{eq}$. GHG emission savings per functional unit used in the calculation above are less than the $9.9 \mathrm{~kg} \mathrm{CO} 2$ eq. $\mathrm{GHG}$ emissions savings determined when system expansion and system expansion via substitution were used. The "missing" $0.32 \mathrm{~kg} \mathrm{CO} 2 \mathrm{eq}$. GHG savings were made when transporting the blocks to market and during their end-of-life treatment. As explained previously, even though these additional transport savings are due to the use of the C8S process, they are not achieved by the APCr or block production processes and will not be realised until a time in the future. It is therefore considered that allocating these savings to the two processes under investigation would be misleading. However, it is recognized that such difficulties are not currently covered by the guidelines.

\section{C.7.4 Conclusions}

A system-wide analysis using system expansion reveals that the impact of switching from the reference system to the C8S system reduces GHG emissions by around 5\%. Once the impacts of the EfW plant have been set aside by the use of system expansion via substitution, it can be seen that switching from the reference production process to the C8S process reduces the GHG emissions by $22 \%$. However, if only the APCr treatment and block production processes are considered, then savings of GHG emissions of $34 \%$ are calculated, if the $\mathrm{CO} 2$ utilised by the mineralization process is allocated to the block production rather than being considered as a reduction in the EfW plant emissions.

Other findings:

- the blocks produced using the C8S process achieved small GHG emissions reductions over the reference blocks when they were transported to market and in their end-of-life treatment, largely due to the reduced mass of the C8S blocks compared to the conventional blocks.

- Cement makes the largest contribution to the impacts of both the C8S and the reference block production processes.

- Cement use has a significantly larger impact upon the reference APCr treatment process than transport, even though the reference process involved transporting the APCr $582 \mathrm{~km}$ for treatment.

- The impact category covering the abiotic depletion of elements was found to be sensitive to the composition of the blocks, as this is reliant upon the use of natural minerals.

When conducting a full LCA study it would be necessary to conduct the analysis using data from all impact categories. Only data from the abiotic GHG emissions impact category was used here as an example to illustrate how the interpretation of LCA data is influenced by the method of analysis. Clearly, the approach taken in analyzing and interpreting the results is key, as is being clear in reporting how the analysis was conducted.

It should be recognized by the author, and acknowledged in the report, that focusing upon only certain processes within a product system has the potential to limit the scope of the study. For example, by focusing the evaluation upon the APCr treatment and block production only, impacts occurring elsewhere in the system due to the changed process are not evaluated. 


\section{C.8 References}

1. Emerald Energy from Waste Inc. (2018). Overview, Process \& Equipment. Available at: http://www.emeraldefw.com/overview.php. Accessed August 2018.

2. Heiri, O., Lotter, A.F. and Lemcke, G. (2001). Loss on ignition as a method for estimating organic and carbonate content in sediments: reproducibility and comparability of results. Journal of Palaeolimnology 25: 101-110.

3. Regional Municipality of Peel (2016). Minutes from the Waste Management Strategic Advisory Committee. Available at: http://www.peelregion.ca/council/subcomm/wmsac/2010s/2016/wmsac-2016-02-18.pdf Accessed October 2018.

4. Government of Ontario (2018). Large landfill sites. Available at: https://www.ontario.ca/data/largelandfill-sites Accessed October 2018. 


\section{Integration Worked Example}




\section{Contents}

D.1 Introduction .93

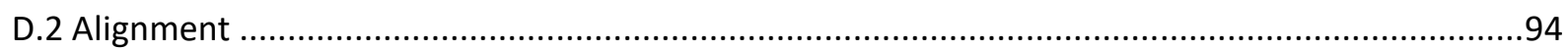

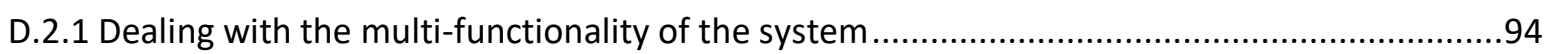

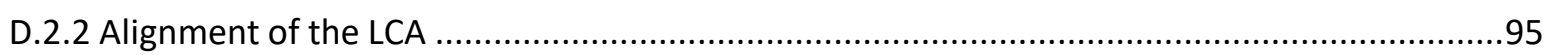

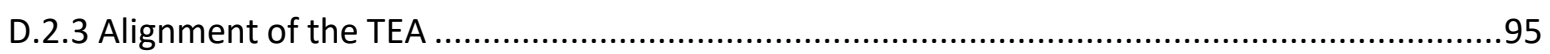

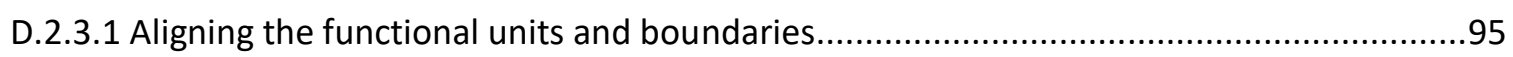

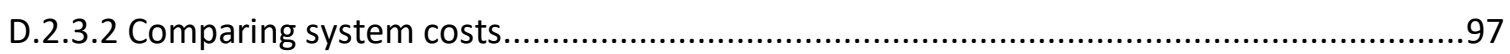

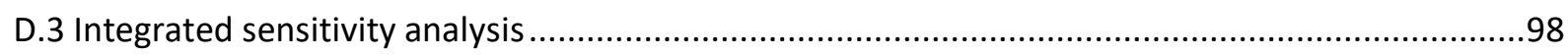

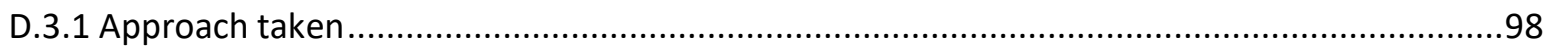

D.3.2 Sensitivity of the distance to APCr treatment ..........................................................99

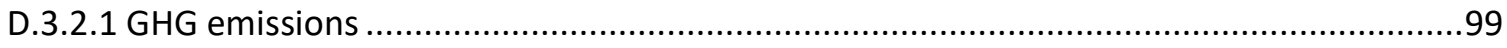

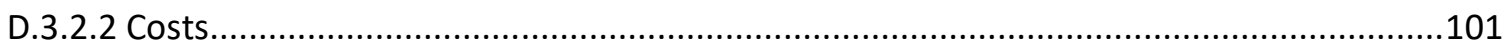

D.3.3 Sensitivity of the cement content of the blocks ...................................................103

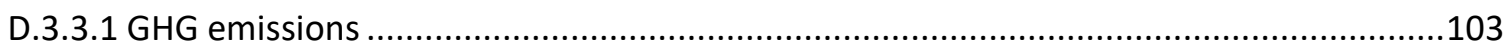

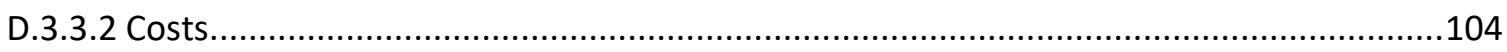

D.3.4 Comparing sensitivity across the two parameters .............................................. 104

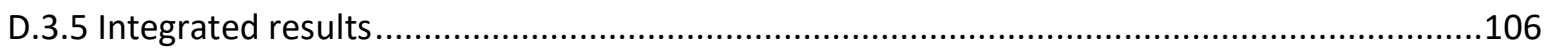

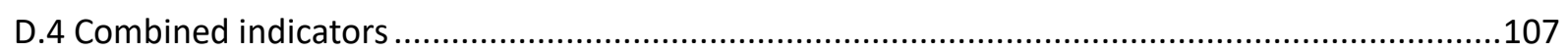

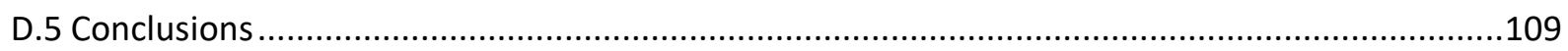




\section{D.1 Introduction}

This section provides a partial integration of combined results arising from the techno-economic assessment (TEA) and life cycle assessment (LCA) worked examples provided in Sections B and C of this worked example. The data used arises from the sensitivity analyses of the production of concrete blocks from $\mathrm{APCr}$ and $\mathrm{CO}_{2}$ arising from a municipal solid waste (MSW) energy from waste (EFW) plant. The selected indicators are the cost ( $\$$ Can per $1 \mathrm{~m}^{2}$ wall and $13.7 \mathrm{~kg} \mathrm{APCr}$ treated) and the GHG emissions ( $\mathrm{kg} \mathrm{CO}_{2}$ eq. per $1 \mathrm{~m}^{2}$ wall and $13.7 \mathrm{~kg} \mathrm{APCr}$ treated) for the TEA and LCA respectively. The aim is to use a holistic approach to determine combined economic and environmental results. The methodology used examines the sensitivity of the parameters identified in the separate TEA and LCA worked examples to have the highest overall economic and environmental impacts. 


\section{D.2 Alignment}

D.2.1 Dealing with the multi-functionality of the system

In the LCA worked example provided in Part C of this document, the multi-functionality of the system was initially solved by using system expansion. One feature of using system expansion with a multi-functional system is that it results in the functional unit with multiple functions (i.e. products). In the life cycle impact assessment described in Part $C$ of this document, the functional unit was $1 \mathrm{~m}^{2}$ wall, $372 \mathrm{KWh}$ electricity and $13.7 \mathrm{~kg}$ APCr treatment.

For a stand-alone LCA report, such a functional unit does not present a problem as LCA is commonly used in systems with multiple products. However, if the LCA study is to be integrated with a techno-economic assessment (TEA), problems can arise. TEA does not commonly use system expansion to include upstream and downstream processes, because the focus of TEA tends to be the cost or market prices of the raw materials and products at the factory gates. If system expansion was used for TEA, in this case it would necessitate the modelling of the upstream EfW facility which produces the $\mathrm{CO}_{2}$ supply in addition to the downstream usage and end-of-life processes. This requires a significant increase in time and effort, plus access to data from other industries which may not be available. To ease this burden, a method of limiting the processes included within the system boundary, and also reducing the number of products (or functions) within the functional unit is required.

In Section C.7 of the LCA worked example, as part of the interpretation the results arising from the use of system expansion were compared to the results when system expansion via substitution and an analysis of the impacts of individual processes was conducted. The following section describes how alignment of the system boundaries facilitated the integration of TEA with LCA in accordance with the LCA Guidelines.

To allow an integrated analysis, the same system boundaries and functional unit needs to be used for the environmental analysis as for the economic analysis. In the LCA worked example provided as Part C of this document, both system expansion and system expansion via substitution were used solve the multifunctionality of the system. Whilst assessment of the entire system using system expansion has some advantages for an LCA analysis, it can result in the overall environmental impact of the system being dominated by a process which is not the process of interest in this study. In this case the EfW plant produces around $80 \%$ of the GHG emissions of the entire system, so any change to GHG emissions in the other processes due to the Carbon8 Systems (C8S) process are relatively small compared to the overall systemwide emissions. Additionally, system expansion results in a functional unit with three functions/products, only two of which are of interest to the process developer.

Since block production containing C8S aggregate is also an APCr treatment process, these two products and the processes which produce them need to remain within the system boundary. However, removing the EfW process and the resulting electricity from the system by substitution and focusing upon the two 
processes of interest eases the integration of the techno-economic assessment as well as the interpretation of the environmental impacts of the C8S process.

To enable an LCA to be integrated with a TEA the goal and scope of the two approaches need to be aligned.

\section{D.2.2 Alignment of the LCA}

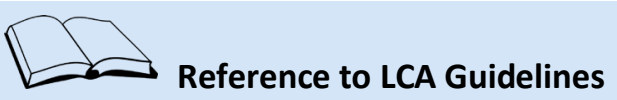

Section C.4.3.2 Solving multi-functionality describes a hierarchy of approaches. According to this hierarchy, after system expansion, the next option is to try system expansion with substitution.

The process used to achieve system expansion via substitution was described in Section C.7.3 of the LCA worked example. In summary, a contribution analysis was performed to break down the impacts arising from the system into component processes. As part of the system modelling, the APCr treatment process was modelled separately from the EfW process so that the impacts arising from each could be assessed separately. The impacts arising from the reference EfW process were substituted/removed from the assessment and the impacts of other processes such as transport to market, use and end-of-life were determined separately to enable the impacts arising from just the APCr treatment and the block production (including C8S aggregate production) processes to be distinguished from the whole system model.

Substitution of the EfW plant results in the removal of the electricity product from the functional unit, leaving the functional unit as "blocks per $1 \mathrm{~m}^{2}$ wall and $13.7 \mathrm{~kg} \mathrm{APCr}$ treated". As a consequence of doing this, an integration of aspects of the LCA and TEA for the C8S process can be undertaken once the system boundary and the scope of the TEA has been expanded to match that of the LCA.

\section{D.2.3 Alignment of the TEA}

\section{D.2.3.1 Aligning the functional units and boundaries}

In Part B the functional unit of the TEA selected was derived to be used for investigating the profitability of the $\mathrm{C} 8 \mathrm{~S}$ secondary aggregate production process.

However, integration of the LCA and TEA studies requires alignment of the functional units in the two studies. To do this, a suitable functional unit and a new boundary must be set to allow for the goals of Part D to be met.

- The functional unit of the TEA in Part B is $\mathrm{m}^{3}$ of aggregate capable of use in the production of 7.6 $\mathrm{N} / \mathrm{mm}^{2}$ blocks.

- The functional unit of the integrated study in Part $D$ is the number of blocks required to produce a $1 \mathrm{~m}^{2}$ wall and the treatment of $13.7 \mathrm{~kg}$ of APCr.

To align the functional units the following data is required:

- The composition of both the reference block and the C8S aggregate containing block (this information is provided in Part $\mathbf{A}$ of this report). 
- Data for modelling the CapEx and OpEx of the block production process.

The process used for the production of concrete blocks is described in Part A of this report. The TRL level for the production of blocks is assumed to be TRL 9 and it is expected that the use of C8S secondary aggregate has no impact on this. Block production is assumed to be radically different to the production of fine chemicals, and thus the methods for estimating costs given in Part B of this report are not likely to provide reliable answers.

An alternative approach was taken based primarily on two sources:

- Source [1] is a census of Canadian industry completed annually by Statistics Canada. The source database is sorted by industry with the "concrete pipe, brick and block manufacturing" industry selected (NAICS code: 32733 ). This source gives an indication on total expenses for the industry and what proportion of these total expenses are from labour (approximately $21 \%$ of total expenses) and the cost of materials and supplies (approximately $41 \%$ of total expenses) but no further details.

- Source [2] is a census of American industry completed annually by United States Census. The database is sorted by industry with the "concrete block and brick manufacturing" industry selected (NAICS code: 327331 ). This source provides a more detailed breakdown of costs and remains relatively consistent with the details given for Canada. The breakdown of costs is given in Figure 1 below, this source is only included to give additional details not provided in the first source. For example, the total CapEx is shown to contribute $7 \%$ to production cost - it would be reasonable to expect the Canadian value to be consistent with this.

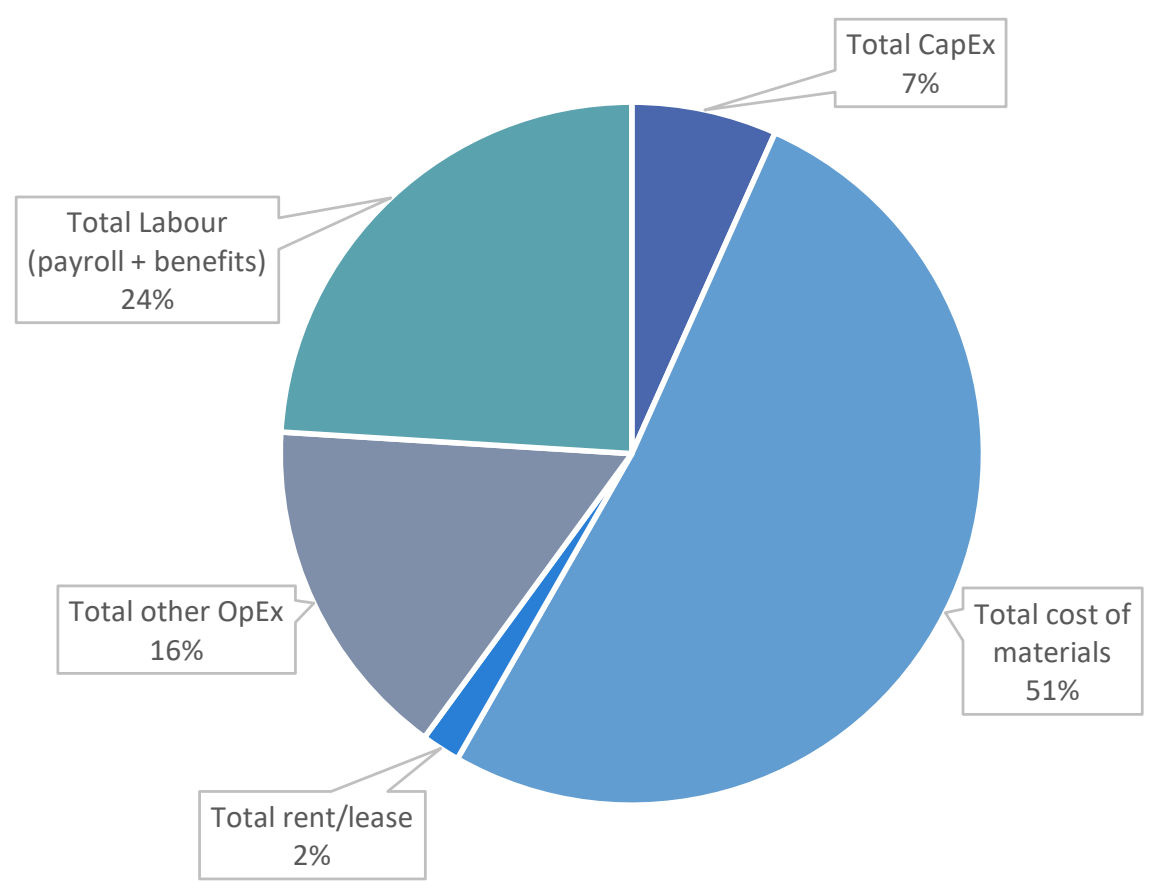

Figure 1. Cost breakdown of block production in the USA

For the estimation of the production cost for blocks the data from the Canadian industry is used, where material costs are assumed to be $40.5 \%$ of the total production expense. As the costs for each material component were known a "fixed cost" was calculated for the non-material fraction of block production. This fixed cost was assumed to be equal for both the reference and the C8S aggregate containing block and was based on the materials cost for the reference block. 
The overall cost for the production of blocks on a per $\mathrm{m}^{2}$ of wall basis is factored into the overall system cost.

\section{D.2.3.2 Comparing system costs}

The functional unit cost (or system cost) reflects the overall cost to achieve all the goals set out in the functional unit - namely treat APCr and produce a specified number of blocks (the number needed to produce $1 \mathrm{~m}^{2}$ of wall). As with Parts $\mathbf{B}$ and $\mathbf{C}$, two systems are considered, with each defined as follows:

- The "Block 1" system: this is the "reference" system and reflects the existing conventional APCr treatment route and independent block production facility.

- The "Block 2" system: this is the CCU system and sees the utilisation of $\mathrm{APCr}$ and $\mathrm{CO}_{2}$ in the production of aggregate, which can then be used to produce blocks.

The overall system cost accounts for three base elements: cost of block production, cost of APCr transportation and the cost for APCr treatment/abatement.

The overall system costs are as follows:

- For the block 1 system (reference) a cost of $14.27 \$$ Can per functional unit is calculated

- For the block $\mathbf{2}$ system (CCU) a cost of $\mathbf{1 1 . 3 0} \$$ Can per functional unit is calculated

The block 1 system is shown to have a higher functional cost, and there are two main reasons suggested for this. The first is that the CCU system does not require transport of APCr for treatment as it is done onsite by $\mathrm{C} 8 \mathrm{~S}$ in the aggregate production process. Secondly, the relative cost of APCr abatement is lower in the CCU system.

In the block 1 system, a gate fee is paid to an external stakeholder for taking tonnes of APCr, in the block 2 system this fee is paid within the system boundaries (i.e. the cost for treatment of the APCr is assumed to be the same for the EfW plant in either scenario) to the aggregate producer. This is then accounted for in the profitability of the aggregate producer but not in the production costs (see section B of this worked example). The actual cost for APCr treatment becomes a function of the production costs for the carbonated secondary aggregate:

Cost of APCr treatment (per tonne) $=\frac{\text { Per tonne production cost of secondary aggregate }}{\text { Mass fraction of APCr in secondary aggregate }}$

The production cost of secondary aggregate is then factored into the production cost of producing CMUs in the system (ultimately integrating the two elements of the functional unit into one). Whilst a value for the gate fee is not specified to protect commercial interests it can be stated that the gate fee (original abatement cost) is larger than the production cost for secondary aggregate. 


\section{D.3 Integrated sensitivity analysis}

By way of an example, an integrated sensitivity analysis was performed on two parameters, one of which is believed to have a significant financial impact and the other which is believed to have a significant environmental impact.

The TEA worked example provided in Part B of this document reveals that the avoided cost of the APCr treatment contributes most to making the C8S block production process economically viable. In the reference process, the distance the APCr is transported to the site of treatment is known to make a significant contribution to the cost of the APCr treatment process. For this reason, this transport component is believed to be economically significant to the whole process, so an integrated assessment will be conducted to determine the sensitivity of the overall costs and GHG emissions to varying the distance that the APCr needs to be transported.

The LCA worked example provided in Part C conducted a contribution analysis which revealed that cement is the major contributor to the GHG emissions arising from both the block production processes evaluated. The use of cement contributed $71 \%$ of the overall GHG emissions arising from the C8S block production and $66 \%$ of the GHG emissions arising from the reference block production. Cement was also shown to have an impact upon the profitability of aggregate production in Part B. An integrated environmental and economic assessment of changes to the cement content of the blocks will therefore be conducted.

The approach taken is the "alignment and combined indicators integration" as described in Chapter A.5 Integrating LCA and TEA, which is included within Part A of the associated Guidelines document.

\section{D.3.1 Approach taken}

\section{Reference to Integration Guidelines}

Section A.5.2 Types of Study describes the different levels of TEA and LCA integration.

Section A.5.3 Alignment describes the data equivalency requirements to enable integration of TEA and LCA data and Section A.5.4 Multi-functionality and system boundaries suggests how to best align the system boundaries of the economic and environmental assessments.

To allow an integrated assessment, the inventory data used for the economic and environmental analyses are aligned and consistent and the functional units used are the same to allow direct comparison of the two sets of results. The functional unit is the number of blocks required to build $1 \mathrm{~m}^{2}$ wall and $13.7 \mathrm{~kg} \mathrm{APCr}$ treated. 
In the reference system, the APCr is transported $582 \mathrm{~km}$ from the EfW plant to the site of stabilization in 30 tonne powder tankers. The effect of reducing this to $50 \mathrm{~km}$ and increasing it to $1000 \mathrm{~km}$ is evaluated as an integrated sensitivity analysis. In the blocks modelled for the LCA and TEA worked examples, the cement content of both the reference block and the C8S block was $174 \mathrm{~kg} / \mathrm{m}^{3}$ of blocks. The effect of reducing and increasing this by $50 \%$ is evaluated.

It should be noted that changing the block composition was done purely to evaluate the environmental and economic sensitivity of varying the cement content for the purposes of this worked example - it is recognized that varying the cement content by such margins would not be possible without severely impacting the technical performance of the blocks.

In the following section, the results of the sensitivity analyses are presented initially with separate analyses of the greenhouse gas emissions and the cost impacts. The integrated results are subsequently presented together in a single graphical representation.

As explained in the LCA worked example provided as Part C, the CML impact category representing the abiotic GHG emissions has been used as an example of how to evaluate environmental impacts. A full study should present as many impact categories as possible to avoid overlooking changes to impacts other than GHG emissions.

\section{D.3.2 Sensitivity of the distance to APCr treatment}

As mentioned above, the distance that the APCr is transported to the treatment site is a significant contributor to the economic cost of the APCr treatment process in the reference system. In the reference system, the APCr is transported $582 \mathrm{~km}$ from the EfW plant to the site of stabilization. The effect of reducing this to $50 \mathrm{~km}$ and increasing it to $1000 \mathrm{~km}$ is evaluated.

\section{D.3.2.1 GHG emissions}

The GHG emissions arising from transporting the APCr $582 \mathrm{~km}$ in 30 tonne loads amount to around $2.2 \%$ of the combined GHG emissions arising from the APCr treatment and block production processes of the reference process. This proportion ranges from $0.22 \%$ when the distance is reduced to $50 \mathrm{~km}$, to $4.45 \%$ when the distance is increased to $1000 \mathrm{~km}$.

The C8S process avoids this transport step completely by combining APCr treatment with block production, so there are various ways of presenting this data. The first presents the GHG emissions data for the two processes together on the same graph which allows comparisons to be made. In Figure $\mathbf{2}$ the values indexed to the baseline distance of $582 \mathrm{~km}$ are presented. 


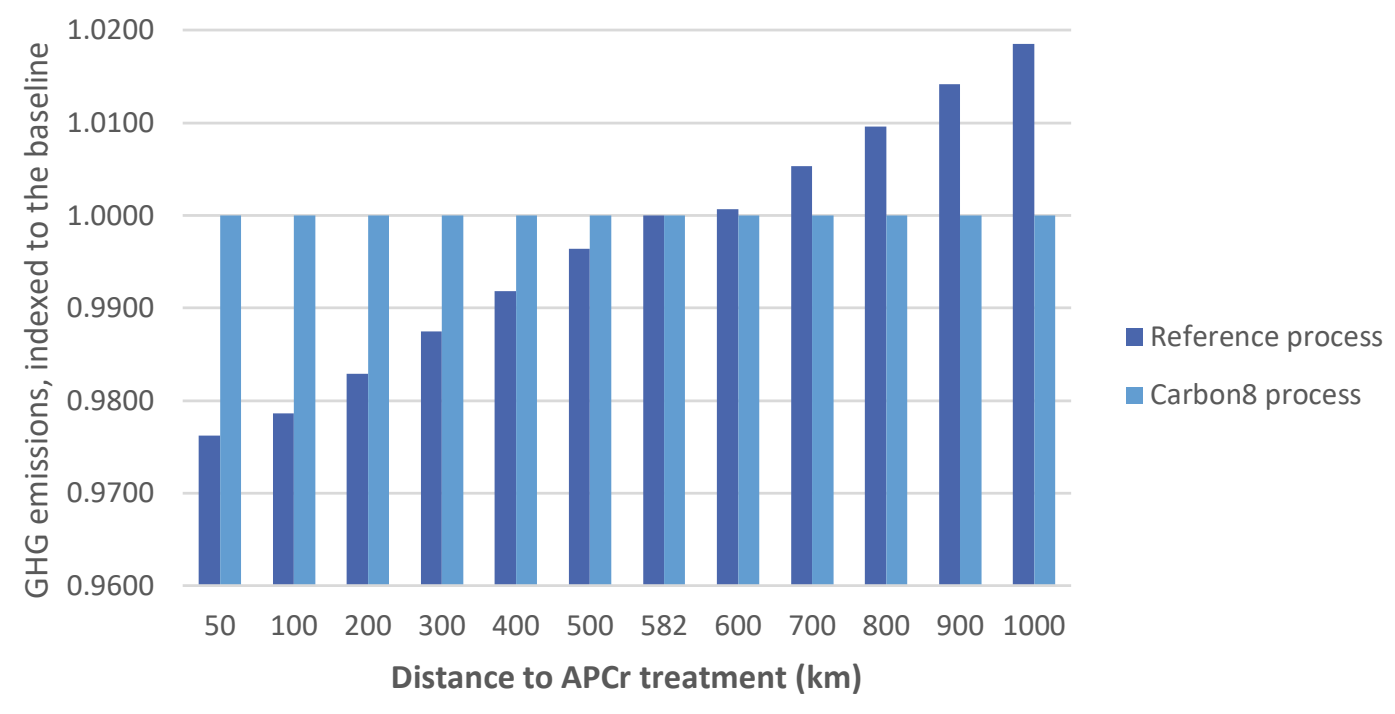

Figure 2. The GHG emissions of the two block production and APCr treatment processes when transporting the APCr different distances for treatment. The GHG emissions are indexed to the baseline values for the reference and C8S process, respectively.

The graph above shows the increasing emissions associated with the reference process as the distance to APCr treatment site is increased, compared to the C8S process whose GHG emissions are independent of this transport distance. One feature of using indexed values in the graph is that it appears at first glance that the GHG emissions arising from the reference process go below that of the C8S process once the distance to APCr treatment is reduced below the baseline $582 \mathrm{~km}$. However this is not the case, the GHG emissions of the reference process remains significantly higher than the C8S process even when the distance is only $50 \mathrm{~km}$.

An alternative approach is to calculate the difference in GHG emissions between the C8S process and the reference process when the APCr transport distances are changed. This data is presented Figure 3.

The GHG emissions presented have been indexed to the baseline reduction in GHG emissions achieved by switching from the reference process (assuming the baseline $582 \mathrm{~km}$ transport distance) to the C8S process. As expected, decreasing the transport distance required by the reference process reduces the GHG emissions "savings" made by switching to the C $8 \mathrm{~S}$ process, whereas increasing the distance increases these potential savings. Figure 3 reveals that altering the distance that the APCr needs to be transported to the treatment site has a limited impact upon GHG emissions, reducing the normalised value to 0.93 when the distance is reduced to $50 \mathrm{~km}$ and increasing it to 1.05 when the distance is increased to $1000 \mathrm{~km}$. 


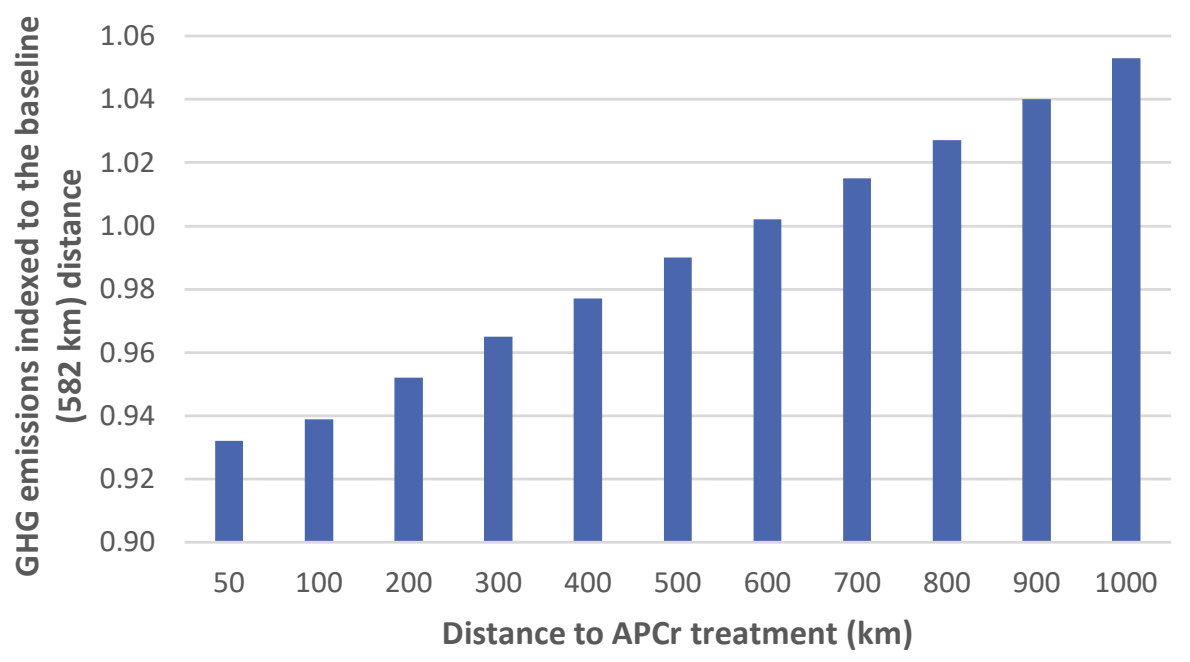

Figure 3. The reduction in GHG emissions when switching from the reference block production process to the C8S process when transporting the APCr different distances for treatment. The GHG emissions are indexed to the baseline reduction value achieved at $582 \mathrm{~km}$.

\section{D.3.2.2 Costs}

The cost of transporting the APCr to the site of treatment was investigated for its impact on the final cost of the functional unit. In this worked example it is assumed that the cost of transporting the APCr to the ash stabilization process is paid by Emerald EfW and that this cost is independent of the gate fee paid for ash stabilization. As detailed in Part A of this report, APCr is known to be transported via powder tanker to the stabilization process. The costs for trucking are derived primarily from two trusted sources:

- The revenue per tonne kilometre for freight is taken from source [1], a government source that states for long haul domestic trucking an average revenue of \$CAD 0.1455 per tonne kilometre was earned. It is assumed that this revenue is equal to the rate charged for transport of materials (in this case APCr).

- A breakdown of the costs for trucking is taken from source [2], a government source that provides details on the breakdown of costs and revenues for different types of trucking in Canada. For this worked example the cost breakdown for long haul domestic transportation is used. Details of the breakdown are given in Figure 4, this can be compared to the cost breakdown in source [3] where the data within Figure $\mathbf{4}$ is shown to be consistent with the data shown in the source.

- The actual cost for APCr transportation paid by Emerald EfW is not used in this calculation to protect commercial sensitivity, the aggregated average data form the above sources is used. 


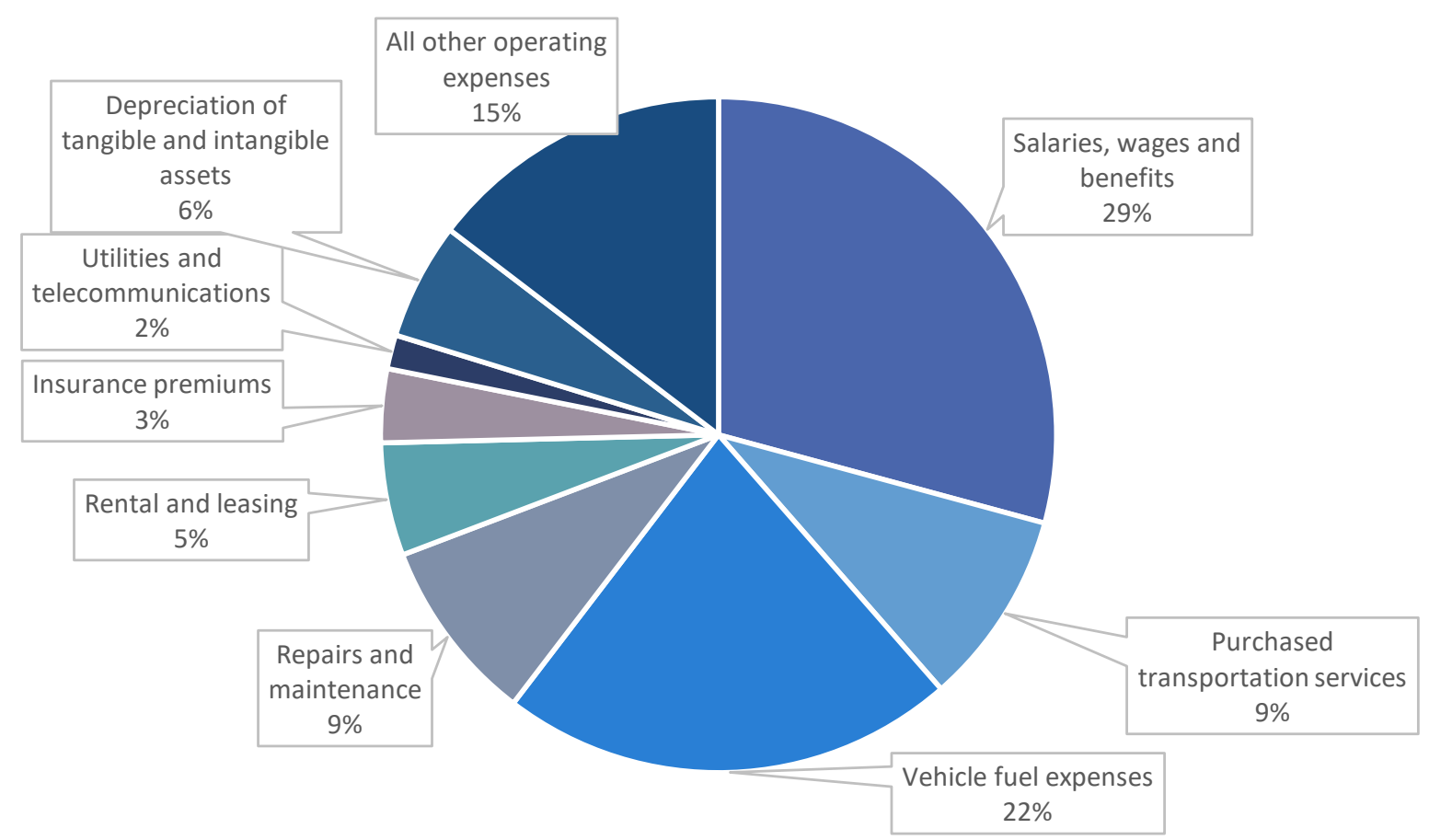

Figure 4. Breakdown of trucking costs.

APCr is transported in bulk loads of 30 tonnes per truck, using the revenue figure above a cost of \$CAD 4.37 per $\mathrm{km}$ is calculated for each truckload. Applying this to the functional unit a cost \$CAD 1.12 is calculated for the current journey. The sensitivity of this cost has been investigated, with the results shown in Figure 5 , a range of $50 \mathrm{~km}$ to $1000 \mathrm{~km}$ to the APCr stabilization facility is considered. The indexed values refer to the overall production cost for the functional unit (production of the $1 \mathrm{~m}^{2}$ wall and the treatment of 13.7 kg APCr).

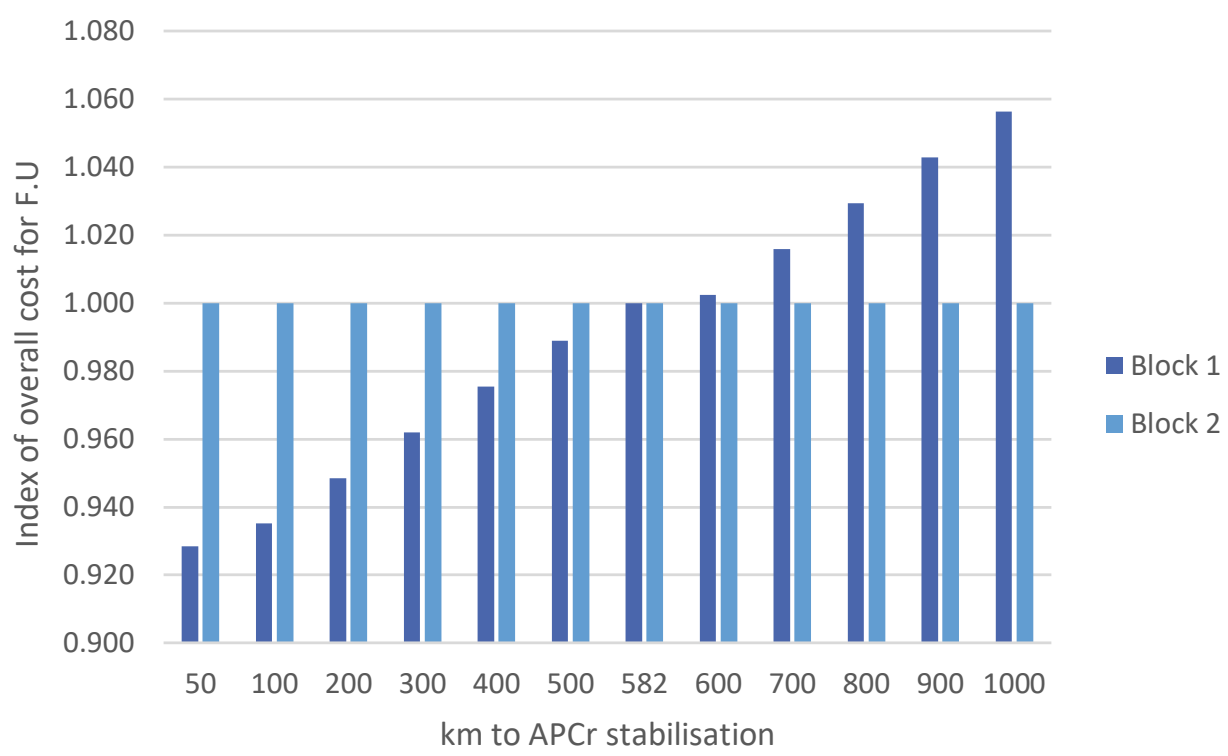

Figure 5. Sensitivity of functional unit cost to APCr stabilization centre transport distance.

As Figure 5 shows, for the C8S aggregate block (block 2) there is no sensitivity on cost based on the distance to the APCr stabilization facility as stabilization is not needed. For block 1 , where the functional unit includes 
APCr treatment at the facility, the overall cost of the functional unit is impacted by the distance travelled. Even with a significant range of distances considered the overall cost for the functional unit does not vary greatly due to the greater costs for APCr treatment and block production.

\section{D.3.3 Sensitivity of the cement content of the blocks}

In the second integrated sensitivity analysis, the cement content of the blocks was increased and decreased by $50 \%$ by mass from the baseline value of $174 \mathrm{~kg} / \mathrm{m}^{3}$ used for both the reference block and the C8S block.

\section{D.3.3.1 GHG emissions}

The impact upon the GHG emissions arising from the C8S and the reference processes are presented in Figure 6.

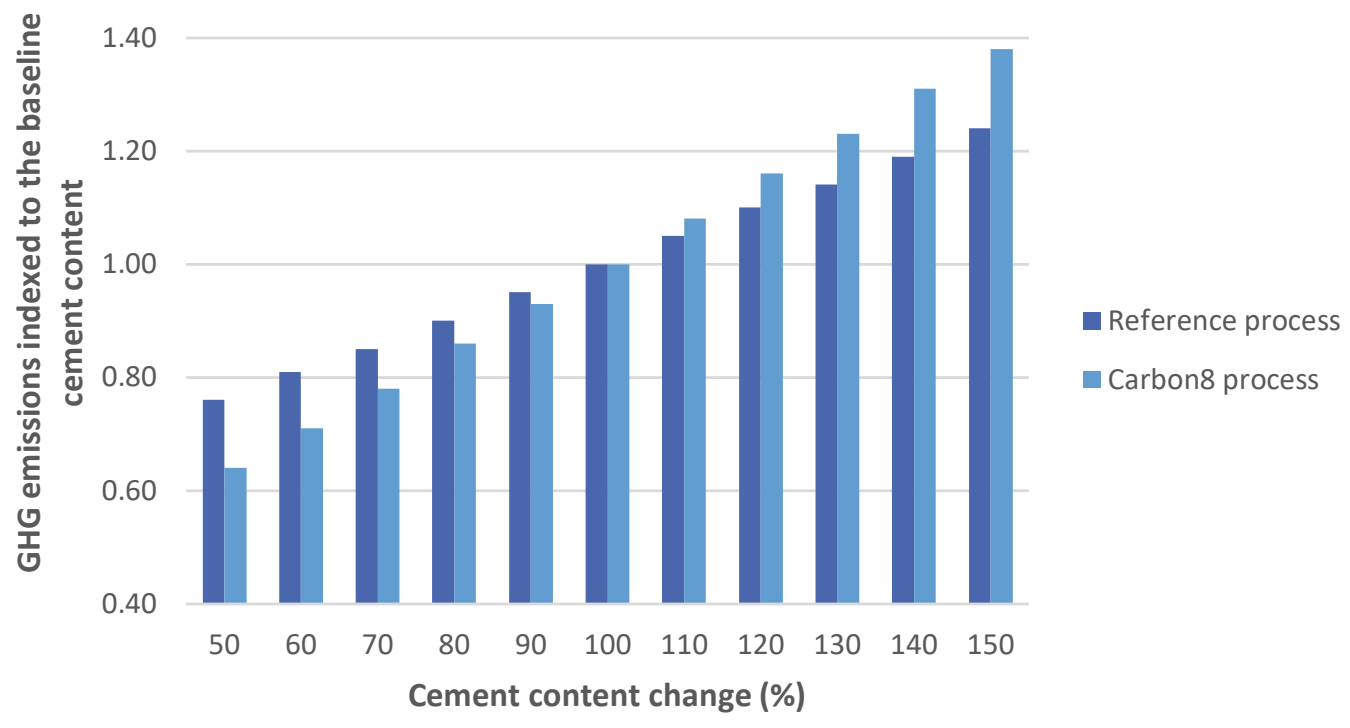

Figure 6. Effect of varying the cement content of the blocks on the greenhouse gas emissions of both block production processes. The GHG emissions are indexed to the baseline block cement content value of $174 \mathrm{~kg} / \mathrm{m}^{3}$.

Rather than presenting the actual GHG emissions, the Y-axis of the graph has been indexed to the baseline (174 kg/m $\mathrm{m}^{3}$ cement content) of $28.1 \mathrm{~kg} \mathrm{CO} 2$ eq. per $1 \mathrm{~m}^{2}$ wall and $13.7 \mathrm{~kg}$ APCr treated for the reference process and $18.5 \mathrm{~kg} \mathrm{CO} 2$ eq. per $1 \mathrm{~m}^{2}$ wall and $13.7 \mathrm{~kg} \mathrm{APCr}$ treated for the C $8 \mathrm{~S}$ process. 


\section{D.3.3.2 Costs}

The resultant impact of varying the cement content by $+/-50 \%$ on the overall function unit cost is shown in Figure 7.

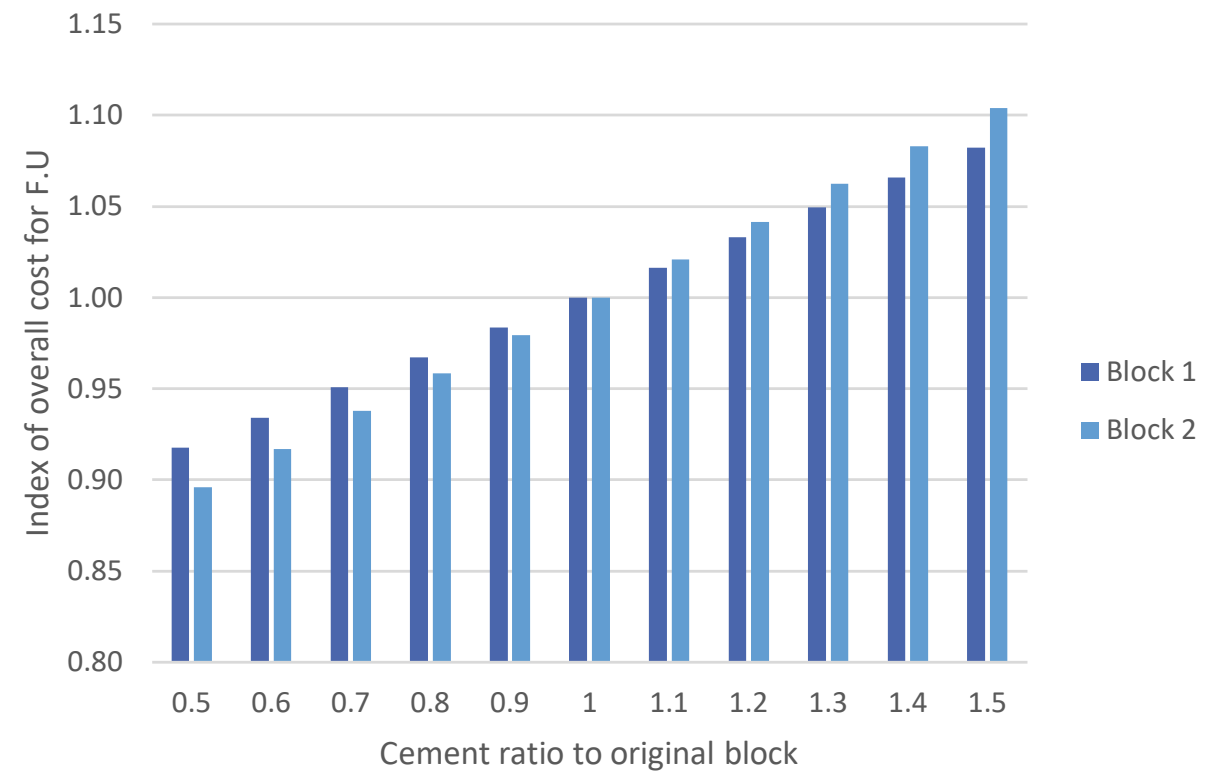

Figure 7. Sensitivity of functional unit cost to varying cement content in the block.

It can be seen that both blocks are relatively sensitive to the variance of the amount of cement used in the block production. This is unsurprising due to the relatively high component cost of cement (in \$Can per tonne) compared to other components such as aggregate, sand and water. The functional unit cost for the C8S process is shown to be more sensitive, with this primarily due to the lower APCr treatment costs and the lack of a transport cost.

\section{D.3.4 Comparing sensitivity across the two parameters}

By indexing the data for the GHG emissions and costs (as presented in Figures 2-7), it becomes possible to present the sensitivity of GHG emissions to varying cement content on the same axis as the sensitivity of GHG emissions to varying APCr transport distances. This enables us to compare the sensitivity of both parameters to determine which parameter variance has the biggest impact on overall system GHG emissions and costs. Such a comparison is presented in Figure $\mathbf{8}$ for GHG emissions and in Figure $\mathbf{9}$ for cost. In these graphs, the lines with steeper gradients show a greater sensitivity of emissions or costs to the variance of the parameter. For instance, GHG emissions show very little sensitivity (the gradients of the lines are very low) to variance of the distance required to transport the APCr to the stabilization facility. This reflects the finding of the LCA worked example in Part C that transport accounted for only $8 \%$ of the GHG emissions arising from the reference APCr stabilization process, $90 \%$ of the resulting GHG emissions were associated with the cement used in the stabilization/solidification process. The same graph reveals that GHG emissions show a much greater sensitivity to variance in the cement content of the blocks. Again, this reflects the dominant contribution that cement was identified to play in GHG emissions arising from both block production processes. 


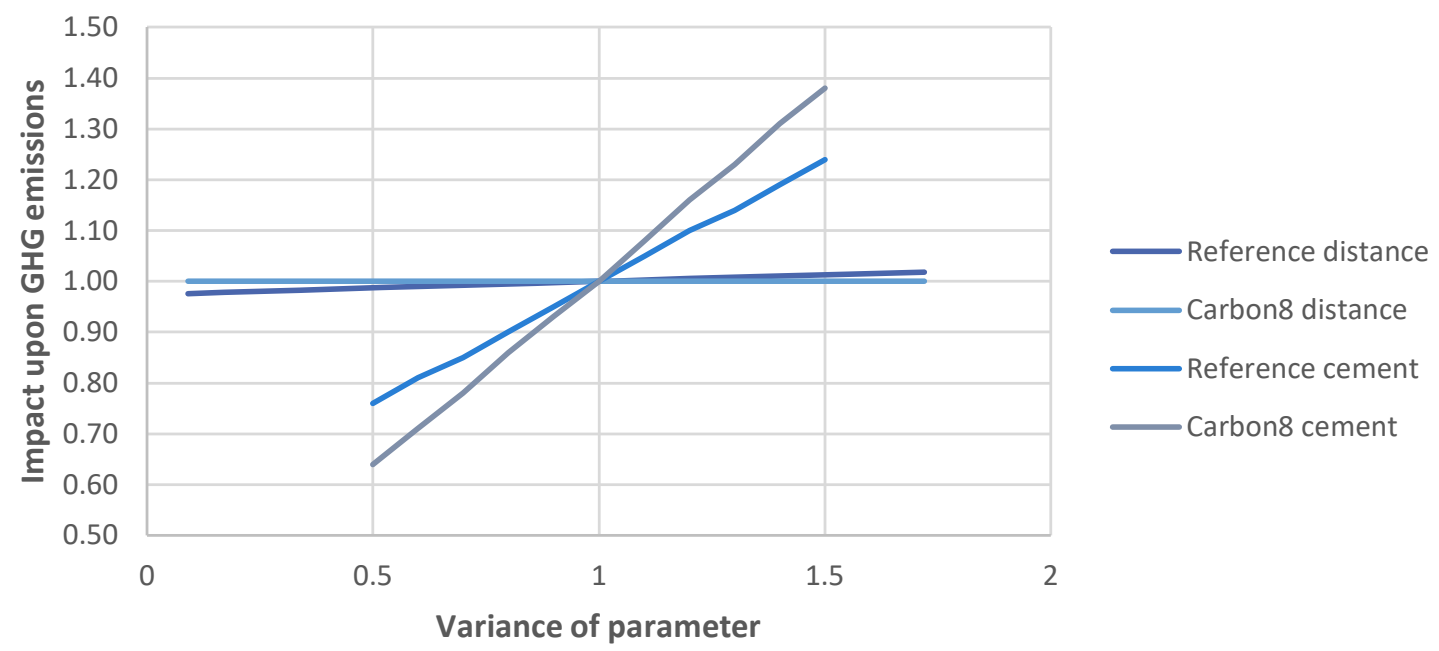

Figure 8. Sensitivity of GHG emissions to the varied parameters.

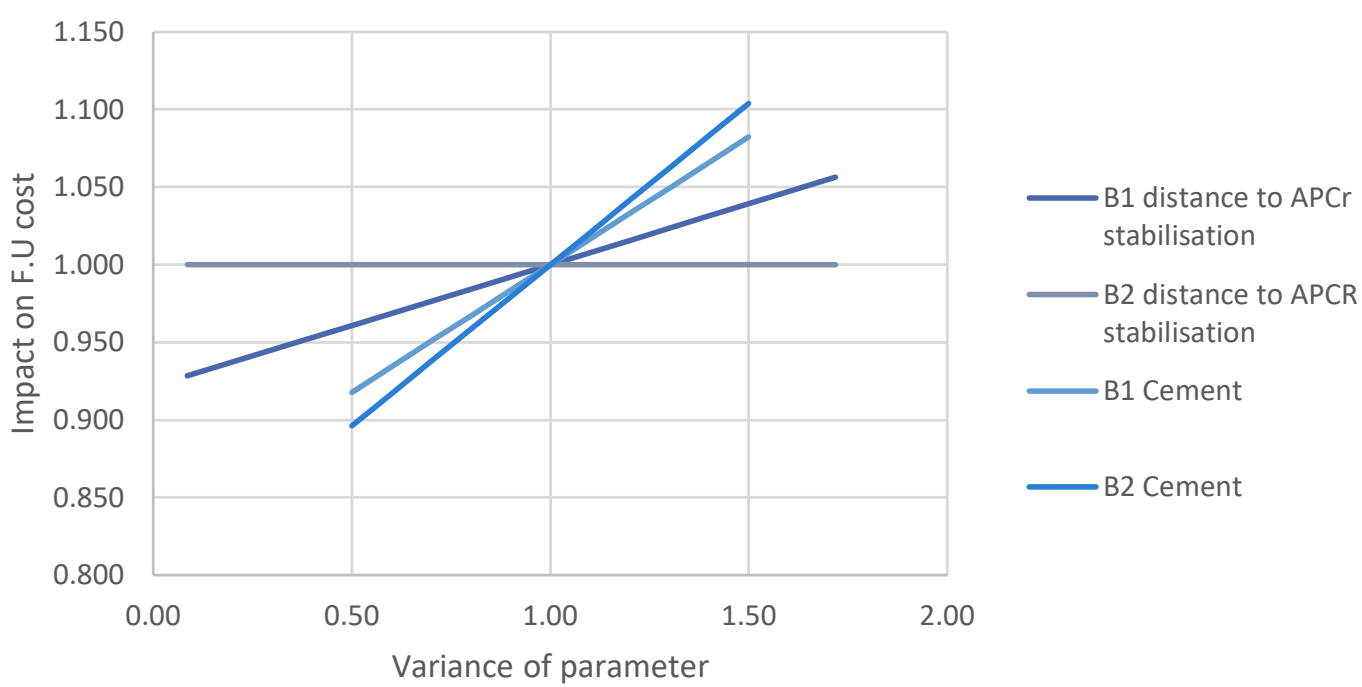

Figure 9. Sensitivity of functional unit cost to parameter

The sensitivity of the costs to variance of the same parameters follows a similar pattern to GHG emissions, with cement content shown to have more influence than APCr transport distance in increasing costs. However, it can be seen that production costs are relatively more sensitive to the APCr transport distance than the GHG emissions were, which would be expected due to the higher proportion of APCr treatment costs found to be associated with transport to the treatment site.

The above method could be further expanded if required, as was done when considering the sensitivity of profitability in Part B of this report. 


\section{D.3.5 Integrated results}

The modelled effects upon greenhouse gas emissions and economic data provided in Sections $\mathbf{3 . 3}$ and $\mathbf{3 . 4}$ were displayed on separate graphs, but the same data can be shown on a single graph, in the form of a nested box chart. The results combined in this way are presented in Figure 10. The benefit of this form of presentation is that it enables the scale of the sensitivity of both costs and GHG emissions to changes in the two variables (APCr transport distance and block cement content) to be compared relative to each other.

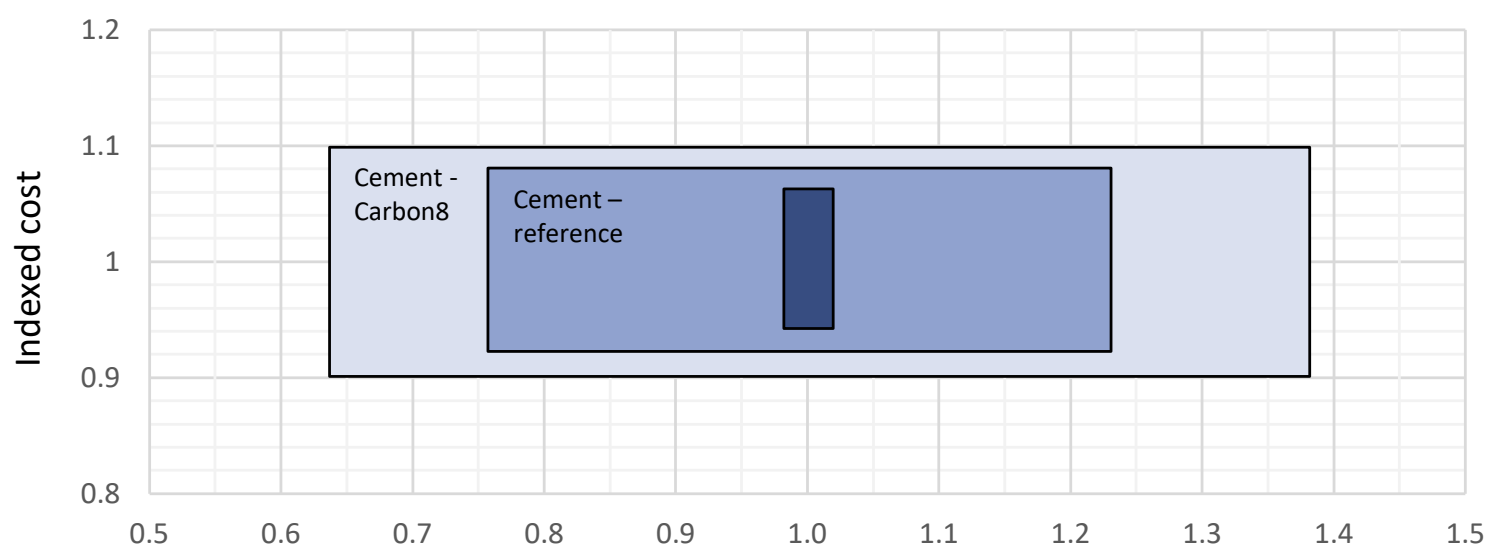

Indexed GHG emissions

Figure 10. Combined LCA and TEA results considering the effect of the cement content and APCr transport distance upon production costs and GHG emissions. The smallest box (dark blue) is the effect of distance to APCr treatment upon production costs and GHG emissions of the reference process (the C8S process has no equivalent transportation requirement).

In the nested box chart above, the size of the boxes indicates the relative sensitivity of the cost and GHG emissions to changes in the selected parameter. Since the boxes are plotted on the same indexed scale for both indicators, the shape of the boxes indicates the relative significance of each parameter to the cost and GHG emissions. The chart reveals that varying the cement content of the C8S blocks has a larger impact upon both costs and GHG emissions than in the reference blocks. The C8S process is therefore more sensitive to such changes than the reference process. The cement boxes are oblong in shape, showing that the GHG emissions are more sensitive to changes in cement content than the costs. The dark central box shows the sensitivity of costs and GHG emissions to the distance to APCr treatment for the reference process. Its columnar shape reflects that GHG emissions show less sensitivity to changes in this parameter than do costs. However, the costs are less sensitive to the distance to APCr treatment than to the cement content.

It is important to recognize that the scale of the sensitivity observed may be partly a reflection of the scale of the changes modelled, so some caution is required when interpreting such a diagram. However, the shape of the boxes does allow a useful comparison of the sensitivity of the system to the different variables plotted. 


\section{D.4 Combined indicators}

\section{Reference to Integration Guidelines}

Section A.5.6 Calculating combined economic and environmental indicators provides an example of the calculation of $\mathrm{CO}_{2}$ abatement costs, as an example of a combined indicator of relevance to $\mathrm{CCU}$ processes.

A combined indicator that is used widely is the abatement cost of $\mathrm{CO}_{2}, \mathrm{C}_{\text {abated }}$ ( $\$ \mathrm{Can} / \mathrm{t} \mathrm{GHG}$ abated). Equation 1 shows that different technologies should be compared with each other against a reference system.

$$
c_{\text {abated }}=\frac{C_{C C U}-C_{\text {ref }}}{\text { GHG emissions }_{\text {ref }}-\text { GHG emissions }_{C C U}}
$$

The reference technology is conventional block making combined with conventional APCr treatment. Using data from the aligned LCA and TEAs and scaled to the functional unit of per $1 \mathrm{~m}^{2}$ wall and $13.7 \mathrm{~kg} \mathrm{APCr}$ treated, the GHG emissions of the conventional process is $28.1 \mathrm{~kg} \mathrm{CO} 2 \mathrm{eq}$, and the cost of producing conventional blocks and APCr treatment in 2018 is 14.27 \$Can. In comparison, the GHG emissions associated with the $\mathrm{C} 8 \mathrm{~S}$ process are $18.5 \mathrm{~kg} \mathrm{CO} 2$ eq and the cost of the C8S process is $11.30 \$ C A D$. Using the above equation, these values give a cost of GHG abatement of:

$C_{\text {abated }}=(11.30-14.27) /(0.0281-0.0185)=-\$ 2.97 / 0.0096 t=-309 \$ C a n / t$ GHG abated .

In this case the production cost of the blocks together with the estimated costs associated with the APCr treatment were used to derive a cost per functional unit.

The lower the abatement cost, the higher the economic efficiency of the impact abatement, therefore the negative cost of abating GHG emissions revealed suggests that this is a cost-efficient method of reducing such emissions.

Important - the negative abatement cost achieved in this instance does not automatically indicate that the process is environmental viable. The risk in doing so is that the environmental burden of block-making and APCr treatment has been inadvertently shifted from GHG emissions to another impact category. Just as when performing LCA, it is therefore important that when evaluating the abatement of environmental burdens, other impact categories apart from just $\mathrm{CO}_{2}$ are thoroughly evaluated to rule this out. 
Another abatement cost which was considered is the cost of abating resource depletion, i.e. the natural minerals/aggregate which does not need to be used due to the utilization of aggregates produced from waste APCr. The equation used (2) is the same as equation (1), but the environmental impact has been changed from GHG emissions to aggregate used:

$$
c_{\text {abated }}=\frac{C_{C C U}-C_{\text {ref }}}{\text { aggregate used }_{\text {ref }}-\text { aggregate used }_{C C U}}
$$

The mass of aggregate used in the conventional process per functional unit (per $1 \mathrm{~m}^{2}$ wall and $13.7 \mathrm{~kg} \mathrm{APCr}$ ) is $95.7 \mathrm{~kg}$ and the average market price of conventional blocks and APCr treatment in 2018 is 14.3 \$Can per $1 \mathrm{~m}^{2}$ wall and $13.7 \mathrm{~kg}$ APCr. In comparison, the mass of aggregate used and costs associated with the C8S process are $72.4 \mathrm{~kg}$ and the cost is $11.30 \$ \mathrm{Can}$. The cost of abating (or reducing) aggregate use is therefore:

$C_{\text {abated }}=(11.30-14.27) /(0.0957-0.0724)=(-2.97 / 0.0233)=-127 \$$ Can $/ \mathrm{t}$ aggregate abated

Note - included within the overall block production and APCr treatment costs (i.e. per functional unit) used in the calculations above was a "gate fee" for taking in the APCr. If such a fee was not obtainable, then the abatement costs are no-longer negative but positive.

Other options which could be explored (but are beyond the scope of this worked example) include the costs of avoided land-use impacts associated with quarrying these minerals and the profitability of the land use - could it be used more profitably for purposes other than quarrying?

Abatement costs can be calculated per functional unit (as above), or per annual plant output, or the worldwide abatement potential could be explored to allow comparison of abatement by this method with alternative abatement technologies (assuming the utilization of all available APCr and full market acceptance of the associated products). 


\section{D.5 Conclusions}

In conclusion, the integrated sensitivity analyses described here, especially the depiction of the system sensitivity to the two variables tested using a nested box chart, enabled the relative scale of the resulting impacts to be appreciated. The GHG emissions were shown to be have a low sensitivity to changes to the distance that the APCr needs to be transported to treatment. The costs of the process, however, are more sensitive to such changes. GHG emissions and costs were both shown to be more sensitive to changes to the cement content of both the reference and the C8S blocks, with $\mathrm{GHG}$ emissions relatively more sensitive than costs. This reflects the significant costs that cement adds to the block-making process, and the even greater environmental impacts in the form of GHG emissions that the use of cement causes.

The use of combined economic and environmental indicators allows the costs of environmental impact abatement to be appreciated. The cost of GHG emissions abatement and aggregate use reduction achieved by switching from the reference processes to the $\mathrm{C} 8 \mathrm{~S}$ process were shown to be negative - up to $300 \$ \mathrm{Can}$ per tonne of $\mathrm{CO}_{2}$ eq. abated. This was due to the inclusion in the calculations of fees for taking in and treating the APCr instead of transporting it for stabilization/solidification followed by landfilling. Such abatement costs were found to be positive without the inclusion of such fees.

This chapter does not aim to provide a template or a definitive guide to performing an integrated TEA/LCA assessment of a CCU process. Rather, it hopes to give some initial direction and signpost practitioners towards possible routes towards integration of these two forms of assessment.

The approach taken enables the comparison of the $\mathrm{CO}_{2}$ abatement costs achieved by mineralizing $\mathrm{CO}_{2}$ to produce aggregate blocks, compared with other $\mathrm{CO}_{2}$ abatement technologies. However, the APCr treatment function of this technology arguably provides greater environmental benefits than just the $\mathrm{CO}_{2}$ abatement function.

As explained in the LCA worked example presented in Part $\mathbf{C}$, the examples of environmental impact provided have focused upon the impact category which provides a calculation of the GHG emissions. This was done because this is of direct interest (and is often a driver) to those developing CCU processes. However, a focus upon the GHG emissions alone risks failing to identify other environmental impacts resulting from a CCU process which would have been identified by analysis of the other environmental impact categories. For this reason, it must be emphasized that when conducting an LCA of CCU processes, whether integrated with TEA or not, all impact categories need to be assessed. 
PUBLISHED BY CO2CHEM MEDIA AND PUBLISHING LTD

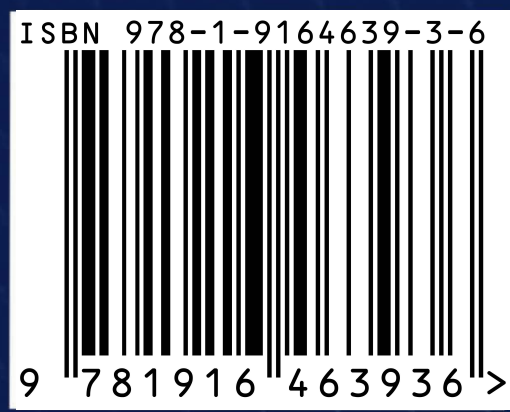

DOI: $10.3998 / 2027.42 / 147467$

http://hdl.handle.net/2027.42/147467

SUPPORTED BY

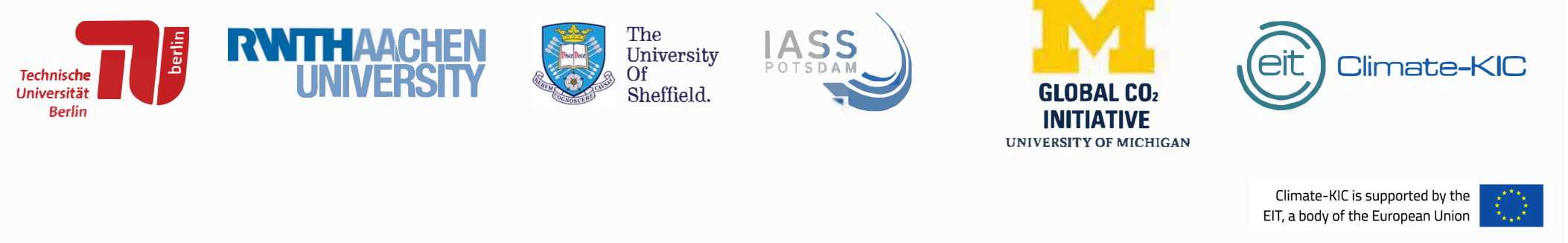

